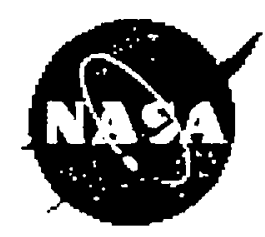

Functional groups based on leaf physiology: Are they spatially and temporally robust?

Foster, T.E. and J.R. Brooks 


\section{Functional groups based on leaf physiology: Are they spatially and temporally robust?}

Foster, T.E. and J.R. Brooks

Dynamac Corporation, Kennedy Space Center

Western Ecology Division, U.S. EPA/NHEERL 


\section{Table of contents}

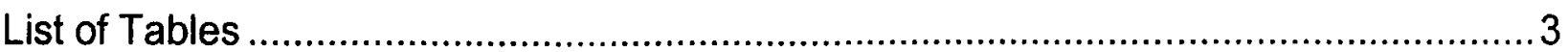

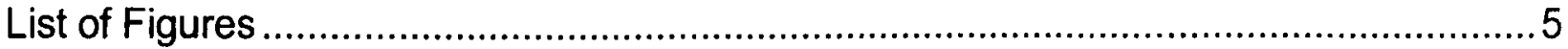

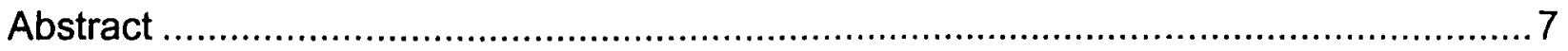

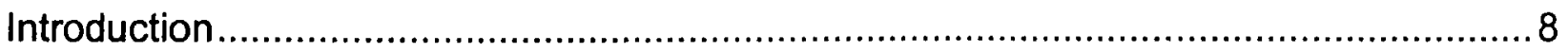

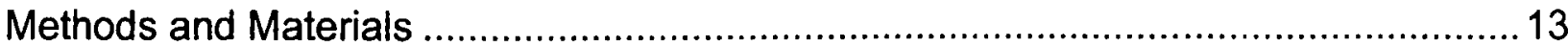

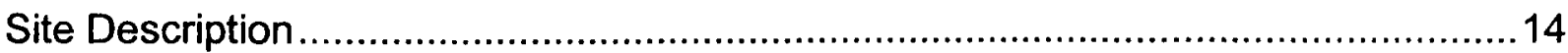

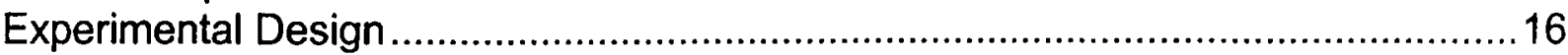

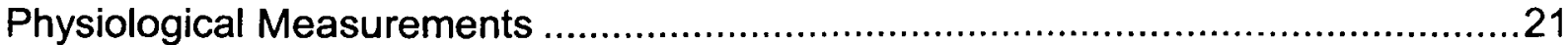

Instantaneous Gas Exchange Measurements ............................................21

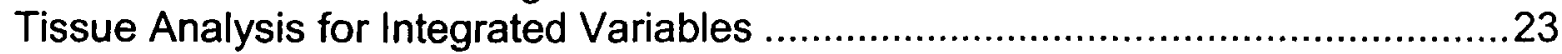

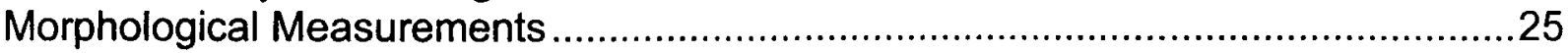

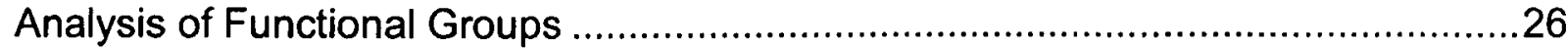

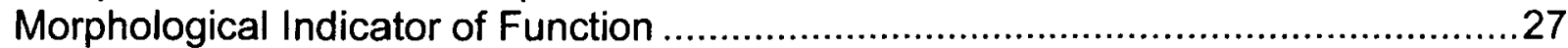

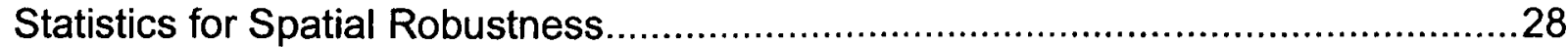

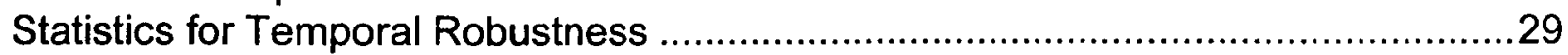

Statistics for Robustness of Morphological Indicators of Function .............................32

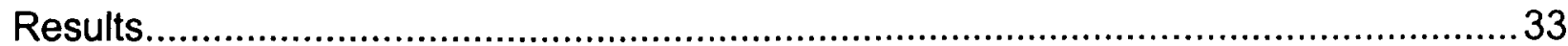

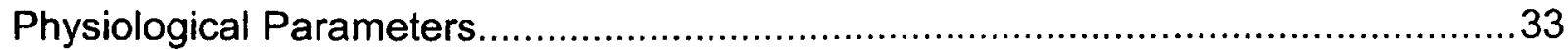

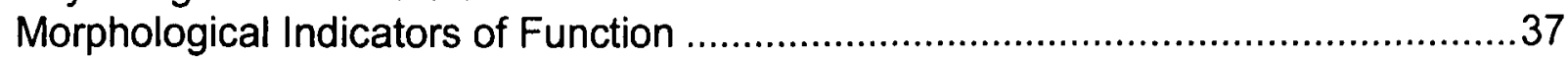

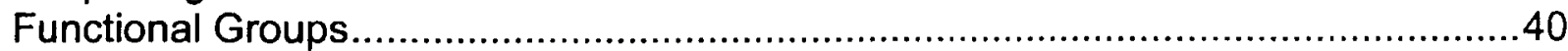

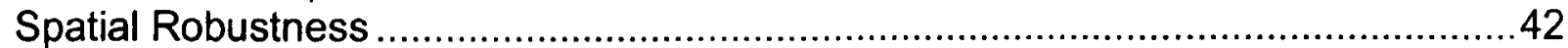

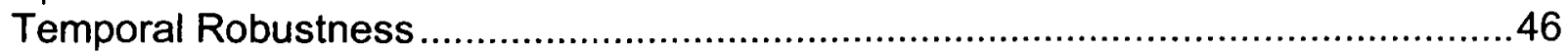

Robustness of Morphological Indicators of Function .........................................50

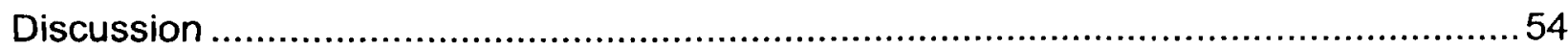

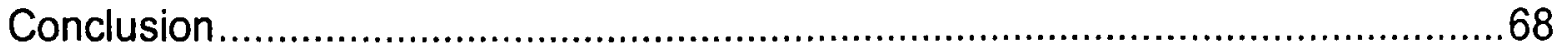

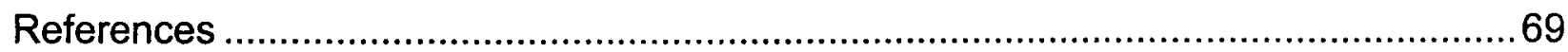

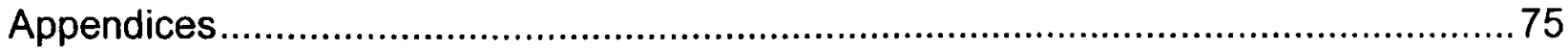

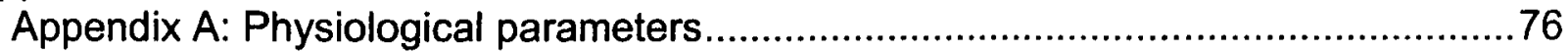




\section{List of Tables}

Table 1: Characteristics of the nine study plots. 18

Table 2: Life-form designations for the twelve scrub species

Table 3: List of physiological parameters that were used in the hierarchial cluster analysis to determine functional groups.

Table 4: Summary of statistical tests used for data analysis.

Table 5: Summary of physiological parameters for the different life form classifications taken in 1999 at the Camera pad burn plot.

Table 6: The species included in each physiological functional group based on species responses to carbon, nitrogen, and water.

Table 7: Comparison of the integrated physiological measures for the functional groups from 1999 data in the Camera Pad burn plot.

Table 8: Summary of analysis of similarities (ANOSIM) for determination of spatial robustness between plots of the physiologically based functional groups (PFG).

Table 9: Summary of analysis of similarities (ANOSIM) for determination of spatial robustness between management regimes of the physiologically based functional groups (PFG).

Table 10: Summary of Mantel Test results for temporal robustness.

Table 11: Summary of analysis of similarities (ANOSIM) for determination of temporal robustness of the physiologically based functional groups (PFG).

Table 12: Summary of analysis of similarity (ANOSIM) to determine the acceptable morphological indicator of physiological function.

Table 13: Physiological parameters for species in the Camera Pad burn plot. 76

Table 14: Physiological parameters for species in the Camera Pad fire suppressed plot

Table 15: Physiological parameters for species in the Camera Pad mechanical treated plot 78

Table 16: Physiological parameters for species in the Happy Creek burn plot 79 
Table 17: Physiological parameters for species in the Happy Creek fire suppressed plot

Table 18: Physiological parameters for species in the Happy Creek mechanically treated plot $(n=3)$

Table 19: Physiological parameters for species in the Kennedy Parkway burn plot.

Table 20: Physiological parameters for species in the Kennedy Parkway fire suppressed plot

Table 21: Physiological parameters for species in the Kennedy Parkway mechanically treated plot. 


\section{List of Figures}

Figure 1: Location and map of study area at the Kennedy Space Center / Merritt Island National Wildlife Refuge with approximate site locations shown.

Figure 2: Depth to the water table taken in the burn plots for all three sites during the summer of 2000 .

Figure 3: Example of a light response curve and some of the physiological traits that can be derived from the curve.

Figure 4: Photosynthesis and conductance at light saturation for scrub species in 1999 at the Camera Pad burn plot

Figure 5: The water-use efficiency of the ten scrub species present in the Camera Pad burn plot in 1999

Figure 6: Leaf nitrogen concentrations as a function of photosynthesis at light saturation (a), leaf carbon concentration (b), and the nitrogen isotope ratio (c) in 1999 for the Camera Pad burn plot.

Figure 7: Instantaneous gas exchange measures from scrub species for the $\mathrm{CPb}$ plot in 1999

Figure 8: Specific leaf area as a function of (a) photosynthesis at light saturation and (b) percent nitrogen for scrub species in 1999 at the Camera Pad burn plot.

Figure 9: Dendrogram depicting physiological based functional groups and how they relate to the morphological classifications: life form, leaf thickness

(LT), and specific leaf area (SLA)

Figure 10: Robustness of the physiological responses of eleven scrub species in 2000 between two plots with varying management regimes; the Camera pad burn plot and the Camera Pad mechanically treated plot

Figure 11: Temporal comparisons of species responses at the Camera Pad burn plot for the years 1999 and 2000

Figure 12: Temporal comparison of species carbon isotope values for the eight plots that were sampled in 1999 and 2000

Figure 13: Dendrograms depicting physiological based functional groups in 2000 for life form classifications and species based on 48 species mean values from the nine plots. 
Figure 14: Dendrograms depicting physiological based functional groups in 2000 for life form classifications and species based on 64 species mean values from the nine plots.

Figure 15: Non-metric multidimensal scaling (MDS) of the physiological functional groups (stress $=0.08$ ) depicted by (a) specific leaf area, (b) life form, (c) leaf thickness, and (d) life forms + Ximenia americana as a separate catagory .53 


\begin{abstract}
The functional grouping hypothesis, which suggests that complexity in function can be simplified by grouping species with similar responses, was tested in the Florida scrub habitat. Functional groups were identified based on how species in fire maintained Florida scrub function in terms of carbon, water, and nitrogen dynamics. The suite of physiological parameters measured to determine function included both instantaneous gas exchange measurements obtained from photosynthetic light response curves and integrated measures of function (percent carbon, percent nitrogen, stable carbon isotope ratio, stable nitrogen isotope ratio, and the carbon to nitrogen ratio). Using cluster analysis, five distinct physiologically-based functional groups were identified. Using non-parametric multivariate analyses, it was determined that these five physiologically-based groupings were not altered by plot differences or by the three different management regimes; prescribed burn, mechanically treated and burn, and fire-suppressed. The physiological groupings also remained robust between the two years 1999 and 2000. In order for these groupings to be of use for scaling ecosystem processes, there needs to be an easy-to-measure morphological indicator of function. Life form classifications were able to depict the physiological groupings more adequately than either specific leaf area or leaf thickness. The ability of life forms to depict the physiological groupings was improved by separating the parasitic Ximenia americana from the shrub category. The life form classifications including parasite were determined to be good indicators of the physiological processes of scrub species, and would be a useful method of grouping for scaling physiological processes to the ecosystem level.
\end{abstract}




\section{Introduction}

Current interest in modeling the role vegetation has on ecosystem and larger scale processes (e.g. regional and global) has lead to a need for an adequate method for simplifying complex terrestrial systems. Process-based models that are spatially explicit across landscapes must generalize vegetation and their responses into a few categories rather than represent every species or individual. The current methodology for this simplification is grouping species into a smaller number of functional groups. This concept that the complexity of nature can be reduced in models by treating a smaller number of functional groups is currently the central method for understanding how changes in the terrestrial surface may influence atmospheric dynamics (Steffen et al. 1992). However current methods for grouping species have not been fully tested to see that these functional groups are linked with processes that influence biosphere atmospheric interactions.

The plant - atmosphere interactions that are of prime interest for regional and global simulations are the cycling of carbon, water, and nitrogen. These ecosystem cycling processes are strongly linked to plant physiology and may be adequately simulated using plant functional types rather than individual species. Functional groups need to be designed based on physiological functions that are associated with the ecosystem process of interest; often carbon, nitrogen, and water dynamics. However functional groups are often defined on attributes that are not related to these ecosystem processes. For instance functional types were defined using a combination of demographic, structural, moisture requirements and phenological characteristics for modeling the response of tropical forests to climate change (Condit et al: 1996). While 
these groupings may prove useful for models simulating succession, these groupings were not specifically tested for differences in processes such as carbon uptake and water loss, and thus may be inadequate for atmosphere-biosphere interaction models.

For adequate simulation of a process, functional groups must be based on physiological traits that are important for that ecosystem process. In the case of carbon and water dynamics between the atmosphere and biosphere, physiological traits related to leaf gas-exchange would be important indicators for basing functional groups. Gasexchange potential of a leaf can be determined from the photosynthetic response curves to light along with $\% \mathrm{~N}$ of the leaf tissue and stomatal conductance. Percent nitrogen is also an indicator of the biochemical potential of photosynthesis since the majority of nitrogen in leaves is associated with photosynthetic enzymes (Evans 1989; Reich et al. 1994) and respiration (Ryan 1991). Photosynthesis $\left(A_{\max }\right)$ and stomatal conductance $\left(\mathrm{g}_{\max }\right)$ at light saturation are indicators of the maximum potential exchange of $\mathrm{CO}_{2}$ and water vapor between the biosphere and atmosphere. $A_{\max }$ is the maximum potential for carbon uptake from the atmosphere and is determined by investment of nitrogen in photosynthetic enzymes. Stomatal conductance plays a dual role in regulating water loss from the leaf and carbon entering the leaf. The ratio between $A_{\max }$ and $g_{\max }$ gives the plants water-use efficiency, or the amount of carbon gained as compared to the potential water loss.

The carbon isotope ratio $\left(\delta^{13} \mathrm{C}\right)$ is another good indicator of carbon and water fluxes because it has often been related to a plant's intrinsic water-use efficiency. The $\delta^{13} \mathrm{C}$ of a leaf is influenced by the interplay between stomatal conductance and 
photosynthesis (Ehleringer et al. 1993). The $\delta^{13} \mathrm{C}$ is related to the internal $\mathrm{CO}_{2}$ concentration in a leaf $\left(c_{i}\right)$ with the following equation:

$$
\delta^{13} \mathrm{C}_{\text {plant }}=\delta^{13} \mathrm{C}_{\text {air }}-\mathrm{a}-(\mathrm{b}-\mathrm{a}) \mathrm{c}_{\mathrm{i}} / \mathrm{c}_{\mathrm{a}}
$$

where $a$ is the isotopic fractionation associated with diffusion of $\mathrm{CO}_{2}$ through the stomata $(4.4 \mathrm{ppm}), \mathrm{b}$ is the isotopic fractionation associated with carboxylation by Rubisco (30 ppm), and $\mathrm{C}_{\mathrm{a}}$ is the ambient $\mathrm{CO}_{2}$ concentration (Farquhar et al. 1989). The $c_{i} / c_{a}$ gradient is influenced by the rate of photosynthetic uptake of carbon and the stomatal opening allowing $\mathrm{CO}_{2}$ to diffuse into the leaf.

The nitrogen isotopic ratio $\left(\delta^{15} \mathrm{~N}\right)$ gives insight into the cycling of nitrogen within an ecosystem and potential sources. Nadelhoffer et al. (1996) found that $\delta^{15} \mathrm{~N}$ values for tundra plants reflect differences in the content of ${ }^{15} \mathrm{~N}$ within the $\mathrm{N}$ pools and the strategy the plant uses to acquire $\mathrm{N}$. The nitrogen isotope ratio $\left(\delta^{15} \mathrm{~N}\right)$ has been used in combination with \% $\mathrm{N}$ to indicate nitrogen fixation (Roggy et al. 1999).

The carbon to nitrogen ratio $(\mathrm{C}: \mathrm{N})$ is another indicator of the nitrogen cycle in that it indicates the suitability of the leaf for decomposition. Plants with low $\mathrm{C}: \mathrm{N}$ ratios have high rates of decomposition and those with high $\mathrm{C}: \mathrm{N}$ ratios have low rates of decomposition. Leaves (litter) with high carbon to nitrogen ratios are not readily utilizable by microorganisms unless additional nitrogen sources are available (Larcher 1995). All of these measures are direct indicators of processes that affect the biosphere-atmosphere interactions of carbon and water cycling. Functional groups based on these parameters would be more successful in modeling simulations than ones based on reproductive or other strategies. However, measuring all these parameters to determine groups for every ecosystem would be tedious and impractical. 
In order for these physiological groupings to be useful for modeling, there needs to be an easy-to-measure indicator of function. Box (1996) suggested an approach in which structure would be used as a substitute for function. Specifically, Chapin (1993) suggests that ecophysiological traits may be linked to ecosystem processes by using morphological functional types; species of the same growth form had similar physiological characteristics. For example, species that grow rapidly also have high rates of photosynthesis, transpiration and decomposition (Chapin 1993). However it remains to be determined whether a physiological basis to these morphological classifications exists. This connection between the groups and their function is critical for models to accurately predict the role of vegetation in atmosphere-biosphere interaction models.

The use of life forms as indicators of functional groups is appealing because classification into trees, shrubs, epiphytes, vines and forbs, as well as distinguishing between deciduous and evergreen, is not only easy but is based on morphological features of a species that are insensitive to environmental change (Schulze 1982). Indeed several studies have found relationships between physiognomic features and function relating to carbon, nitrogen, and water dynamics. Brooks et al. (1997) found that classification of plant species into seven different life forms was successful in accounting for approximately half of the variation in stable carbon isotopes (water and carbon fluxes) among different plant species in each of three boreal forest ecosystems. In the rainforests of French Guiana, Bonal et al. (2000) also found that stable carbon isotope values varied between deciduous-leaved trees and evergreen leaved trees, with the deciduous trees being more water-use efficient than evergreen leaved species. 
Jackson et al. (1995) found that evergreen tree species accessed deeper water sources than deciduous species in tropical forests. Reich et al. found that forbs have higher respiration (Reich et al. 1998) and greater maximum photosynthesis (Reich et al. 1998) for a given level of leaf $\mathrm{N}$ than woody broad leafed species, while needle leafed conifers have the lowest respiration and photosynthesis for a given level of $\mathrm{N}$.

Leaf characteristics may also be another possible indicator of physiological function since leaf morphology and leaf function have been found to be interrelated. Reich et al. (1991) found that longer-lived leaves have lower net photosynthetic rates and nitrogen contents. Koike (1988) found that in temperate ecosystems, leaf thickness and photosynthesis at light saturation were highly correlated for a broad range of tree species. Reich et al. (1997) found that the relationship between leaf lifespan and photosynthetic function was robust even on a global scale. Species with higher specific leaf area were found to have shorter life spans (Reich et al. 1997) as well as higher maximum photosynthesis (Reich et al. 1998) and higher respiration (Reich et al. 1998) per unit leaf $\mathrm{N}$ accompanied by a steeper slope between photosynthesis and leaf $\mathrm{N}$. This relationship was true at the species, genera, and functional group level of organization.

These studies collectively indicate a strong relationship between morphology and physiological function. However, do such relationships continue to exist when examining a suite of physiological parameters involved in the carbon, nitrogen, and water dynamics of an ecosystem? This study tests the functional grouping hypothesis, which suggests that natural complexity can be reduced by grouping functionally similar species into a simple classification scheme (Steffen 1996), by comparing species 
responses to a suite of physiological parameters. Florida scrub is the ideal habitat to test the functional grouping hypothesis. Scrub is a xeromorphic shrub community that occurs on infertile, well-drained, sandy soils (Myers 1990). The dwarfed and stunted growth of the vegetation is a stress-tolerating strategy in that the plants have conservative growth strategies, nutrient storage mechanisms and water use patterns. When stress-tolerating plants are provided with less stressful conditions, they still maintain slow stable growth rates. This fixed growth implies that the function in terms of nutrients, carbon and water dynamics would remain stable across a wide range of environmental conditions as might be found along a disturbance gradient. Because of the stress tolerating nature of the Florida scrub, we would expect functional groups to be robust across a wide range of conditions.

Functional groups were assessed in the Florida scrub using a data based approach to determine if groups of species had similar physiological responses to available resources. Our objectives were to identify functional groups based on how species in fire maintained Florida scrub function in terms of carbon, water, and nitrogen dynamics, and to determine whether there is an easy-to-measure morphological characteristic (life form, specific leaf area, leaf thickness) that indicates physiological function. We were also interested in determining whether these functional groups were temporally and spatially robust by comparing functional groups between years and between different management regimes (prescribed burning, mechanical treatment, and fire suppression). 


\section{Methods and Materials}

Site Description

This study was conducted at the John F. Kennedy Space Center (KSC), Merritt Island National Wildlife Refuge (MINWR) in east central Florida ( $28^{\circ} 37^{\prime} \mathrm{N}, 80^{\circ} 43^{\prime} \mathrm{W}$ ). KSC/MINWR is located on the northern end of Merritt Island, and is part of the Merritt Island - Cape Canaveral barrier island complex. The climate at KSC is warm and humid. Mean annual air temperature is $22.8^{\circ} \mathrm{C}$ with the annual low temperatures occurring in January $\left(15.6^{\circ} \mathrm{C}\right)$ and the annual high temperatures in July $\left(27.8^{\circ} \mathrm{C}\right)$. Annual precipitation averages $1394 \mathrm{~mm}$ with $66 \%$ occurring during the wet season between the months of May and October. Relative humidity during the wet season averages $93 \%$ in the early morning and $65 \%$ in the early afternoon (data obtained from the Air Force Combat Climatology Center).

The total area of KSC is approximately 56,700 ha. The National Aeronautics and Space Administration (NASA) maintains operational control over $4 \%$ of the area (2430 ha), which is used for facilities, roads, lawns, right-of-ways and buffer zones. The remaining $96 \%$ is managed by the National Park Service (NPS) (2690 ha) and the U.S. Fish and Wildlife Service (USFWS) (51120 ha) (EG\&G Florida 1994). Forty percent (22700 ha) of the total area of KSC consists of open water (Indian River, Banana River, Mosquito Lagoon, and Banana Creek). Most of the remaining non-operational land is occupied by either upland (12200 ha) or wetland (15566 ha) systems (EG\&G Florida 1994).

Scrub, a major upland system, occurs on approximately 1600 ha of KSC (Schmalzer et al. 1999). This xeromorphic shrub community is dominated by evergreen 
oaks or Florida rosemary (Ceratiola ericoides) occurring on infertile, well-drained, sandy soils (Myers 1990). Ericads and Serenoa repens also are prevalent species in Florida scrub. This system is pyrogenic; adapted to high intensity, stand-replacing fires. Most scrub occurs on entisol soils derived from quartz sand that have little development of soil horizons (Myers 1990). The soils supporting scrub vegetation are excessively to moderately well drained sand and are extremely nutrient poor.

Four types of scrub communities are present on KSC; sand pine scrub, oak and oak - saw palmetto scrub, scrubby flatwoods, and coastal strand and scrub; with the most abundant community type being oak and oak - saw palmetto scrub (909.2 ha) (Schmalzer et al. 1999). Oak and oak - saw palmetto scrub at KSC occurs mainly in the inland portion of Merritt Island on either excessively drained Paola sand or moderately well drained Pomello sand, with a mean grain size of $0.17 \mathrm{~mm}$ (2.6 phi) (Schmalzer et al. 2001). These soils are acidic, low in nutrients, and leached of shell fragments (Schmalzer and Hinkle 1992).

Oak - saw palmetto scrub is dominated by shrub species that resprout after fire (Menges and Kohfeldt 1995); this typically includes three evergreen oaks (Quercus chapmanii, Q. geminata, and Q. myrtifolia), Serenoa repens, and ericads (Lyonia ferrigenea, L. fruticosa, L. lucida, and Vaccinium myrsinites). Herbaceous species are not a major component of oak - saw palmetto scrub on Merritt Island (Schmalzer and Hinkle 1992).

Oak - saw palmetto scrub, along with the other upland vegetation on KSC/MINWR, was subject to at least twenty years of fire suppression until prescribed burning was initiated in 1981 (Adrian et al. 1983). Active restoration of scrub habitat 
was begun in 1992. This restoration includes prescribed burning and on the more overgrown sites mechanical treatment followed by prescribed burns. Scrub at KSC/MINWR is managed for structural characteristics that benefit the threatened Florida Scrub Jay (Aphelocoma coerulescens coerulescens), which includes keeping the height around 1.7 meters and maintaining sandy openings. Scrub at KSC/MINWR has been found to grow more quickly than at other locations, and the number and size of openings greatly decrease by three years post-burn. Therefore the fire return interval for scrub at KSC/MINWR needs to be no longer than 10 years (personal communication Paul Schmalzer).

\section{Experimental Design}

Three sites were selected in the oak - saw palmetto scrub on KSC/MINWR; the Camera Pad Site $\left(28^{\circ} 37.676^{\prime} \mathrm{N} ; 8^{\circ} 39.305^{\prime} \mathrm{W}\right)$, the Kennedy Parkway Site $\left(28^{\circ} 36.957^{\prime} \mathrm{N} ; 80^{\circ} 40.826^{\prime} \mathrm{W}\right)$, and the Happy Creek Site $\left(28^{\circ} 37.983^{\prime} \mathrm{N} ; 80^{\circ} 39.904^{\prime} \mathrm{W}\right)$ (Figure 1). Each site had three land management regimes in close proximity (fire suppressed scrub, mechanically treated and burned scrub, and burned scrub) for a total of nine plots. The plots were $30 \mathrm{~m}$ by $30 \mathrm{~m}$ when possible (Camera pad burn [CPb] and fire suppressed [CPfs], Happy Creek burn [HCb], and the Kennedy Parkway burn [KPb], fire suppressed [KPfs] and mechanically treated [KPmt]). However size limitations existed for three plots due to either patchy burns or management strategy (Camera pad mechanically treated [CPmt], Happy Creek fire suppressed [HCfs] and mechanical treatment $[\mathrm{HCmt}]$ ). All plots were located on well-drained Pomello soils (Huckle et al. 1974), with the exception of the Kennedy Parkway burn plot that occurs on Immokalee a 
poorly drained soil. Both soils are Spodosols with the main difference being that Immokalee tends to have a shallower water table than Pomello (Huckle et al. 1974).

Figure 1: Location and map of study area at the Kennedy Space Center / Merritt Island National Wildlife Refuge with approximate site locations shown.

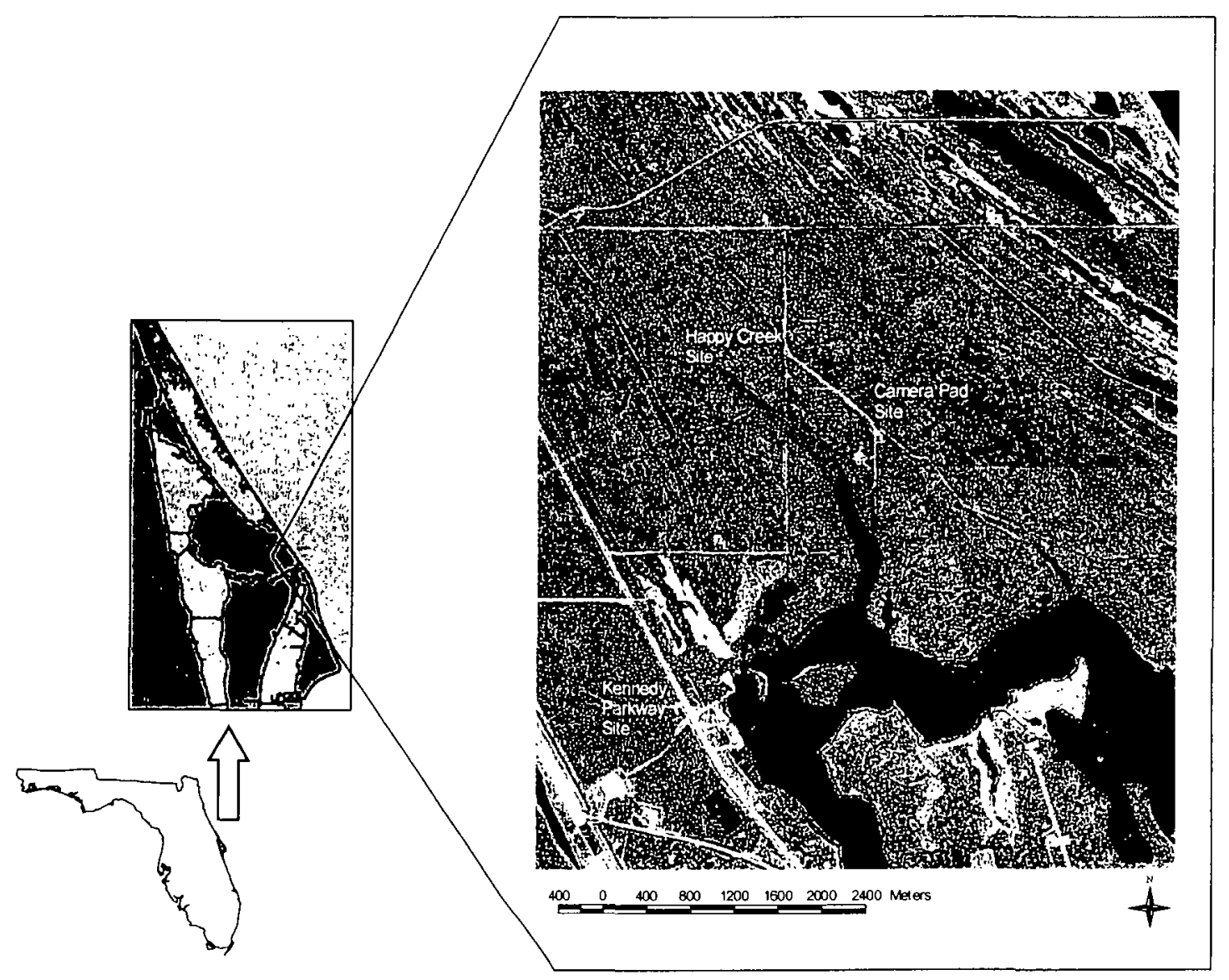

The nine plots vary in two respects; time since burn (Table 1) and distance to the water table (Figure 2). Since oak - saw palmetto scrub recovers rapidly after fire exhibiting little change in composition or species richness (Schmalzer and Hinkle 1992), the short variation between time since burn for the recently burned and mechanically treated plots should not exhibit much of an influence on species responses. Firesuppressed scrub may differ in species composition and cover compared to fire- 
maintained scrub (Schmalzer et al. 1994; Schmalzer and Adrian 2001), and is more likely to exert influence on species response. Aside from land management regimes the main difference between these plots is the distance to the water table (Figure 2). This is particularly important since the composition of oak - saw palmetto scrub is closely related to water table depth with oak dominated scrub on the drier sites and saw palmetto dominating the wetter sites (Schmalzer and Hinkle 1992). A difference of approximately a half-meter existed between the plots, with the Camera Pad site consistently having the shallowest water table and Happy Creek the deepest water table through the growing season (Figure 2).

Table 1: Characteristics of the nine study plots.

\begin{tabular}{|c|c|c|c|}
\hline & $\begin{array}{c}\text { Year } \\
\text { burned }\end{array}$ & $\begin{array}{c}\text { No. } \\
\text { species } \\
\text { present }\end{array}$ & Species absent \\
\hline \multicolumn{4}{|l|}{ Camera Pad } \\
\hline Burn & 1997 & 11 & Lyonia ferruginea \\
\hline Fire-suppressed & 1986 & 8 & $\begin{array}{c}\text { Lyonia fruticosa, Lyonia lucida, Smilax auriculata, } \\
\text { Ximenia americena }\end{array}$ \\
\hline Mechanically treated & 1997 & 12 & \\
\hline \multicolumn{4}{|l|}{ Happy Creek } \\
\hline Burn & 1997 & 10 & Lyonia ferruginea, Lyonia fruticosa \\
\hline Fire-suppressed & 1986 & 10 & Lyonia ferruginea, Ximenia americana \\
\hline Mechanically treated & 1997 & 10 & Lyonia ferruginea, Lyonia fruticosa \\
\hline \multicolumn{4}{|l|}{ Kennedy Parkway } \\
\hline Burn & 1998 & 8 & $\begin{array}{c}\text { Galactia elliottii. Lyonia ferruginea, Smilax auriculata, } \\
\text { Ximenia americans }\end{array}$ \\
\hline Fire-suppressed & $>20$ yis & 9 & Lyonia fruticosa, Lyonia lucida, Serenoa repens \\
\hline Mechanically treated & 1997 & 12 & \\
\hline
\end{tabular}

Twelve of the dominant scrub species present on KSC/MINWR, that covered the range of life forms (Table 2) and leaf characteristics, were selected for inclusion in this study. For example Quercus geminata, an evergreen tree, has noticeably thick leaves whereas Galactia elliottii, a vine, has thinner leaves. 
Figure 2: Depth to the water table taken in the burn plots for all three sites during the summer of 2000 .

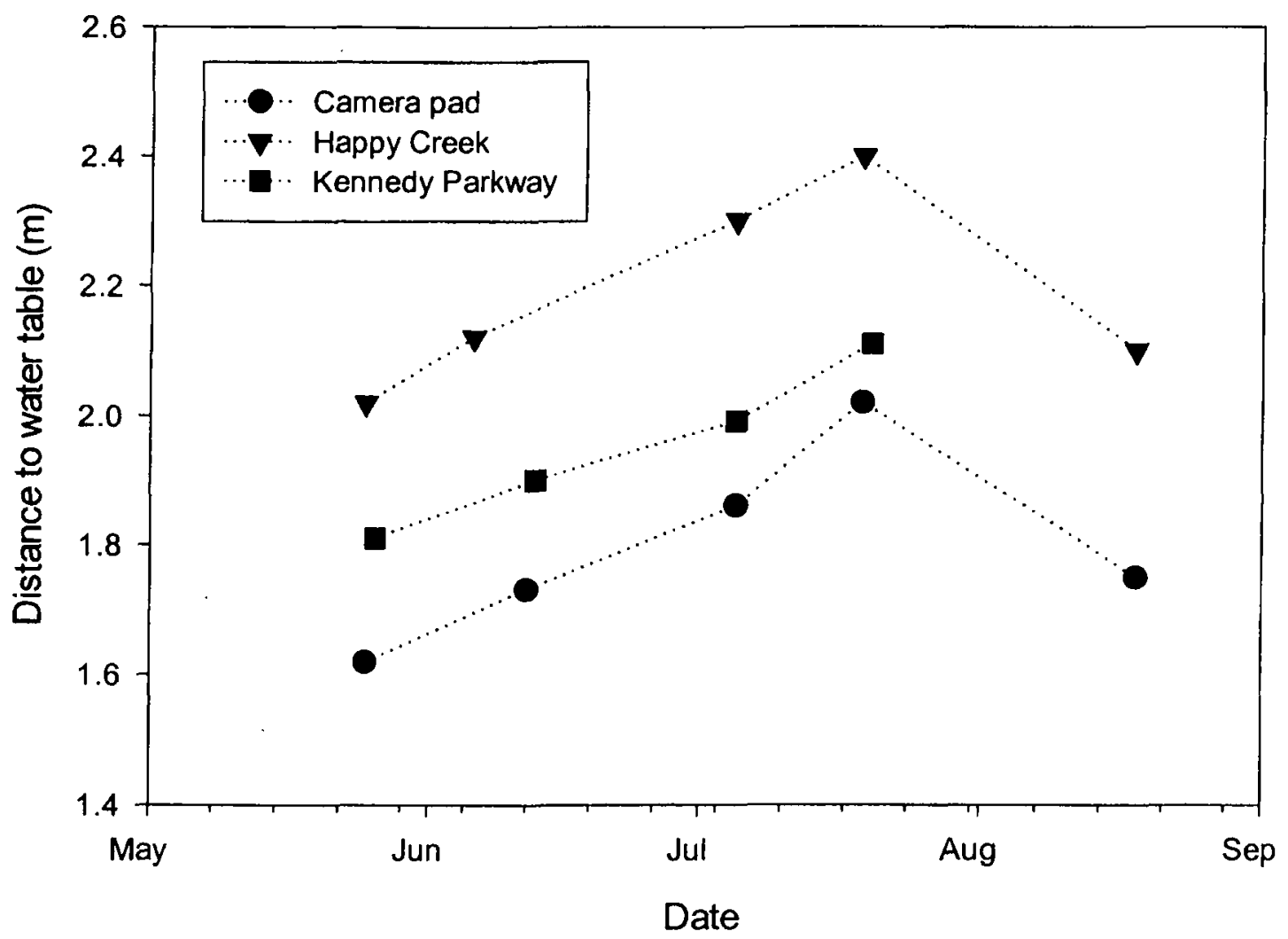

Table 2: Life-form designations for the twelve scrub species. An asterisk indicates that the species was included in the subset on which gas-exchange measurements were taken to address spatial robustness.

\begin{tabular}{|c|c|c|c|}
\hline $\begin{array}{c}\text { Trees } \\
\end{array}$ & $\begin{array}{l}\text { Shrubs } \\
\end{array}$ & Vines & Palmetto \\
\hline $\begin{array}{l}\text { Quercus chapmanii } \\
\text { Quercus geminata* } \\
\text { Quercus myrtifolia* } \\
\text { Myrica cerifera }\end{array}$ & $\begin{array}{c}\text { Lyonia ferruginea } \\
\text { Lyonia fruticosa } \\
\text { Lyonia lucida* } \\
\text { Vaccinium myrsinites } \\
\text { Ximenia americana* }\end{array}$ & $\begin{array}{l}\text { Galactia elliottii }^{\star} \\
\text { Smilax auriculata }\end{array}$ & Serenoa repens ${ }^{\star}$ \\
\hline
\end{tabular}

However not all species were present in each plot (Table 1). The physiological function of these species were examined using a suite of instantaneous and integrated indicators of carbon, water, and nitrogen dynamic: leaf carbon isotope ratio $\left(\delta^{13} \mathrm{C}\right)$, leaf nitrogen isotope ratio $\left(\delta^{15} N\right)$, leaf $\% C$, leaf $\% N$, leaf $C / N$ and photosynthetic response curves to light. 
The first objective was accomplished by identifying functional groups of species in a fire-maintained Florida scrub plot, the Camera Pad burn plot, based on common physiological traits measured during the summer of 1999 (May-August). A firemaintained plot was used for this initial determination of functional groups because typical scrub characteristics were exhibited, such as vegetation composition, vegetation cover, and presence of openings. Eleven of the twelve dominant species were present in this plot (Table 1). Five individuals for each species were evaluated for their physiological characteristics by using the suite of instantaneous and integrated measures ( 2 and 3 individuals respectively) that indicates physiological function (see below for more detail on specific measurement techniques). Each set of measurements was taken on spatially segregated individuals to decrease the likelihood of sampling the same clone. Species with similar physiological responses were identified as members of the same functional group (see statistical details below). To determine if a morphological indicator of function exists, these physiologically-based functional groups were compared to three groupings based on morphological characteristics: life form, specific leaf area, and leaf thickness.

To determine if these groupings were spatially robust the suite of instantaneous gas-exchange variables were measured on a subset of species (Table 2) at each of the nine plots (Table 1) during the summer of 2000 (May - August). Not all species in the subset were present at each plot (Table 1, Appendix A). The integrated measurements were taken on all species present at each plot (Table 1). Instantaneous and integrated measurements were each taken on three spatially segregated individuals per species at each plot. Since these measurements were taken to examine species responses 
across plots, it was necessary to minimize variations in environmental parameters that affect instantaneous gas-exchange. Therefore all instantaneous measurements were taken between 9 am and noon and one species was sampled at all plots before the next species was measured. The physiologically based functional groups as defined previously were compared for treatment and site differences.

Temporal robustness of the physiological functional groups was determined by comparing physiological responses of ten species over two summers (1999 and 2000) in the fire-maintained scrub plot where the initial group determinations were made. The species responses that were evaluated on the suite of physiological characteristics in 1999 were compared to the responses of each species in 2000 . These physiological responses were also used to compare the previously defined functional groups for differences between years (more details below).

Physiological Measurements

Instantaneous Gas Exchange Measurements

Instantaneous gas exchange was measured using a portable photosynthesis system (Li-Cor 6400, LI-COR, Lincoln, NE). The measurements were made under controlled levels of $\mathrm{CO}_{2}\left(400 \mu\right.$ mols $\left.\mathrm{CO}_{2} \mathrm{~mol}^{-1}\right)$, flow $\left(500 \mu\right.$ mols s$\left.{ }^{-1}\right)$, and light $(0,100$, $200,500,1000,1500$, and $\left.2000 \mu \mathrm{mols} \mathrm{m}^{-2} \mathrm{~s}^{-1}\right)$. All other conditions were maintained at ambient levels. If the air or leaf temperature exceeded $35^{\circ} \mathrm{C}$, the cooling fan was set to maintain the temperature at $35^{\circ} \mathrm{C}$.

Photosynthetic light response curves were measured on mature sunlit leaves during the summers of 1999 and 2000. In 1999, light response curves were measured on 2 mature individuals of each species present at all three of the Camera Pad plots 
(Table 1), and on selected species in the other plots (see Appendix A). Measurements were taken at six light levels $\left(2000,1500,1000,500,200\right.$, and $\left.0 \mu \mathrm{mols} \mathrm{m}^{-2} \mathrm{~s}^{-1}\right)$, and were collected throughout the day (9am - 3 pm EST).

During the summer of 2000 , light response curves were obtained for two sets of objectives. First, measurements were taken to examine species responses across plots. To achieve this, a subset of species was chosen (Table 2) of which 3 mature individuals were measured for each species at the nine plots. All measurements were taken between 9 am and noon, and one species was sampled at all plots before the next species was measured. The second objective was to compare responses between years, therefore 3 mature individuals of each species present at the Camera Pad burn and mechanically treated plots (Table 1) were measured. Two of the ericads, Lyonia ferruginea and $L$. fruticosa, were excluding from the instantaneous analysis in 2000 because these species possessed rust colored scales that collected and respired in the Li-Cor 6400 , causing a substantial differential in carbon dioxide between the sample and reference cells. These measurements were also collected between 9 am and noon. All light response curves taken in 2000 , had measurements taken at seven light levels $\left(2000,1500,1000,500,200,100,0 \mu\right.$ mols $\left.\mathrm{m}^{-2} \mathrm{~s}^{-1}\right)$.

Six physiological traits were obtained from the light response curves (Figure 3): photosynthesis at light saturation $\left(A_{\max }\right)$, conductance at light saturation $\left(g_{\max }\right)$, dark respiration $\left(R_{d}\right)$, intrinsic water use efficiency $\left(A_{\max } / g_{\max }\right)$, quantum yield $(\Phi)$, and the compensation point $\left(I_{c}\right)$. Photosynthesis and conductance at light saturation $\left(A_{\max }\right.$ and $g_{\max }$ respectively) occur at the point were $\mathrm{CO}_{2}$ uptake is no longer light limited but enzyme limited. Therefore at high light levels photosynthesis and conductance reach a 
stabilizing point, at which additional light does not increase photosynthetic yield or conductance. Dark respiration $\left(R_{d}\right)$ may also be obtained from the light response curves. When the leaf is maintained in the dark $\left(0 \mu\right.$ mols $\left.\mathrm{m}^{-2} \mathrm{~s}^{-1}\right)$, the $\mathrm{CO}_{2}$ assimilation is negative due to respiration from the plant. The intrinsic water use efficiency $\left(A_{\max } / g_{\max }\right)$, quantum yield $(\Phi)$, and the compensation point $\left(I_{c}\right)$ were not directly obtained from the light response curve, but were calculated. Linear regressions were used to model the change in carbon dioxide uptake as the available light changed from 0 to $200 \mu$ mols photons $\mathrm{m}^{-2} \mathrm{~s}^{-1}$ for calculation of both the quantum yield and the light compensation point. The slope of the line indicates how efficient the plant is in using available light energy to fix carbon dioxide, or its quantum yield $\left(\mathrm{mols} \mathrm{CO}_{2}\right.$ fixed/mol photons absorbed). The $y$-intercept of the line (where $y=0$ ) is the compensation point where photosynthesis and respiration are in equilibrium.

In 1999 in addition to the light curves, additional instantaneous measurements of photosynthesis at light saturation $\left(A_{\max }\right)$ were taken on three mature sunlit leaves of three individuals for each species present in the Camera Pad plots (Table 1) as well as some species present in the remaining plots (see Appendix A). Measurements were taken at $1500 \mu \mathrm{mols} \mathrm{m}^{-2} \mathrm{~s}^{-1}$, with the exception of Serenoa repens and Smilax auriculata in which the measurement were made at $2000 \mu \mathrm{mols} \mathrm{m}^{-2} \mathrm{~s}^{-1}$. The light level required to saturate photosynthesis was determined from the light response curves.

Tissue Analysis for Integrated Variables

Several mature leaves were collected from the upper canopy of three spatially segregated individuals for the species present in each of the nine plots at the end of 
Figure 3: Example of a light response curve and some of the physiological traits that can be derived from the curve. $I_{s}=$ light saturation point, $I_{c}=$ light compensation point, $\Phi=$ quantum yield, $R_{d}=$ dark respiration, and $A_{\max }$ $=$ photosynthesis at light saturation.

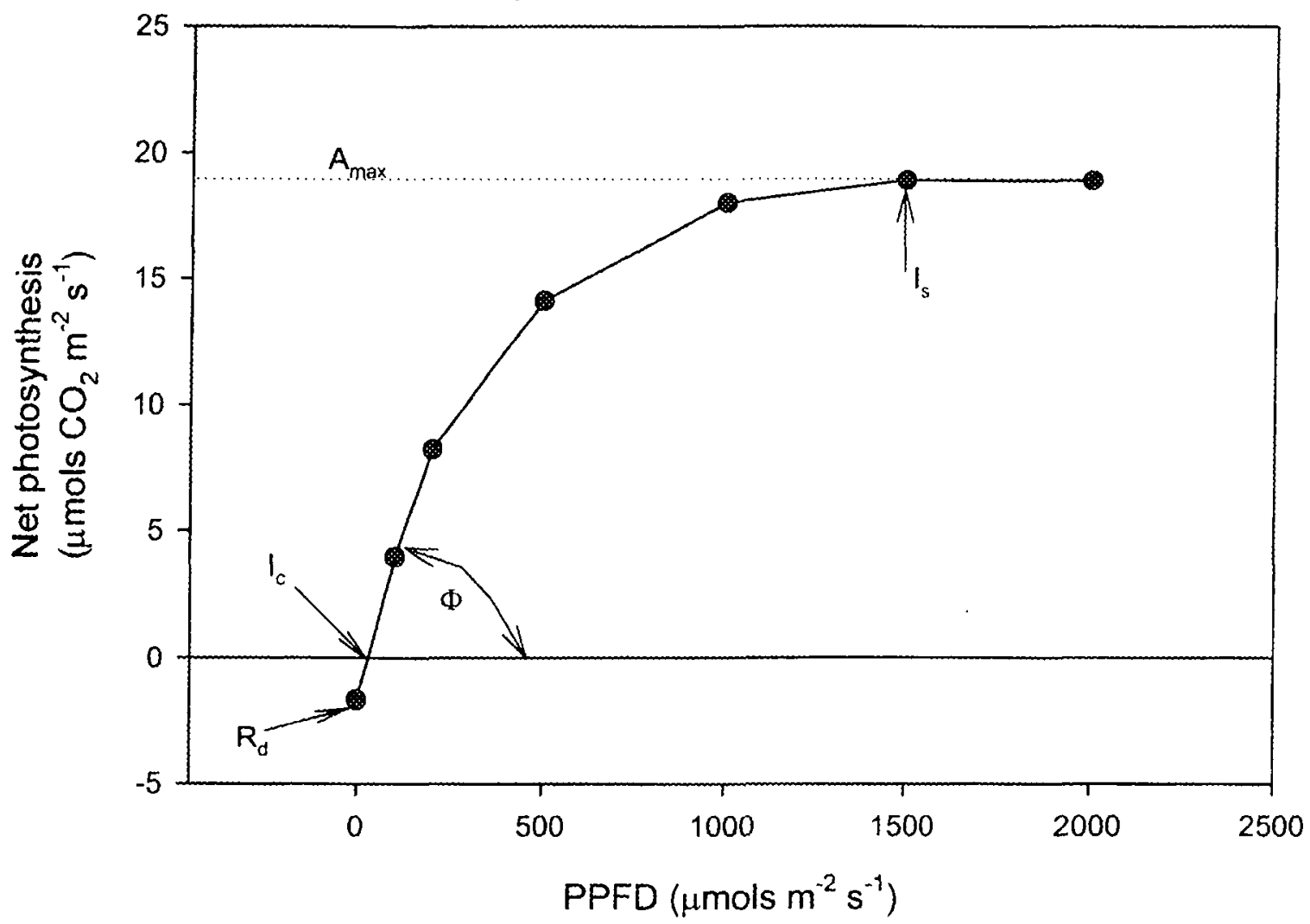

both summers, with the exception of the Happy Creek mechanically treated plot in 1999.

The leaves from each individual were clumped together into a single sample, and were dried and ground. In 1999, 5 mg subsamples were weighed on a microbalance (Cahn C-33, Cahn Instruments Inc. Cerritos, CA) and analyzed for the carbon isotope ratio $\left(\delta^{13} \mathrm{C}\right)$, percent carbon $(\% \mathrm{C})$, nitrogen isotope ratio $\left(\delta^{15} \mathrm{~N}\right)$, and percent nitrogen $(\% \mathrm{~N})$ on a light stable isotope mass spectrometer (Delta Plus, Finnigan, Bremen, Germany) at the Integrated Stable Isotope Research Facility (ISIRF) at Environmental Protection Agency in Corvallis, OR. For the 2000 samples, carbon and nitrogen were analyzed separately on the light stable isotope mass spectrometer (Delta Plus, Finnigan, Bremen, Germany). One-milligram subsamples were weighed (Perkin-Elmer AD 6 Autobalance, 
Norwalk, CT) and analyzed for the carbon isotope ratio $\left(\delta^{13} \mathrm{C}\right)$ and percent carbon $(\% \mathrm{C})$, whereas $8-15 \mathrm{mg}$ samples were weighed and analyzed for the nitrogen isotope ratio $\left(\delta^{15} \mathrm{~N}\right)$ and percent nitrogen $(\% \mathrm{~N})$.

Morphological Measurements

Three morphological characteristics were examined as possible indicators of the physiological functional groups; life form, specific leaf area (SLA), and leaf thickness (LT).

The twelve species were classified into four life form groupings; trees, shrubs, vines, and palmetto based on descriptions by Nelson $(1994 ; 1996)$ and Lakela and Wunderlin (1980) (Table 2). The dominant species in scrub are considered to be shrubs. However in the absence of fire, four of these twelve species will reach tree proportions (8 - $12 \mathrm{~m}$ in height); Quercus chapmanii, Q. geminata, Q. myrtifolia, and Myrica cerifera. Ximenia americana, is also described as being either a shrub or small tree up to $6 \mathrm{~m}$ in height (Godfrey 1988). In long unburned scrub on KSC/MINWR Ximenia americana does not become part of the overstory, but remains in the understory with the other evergreen shrubs. For this reason Ximenia americana is classified as a shrub, along with Lyonia ferruginea, Lyonia fruticosa, Lyonia lucida, and Vaccinium myrsinities. Ximenia americana differs from the remaining four shrubs because it is a hemiparasite on the roots of other plants. This parasitism does not appear to be host-specific or mandatory for survival (Nelson 1994). Galactia elliottii and Smilax auriculata are vines, and Serenoa repens is the only palmetto. All of the scrub species are either evergreen or semi-evergreen, so comparisons between evergreen and deciduous species were not possible. 
The specific leaf area (SLA), or leaf area per leaf mass, was calculated for one mature leaf from 20 individuals for each species at the Camera Pad burn plot. The area of each leaf was obtained using a leaf area meter (Li-Cor 3100, Li-Cor, Lincoln, NE). The leaves were then dried for 48 hours and weighed ( $\pm 0.0001 \mathrm{~g}$; SA120, Scientech). ANOVA and multiple comparisons were used to determine significant species differences (SPSS v. 10.1). The species were then grouped into two categories based on their SLA; high SLA or Iow SLA.

Leaf thickness (LT) was obtained for one mature leaf from 11 individuals for each species present at the Camera Pad burn plot using a thickness gauge $( \pm 0.001$ in [0.0025 cm]; Teclock Corporation, Japan). ANOVA and multiple comparisons were used to determine significant species differences (SPSS v. 10.1). The species were grouped into three categories based on leaf thickness; thick leaves, intermediate leaves, and thin leaves.

Analysis of Functional Groups

The physiological functional groups were identified using hierarchical cluster analysis (PC-ORD v. 4.0, SPSS v. 10.1). The raw data that consisted of species means for each of the ten parameters (Table 3) was transformed to $Z$ scores due to large differences in the scales of the parameters. This transformation converts the raw data into standard deviation units above or below the mean (Pagano 1994). The transformed data was used for the cluster analysis input. The cluster analysis was performed using the average linkage method with the Euclidean distance (ED) measure (eq. 2).

$$
E D_{\mathrm{jk}}=\sqrt{\sum_{i=1}^{p}\left(x_{i j}-x_{i k}\right)^{2}}
$$


Average linkage is not only the most commonly used fusion strategy, but is the recommended strategy when no reason exists for choosing another strategy (McGarigal et al. 2000).

Table 3: List of physiological parameters that were used in the hierarchial cluster analysis to determine functional groups.

\begin{tabular}{|c|c|}
\hline \multicolumn{2}{|c|}{ Physiological Parameters } \\
\hline Instantaneous & Integrated \\
\hline$A_{\max }$ & $\% \mathrm{C}$ \\
\hline$g_{\max }$ & $\% \mathrm{~N}$ \\
\hline$R_{d}$ & $\mathrm{C}: \mathrm{N}$ \\
\hline$\Phi$ & $\delta^{13} C$ \\
\hline$I_{c}$ & $\delta^{15} \mathrm{~N}$ \\
\hline
\end{tabular}

Since clustering techniques are biased to finding clusters of a particular shape, it is best to compare results from several different techniques (McGarigal et al. 2000). Therefore results from the above analysis were compared to results from analyses using a variety of linkage methods (nearest neighbor, furthest neighbor, centroid, median, and Ward's minimum-variance linkage) and distance measures (Euclidean, Minkowski, Chebychev, and Pearson correlation). In general the groupings obtained by the various methods were in agreement. The Mantel test was used to determine whether the clusters were significantly different from clusters obtained by chance (PCORD v. 4.0).

Morphological Indicator of Function

Each physiological parameter was graphed to examine possible relationships with the three morphological characteristics. Groupings based on the morphological characteristics were compared to the physiologically based functional groups, and the characteristic that best represented these functional groups was chosen to serve as the morphological indicator of function. 


\section{Statistics for Spatial Robustness}

Analysis of Similarities (ANOSIM) was used to determine whether the physiological functional groups were robust across plots and management regimes in 2000 (PRIMER-E v. 5). The 2-way cross layout of the ANOSIM is a non-parametric permutation procedure similar to the parametric MANOVA that addresses two null hypotheses simultaneously. Non-parametric tests were used instead of a parametric analysis because data sets are not required to adhere to the assumptions of parametric tests (normality and homogeneity of variances) (McCune and Mefford 1999). The test statistic, $R$, compares the degree of separation of the treatments by comparing the differences between treatments to the differences among the replicates for each treatment using the average rank similarities. R near zero indicates that there is little to no separation among the a priori groups accepting the null hypothesis, whereas an $R$ near 1 indicates complete separation among the groups (Clarke and Warwick 2001). The observed $R$ is compared to a permutation distribution of R's achieved by randomly reshuffling the labels, and if the observed $R$ lies outside of the permutation distribution there is evidence that differences do exist. Each pair of treatments may then be compared to determine where the treatment differences occur (see Clarke and Warwick 2001 for further details on the procedure).

Two sets of two null hypotheses were used to test for spatial robustness of the physiological functional groups: the first set tested for plots and functional group effects and the second set tested for management regimes and functional group effects. The first null hypothesis of a set was that there were no spatial effects (plot or treatment depending on test) allowing for the fact that there may be differences between 
physiological functional groups. The second null hypothesis was that there were no differences in physiological functional groups allowing for spatial differences. In order to maximize the number of species by plot combinations and the number of physiological parameters, these analyses were conducted twice on two different Z-score transformed data sets (Table 4). The first analysis examined the 48 species by plot combinations on which the suite of all 10 physiological measurements had been measured. The second analysis was conducted using only the integrated measures for 64 species by plot combinations. The 2000 measures of species responses were used in these analyses with the exception of the percent nitrogen and the carbon to nitrogen values. A third of the 2000 percent nitrogen values were suspected to be incorrect because of a malfunctioning balance and thus the $\mathrm{C}: \mathrm{N}$ values would also be unusable. However since the remaining percent nitrogen and $\mathrm{C}: \mathrm{N}$ values taken in 2000 were highly correlated with the corresponding values in $1999\left(R^{2}=0.832, p=<0.0001 ; R^{2}=0.898\right.$, $p=<0.0001$ respectively), thus the $1999 \% \mathrm{~N}$ values were substituted in all subsequent spatial analyses.

Statistics for Temporal Robustness

Mantel tests were used to compare the distance matrices for the 1999 and 2000 data sets for a subset of plots to determine if they were similar in terms of species responses (PC-ORD, Table 4). The null hypothesis of the Mantel test is that there is no relationship between two distance matrices. The standardized Mantel statistic, $r$, ranges from -1 to 1 and is a measure of the correlation between the two distance matrices. A permutation test is used to determine the significance of the correlation, by comparing the observed test statistic $(Z)$ to the expected distribution of the test statistic 
(McCune and Mefford 1999). The Monte Carlo randomization test was used to determine the statistical significance of the Mantel statistic for this study (Fortin and Gurevitch 2001). All data used were transformed using the Z-score (see above for details).

Only a subset of plots had a sufficient number of species to test for temporal differences using the Mantel test. The Camera Pad burn and mechanically treated plots had the most inclusive set of species in which all 10 physiological parameters were measured (10 and 9 respectively). Two other plots ( $\mathrm{KPmt}$ and $\mathrm{HCb}$ ) had a sufficient number of species in which only the carbon isotope ratio $\left(\delta^{13} \mathrm{C}\right)$, percent carbon $(\% \mathrm{C})$, nitrogen isotope ratio $\left(\delta^{15} \mathrm{~N}\right)$, percent nitrogen $(\% \mathrm{~N})$, and the carbon to nitrogen ratio (C:N) were obtained for each species for both years. Finally, a more inclusive Mantel test of temporal robustness was done using the integrated responses of all species that were present within a plot for both years. This included 64 species by plot combinations (Table 4).

Robustness of the physiological functional groups temporally between 1999 and 2000 was addressed using a 2-way ANOSIM (Table 4). The first hypothesis for the test was that there was no effect of year while allowing for the fact that there may be differences between physiological functional groups. The second null hypothesis was that there were no differences in physiological functional groups allowing for between year differences. This analysis was conducted on two Z-score transformed data sets: one in order to maximize the number of species by plot combinations, and the other to maximize the number of physiological parameters. The first analysis was conducted on the 58 species by plot combinations in which the integrated measures were collected for 
Table 4: Summary of statistical tests used for data analysis. \# $S \times P$ is the number of species by plot combinations included in the analysis. All plots include data from 8 of the 9 plots, because HCmt was not sampled in 1999.

\begin{tabular}{|c|c|c|c|c|c|}
\hline Robustness & Analysis & $\# \mathbf{S} \times \mathbf{P}$ & Plots & Parameters & Effects \\
\hline \multicolumn{6}{|l|}{ Spatial } \\
\hline & ANOSIM & 48 & All & $A_{\max }, g_{\max }, R_{d}, I_{c}, \Phi, \delta^{13} \mathrm{C}, \delta^{15} \mathrm{~N}, \% \mathrm{~N}, \% \mathrm{C}$ & $\begin{array}{l}\text { Plot, Management regime, } \\
\text { Functional Groups }\end{array}$ \\
\hline & ANOSIM & 64 & All & $\delta^{13} \mathrm{C}, \delta^{15} \mathrm{~N}, \% \mathrm{~N}, \% \mathrm{C}, \mathrm{C}: \mathrm{N}$ & $\begin{array}{l}\text { Plot, Management regime, } \\
\text { Functional Groups }\end{array}$ \\
\hline \multicolumn{6}{|l|}{ Temporal } \\
\hline & Mantel & 10 & $\mathrm{CPb}$ & $A_{\max }, g_{\max }, R_{d}, l_{c} \Phi, \delta_{C: N}^{13} C, \delta^{15} \mathrm{~N}, \% N, \% C$ & Year \\
\hline & & 9 & CPmt & 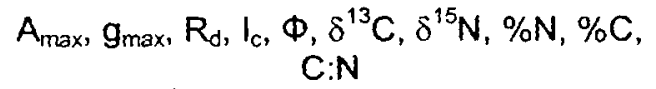 & Year \\
\hline & & 11 & KPmt & $\delta^{13} \mathrm{C}, \delta^{15} \mathrm{~N}, \% \mathrm{~N}, \% \mathrm{C}, \mathrm{C}: \mathrm{N}$ & Year \\
\hline & & 10 & $\mathrm{HCb}$ & $\delta^{13} \mathrm{C}, \delta^{15} \mathrm{~N}, \% \mathrm{~N}, \% \mathrm{C}, \mathrm{C}: \mathrm{N}$ & Year \\
\hline & & 64 & All & $\delta^{13} \mathrm{C}, \delta^{15} \mathrm{~N}, \% \mathrm{~N}, \% \mathrm{C}, \mathrm{C}: \mathrm{N}$ & Year \\
\hline & ANOSIM & 25 & $\begin{array}{l}\mathrm{CPb}, \mathrm{CPmt} \\
\mathrm{HCb}\end{array}$ & $A_{\max }, g_{\max }, R_{d}, I_{c}, \underset{C: N}{\Phi}, \delta^{13} \mathrm{C}, \delta^{15} \mathrm{~N}, \% \mathrm{~N}, \% \mathrm{C}$ & Year, Functional Groups \\
\hline & & 58 & All & $\delta^{13} \mathrm{C}, \delta^{15} \mathrm{~N}, \% \mathrm{~N}, \% \mathrm{C}, \mathrm{C}: \mathrm{N}$ & Year, Functional Groups \\
\hline \multicolumn{6}{|l|}{$\begin{array}{l}\text { Morphological } \\
\text { Indicator }\end{array}$} \\
\hline & Cluster & 48 & All & $A_{\text {max }}, G_{\text {max }}, R_{d}, I_{c}, \Phi, \delta_{C: N}^{13} C, \delta^{15} N, \% N, \% C$ & Functional Groups, Life forms \\
\hline & & 64 & All & $\delta^{13} \mathrm{C}, \delta^{15} \mathrm{~N}, \% \mathrm{~N}, \% \mathrm{C}, \mathrm{C}: \mathrm{N}$ & Functional Groups, Life forms \\
\hline & ANOSIM & 48 & All & 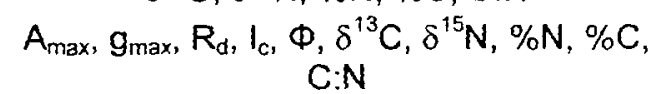 & SLA, Leaf thickness, Life form \\
\hline & & 64 & All & $\delta^{13} \mathrm{C}, \delta^{15} \mathrm{~N}, \% \mathrm{~N}, \% \mathrm{C}, \mathrm{C}: \mathrm{N}$ & SLA, Leaf thickness, Life form \\
\hline
\end{tabular}


both years. The second analysis examined the 26 species by plot combinations on which the suite of all 10 physiological measurements had been measured in 1999 and 2000. For all temporal robustness tests, the nitrogen concentration and the $\mathrm{C}: \mathrm{N}$ ratio data from the respective years (1999 and 2000) was used including the suspect data. This was done in order that a larger data set might be analyzed and with the assumption that if there were any effect of using the suspect $2000 \% \mathrm{~N}$ data, it would be in making the two years more dissimilar.

Statistics for Robustness of Morphological Indicators of Function

Hierarchical Cluster analysis and non-metric Multi-Dimensional Scaling (MDS) were used to assess which morphological indicator best represented the species clusters based on physiological function across all the plots using 2000 data with the exception of the $\% \mathrm{~N}$ and $\mathrm{C}: \mathrm{N}$ ratios (see details above). All plot by species combination of data were included for this analysis (Table 4). For instance, G. elliottii would have a separate entry for each of the plots in which it was present. The Hierarchical Cluster Analysis and the MDS were computed from the same distance matrices, in which the physiological variables were transformed with the Z-score (see above for details) and the Euclidean distance measure was used. A hierarchal cluster analysis and MDS were computed using all ten of the physiological parameters for 48 species by plot combinations. Another hierarchal cluster analysis was also computed using only the integrated measures for 64 species by plot combinations.

To examine which morphological indicator was more adequate for depicting the physiologically based functional groups, the MDS ordination output was examined in 3dimensional space, with the different morphological groupings (life form, life form + 
Ximenia americana, SLA, and leaf thickness) superimposed on the ordination. ANOSIM was used to determine whether differences existed between the groups of each morphological indicator. For example, were trees different than shrubs or were thick leaves different than thin leaves. The best indicator of physiological function was determined based on the value of the R statistic from the ANOSIM. The closer $R$ is to 1 the more complete the separation between the groups.

Results

Physiological Parameters

Photosynthesis at light saturation $\left(A_{\max }\right)$ ranged two-fold between the scrub species at the Camera Pad burn plot $(\mathrm{CPb})$, with Ximenia americana having the lowest mean $A_{\max }\left(10.57 \pm 0.53 \mu\right.$ mols $\left.\mathrm{CO}_{2} \mathrm{~m}^{-2} \mathrm{~s}^{-1}\right)$ and Quercus geminata having the highest mean $A_{\max }\left(21.89 \pm 1.16 \mu\right.$ mols $\left.\mathrm{CO}_{2} \mathrm{~m}^{-2} \mathrm{~s}^{-1}\right)$ in 1999 (Figure 4). However, the range of stomatal conductance at light saturation overlapped for most species $(0.137-0.465$ mols $\mathrm{H}_{2} \mathrm{O} \mathrm{m}^{-2} \mathrm{~s}^{-1}$ ) with the major exception being the hemiparasitic Ximenia americana which exhibited a greater loss of water from the leaves $\left(0.4-0.76\right.$ mols $\left._{2} \mathrm{O} \mathrm{m}^{-2} \mathrm{~s}^{-1}\right)$ than did the other species $(p \leq 0.001)$ (Figure 4).

All scrub species studied fix carbon using the $C_{3}$ photosynthetic pathway based on mean carbon isotope ratios $\left(\delta^{13} \mathrm{C}\right)$ that ranged between -26.93 and $-31.66 \%$ (Figure 5, Appendix A). Since all species were $C_{3}$, the $\delta^{13} \mathrm{C}$ served as an integrated measure of water-use efficiency (WUE). Both $\delta^{13} \mathrm{C}$ and the intrinsic water-use efficiency $\left(A_{\max } / g_{\max }\right)$ indicated that Ximenia americana was the least efficient scrub species in its water use $\left(20.08 \pm 1.55 \mu\right.$ mols $\mathrm{CO}_{2} / \mathrm{mols}_{2} \mathrm{O}, \mathrm{p} \leq 0.003 ;-31.66 \pm 0.10 \%, \mathrm{p} \leq 0.001$ 
Figure 4: Photosynthesis and conductance at light saturation for scrub species in 1999 at the Camera Pad burn plot. The data point is the mean value of photosynthesis and conductance for each species. The regression line shows the variation in $A_{\max }$ as a function of $g_{\max }$. The life form categories are depicted in the color scheme (palmetto $=$ red, shrubs $=$ green, trees = yellow, and vines $=$ white $)$.

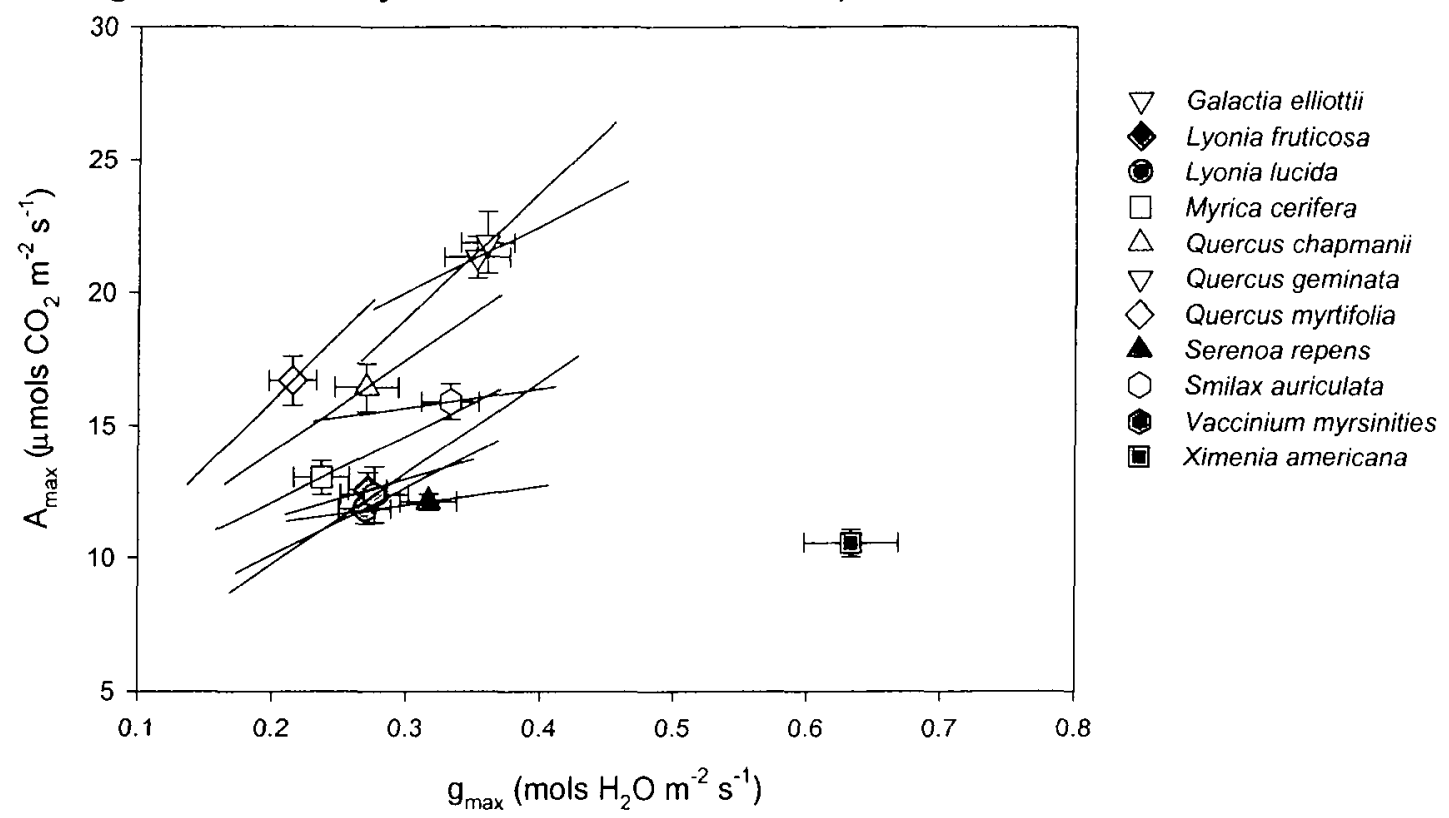

Figure 5: The water-use efficiency of the ten scrub species present in the Camera Pad burn plot in 1999. The data point is the species mean and the error bars indicate standard error.

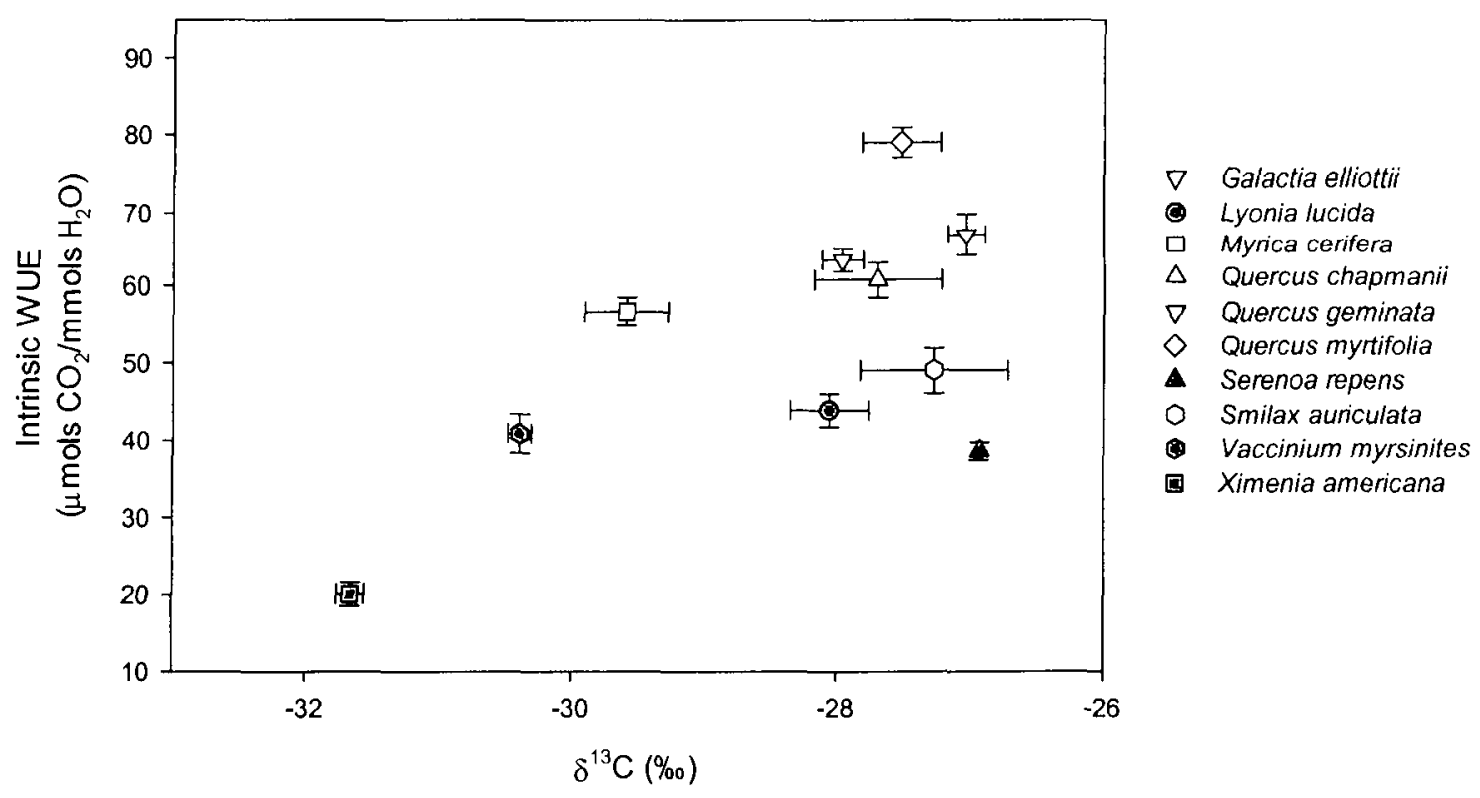


respectively) (Figure 5). However, there was not good agreement between these techniques as to which species was the most water-use efficient. The intrinsic WUE, an instantaneous measure of efficiency, indicated that Quercus myrtifolia was the most water-use efficient species $\left(79.01 \pm 1.95 \mu\right.$ mols $\left.\mathrm{CO}_{2} / \mathrm{mmols}_{2} \mathrm{O}, \mathrm{p} \leq 0.024\right)$, whereas the carbon isotope analysis indicated that several species were similar in their ability to conserve water (Serenoa repens, Galactia elliottii, Smilax auriculata as well as all three of the oaks) (Figure 5).

Mean dark respiration ranged from -2.02 to $-3.52 \mu$ mols $\mathrm{CO}_{2} \mathrm{~m}^{-2} \mathrm{~s}^{-1}$ for the scrub species. The mean light compensation point, or the amount of light required to achieve equilibrium between respiration and photosynthesis, ranged two fold with a low of $35.44 \mu$ mols photons $\mathrm{m}^{-2} \mathrm{~s}^{-1}$ and a high of $73.65 \mu$ mols photons $\mathrm{m}^{-2} \mathrm{~s}^{-1}$ (Myrica cerifera and Lyonia fruticosa respectively). The moles of carbon fixed per photon absorbed varied between a low of $0.039 \mu \mathrm{mols} \mathrm{CO}_{2} / \mu \mathrm{mols}$ photons and a high of 0.057 $\mu$ mols $\mathrm{CO}_{2} / \mu$ mols photons. No significant species differences were found for dark respiration $\left(R_{d}\right)$, light compensation point $\left(l_{c}\right)$, or quantum efficiency $(\Phi)$. This is most likely a product of small sample size $(n=2)$ (see Appendix A).

A positive relationship existed between photosynthesis at light saturation on a mass basis and percent nitrogen for the scrub species present at the Camera Pad burn plot (Figure 6a), while a negative association existed between percent carbon and percent nitrogen (Figure 6b). Galactia elliottii, which contained the highest mean concentration of nitrogen in the leaf $\left(2.25 \pm 0.186 \mathrm{~g} \mathrm{~g}^{-1}\right)$, exhibited the highest mean photosynthesis at light saturation on a mass basis but had a low mean concentration of carbon in the leaf $\left(44.48 \pm 0.16 \mathrm{~g} \mathrm{~g}^{-1}\right)$ leading to a low C: $\mathrm{N}$ ratio $(20.05 \pm 1.73)$. In 
general, those species with higher leaf nitrogen concentrations tended to have more enriched nitrogen isotope ratio (Figure 6c).

Figure 6: Photosynthesis at light saturation (a), leaf carbon concentration (b), and the nitrogen isotope ratio (c) as a function of leaf nitrogen concentration in 1999 for the Camera Pad burn plot. The data point is the species mean and the error bars indicate the standard error.

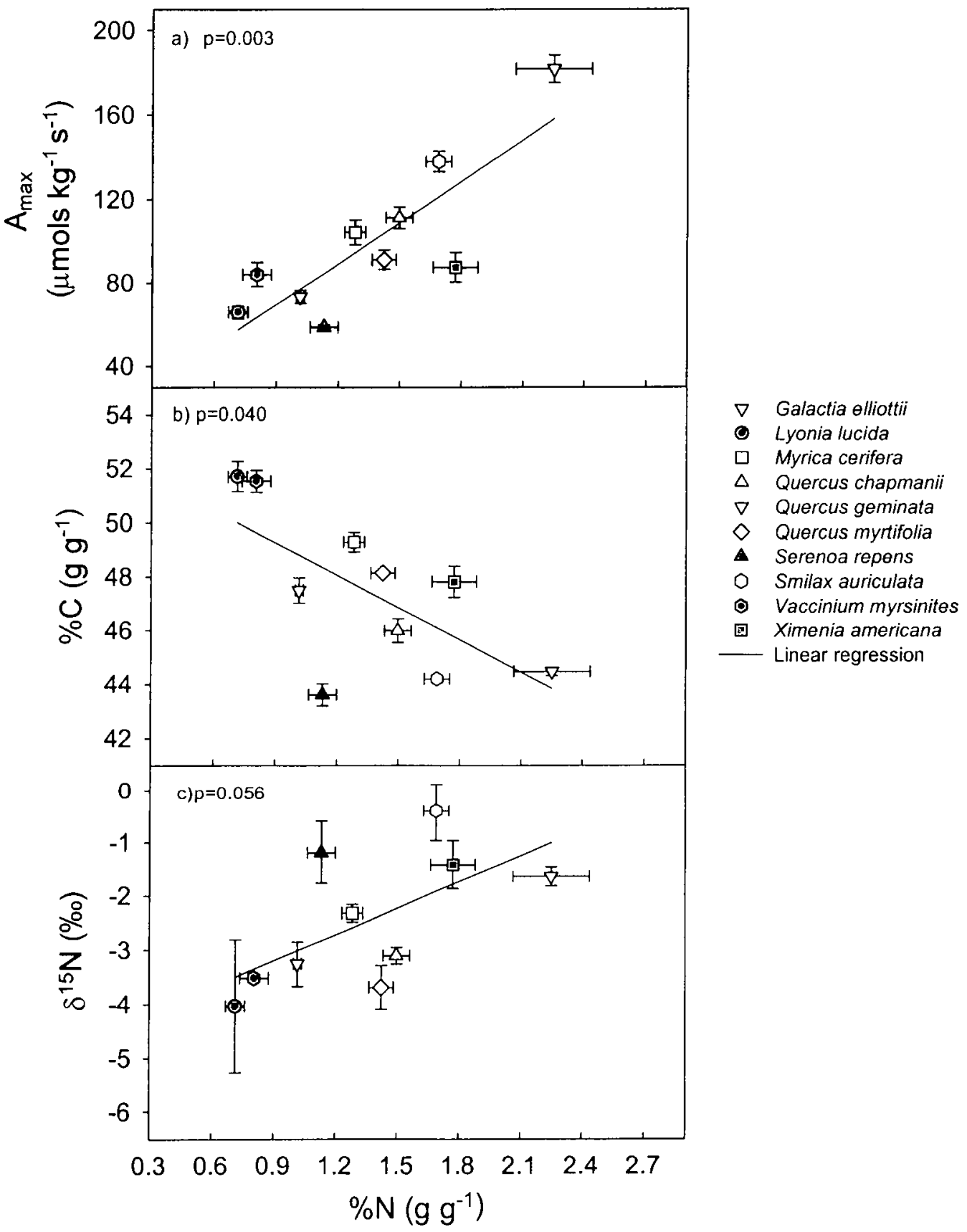


Morphological Indicators of Function

Trends existed between life form classifications and many of the physiological parameters (Table 5). Trees and vines had higher maximum photosynthesis $\left(A_{\max }\right)$ on an area basis $(p \leq 0.017)$ and intrinsic water-use efficiencies $(p \leq 0.002)$ than did evergreen shrubs and palmetto (Figures 4 and 5). Calculating maximum photosynthesis at light saturation on a mass basis further separated the life forms, with the vines having higher maximum carbon assimilation than the evergreen trees $(p<$ 0.001) (Figure 6a). The shrubs typically had low leaf nitrogen concentrations and more depleted nitrogen isotope ratios $\left(\delta^{15} \mathrm{~N}\right)$ than the vines, which had high leaf nitrogen and $\delta^{15} \mathrm{~N}$ near zero. The palmetto and trees both had intermediate nitrogen concentrations; however, the trees had a similar $\delta^{15} \mathrm{~N}$ signal to the shrubs while the palmettos signal was similar to the vines (Figure 6c). For species that exhibited similar respiration (Figure 7), the trees and vines not only had higher photosynthesis at light saturation $\left(A_{\max }\right)$ but also fixed more carbon per photon absorbed than did the evergreen shrubs and palmetto. The trees and vines also reached equilibrium between photosynthesis and respiration at a lower level of light when compared to shrubs and vines with similar dark respiration and quantum efficiencies (Figure 7).

Table 5: Summary of physiological parameters for the different life form classifications taken in 1999 at the Camera pad burn plot.

\begin{tabular}{|c|c|c|c|c|c|c|c|}
\hline Life form & $\begin{array}{c}A_{\max } \\
\text { (mass-based) }\end{array}$ & $\mathbf{R}_{\mathrm{d}}$ & WUE & $\% N$ & $\delta^{15} \mathrm{~N}$ & $\delta^{13} \mathrm{C}$ & $C: N$ \\
\hline Trees & Mid & Low & High & Mid & Low & Mid & Mid \\
\hline Shrubs & Mid-Low & High & Mid* & Low L $^{*}$ & Low ${ }^{*}$ & Variable & High* \\
\hline Vines & High & Variable & Mid-High & High & High & High & Low \\
\hline Palmetto & Low & Low & Mid & Mid & High & High & Mid \\
\hline
\end{tabular}

${ }^{*}$ w/ exception of Ximenia americana 
Figure 7: Instantaneous gas exchange measures from scrub species for the $\mathrm{CPb}$ plot in 1999. Data points are mean species values and error bars indicate standard error.

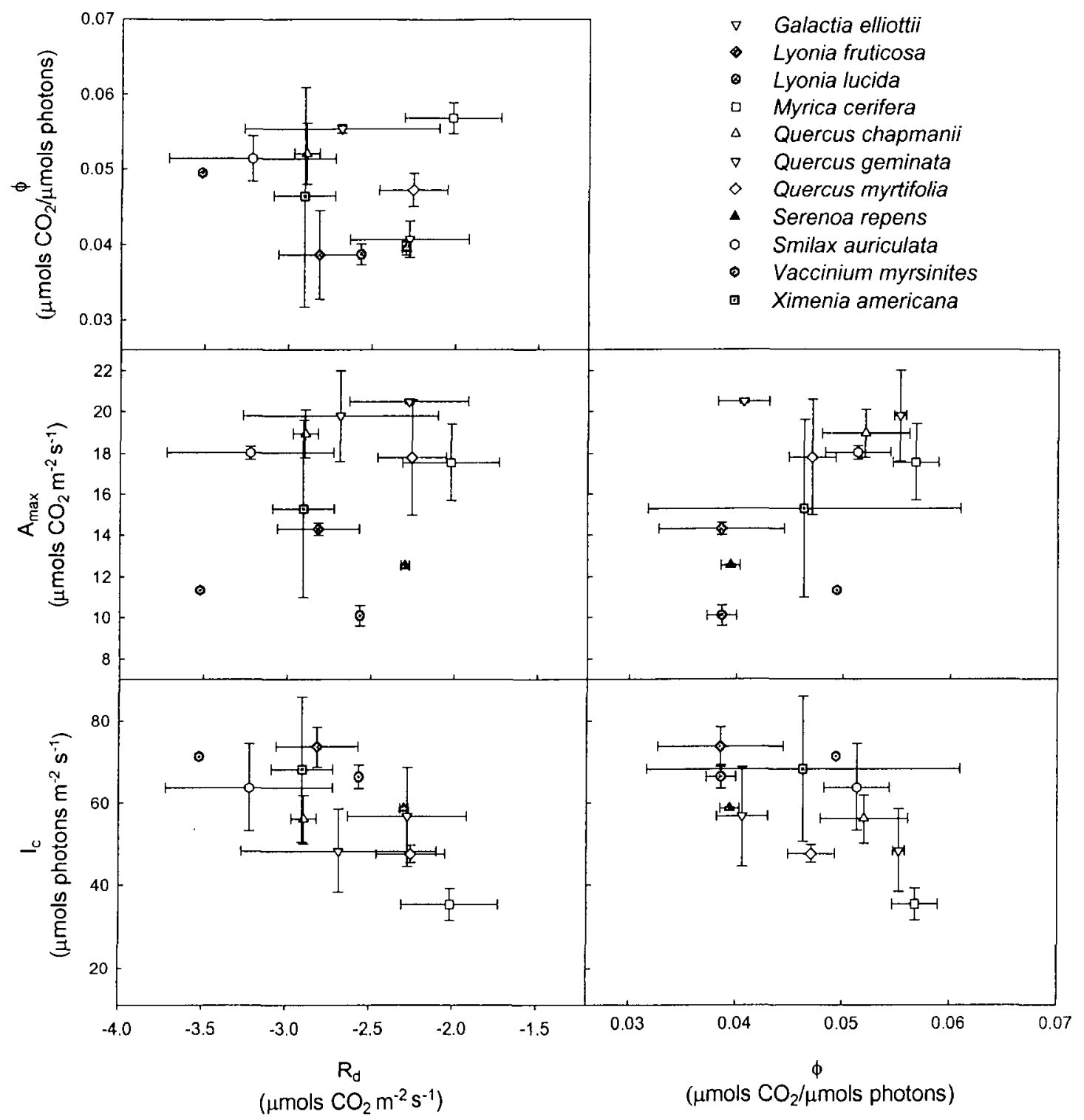

For several of the physiological parameters Ximenia americana, the hemi-

parasitic shrub, responded differently than the other shrubs. For instance, it had a higher maximum conductance at light saturation (Figure 4) and was less efficient in its water use (Figure 5). Ximenia americana also had a higher leaf nitrogen concentration and more enriched $\delta^{15} \mathrm{~N}$ than the other shrubs (Figure 6). 
Few relationships existed between the other two morphological characteristics and the physiological parameters. Specific leaf area (SLA) was positively associated with leaf nitrogen concentration as well as photosynthesis at light saturation on a mass basis (Figure 8). Leaf thickness was positively associated with $\delta^{13} \mathrm{C}$ and photosynthesis at light saturation on an area basis (data not shown). No other associations were identified.

Figure 8: Photosynthesis at light saturation (a) and percent nitrogen (b) as a function of specific leaf area for scrub species in 1999 at the Camera Pad burn plot.

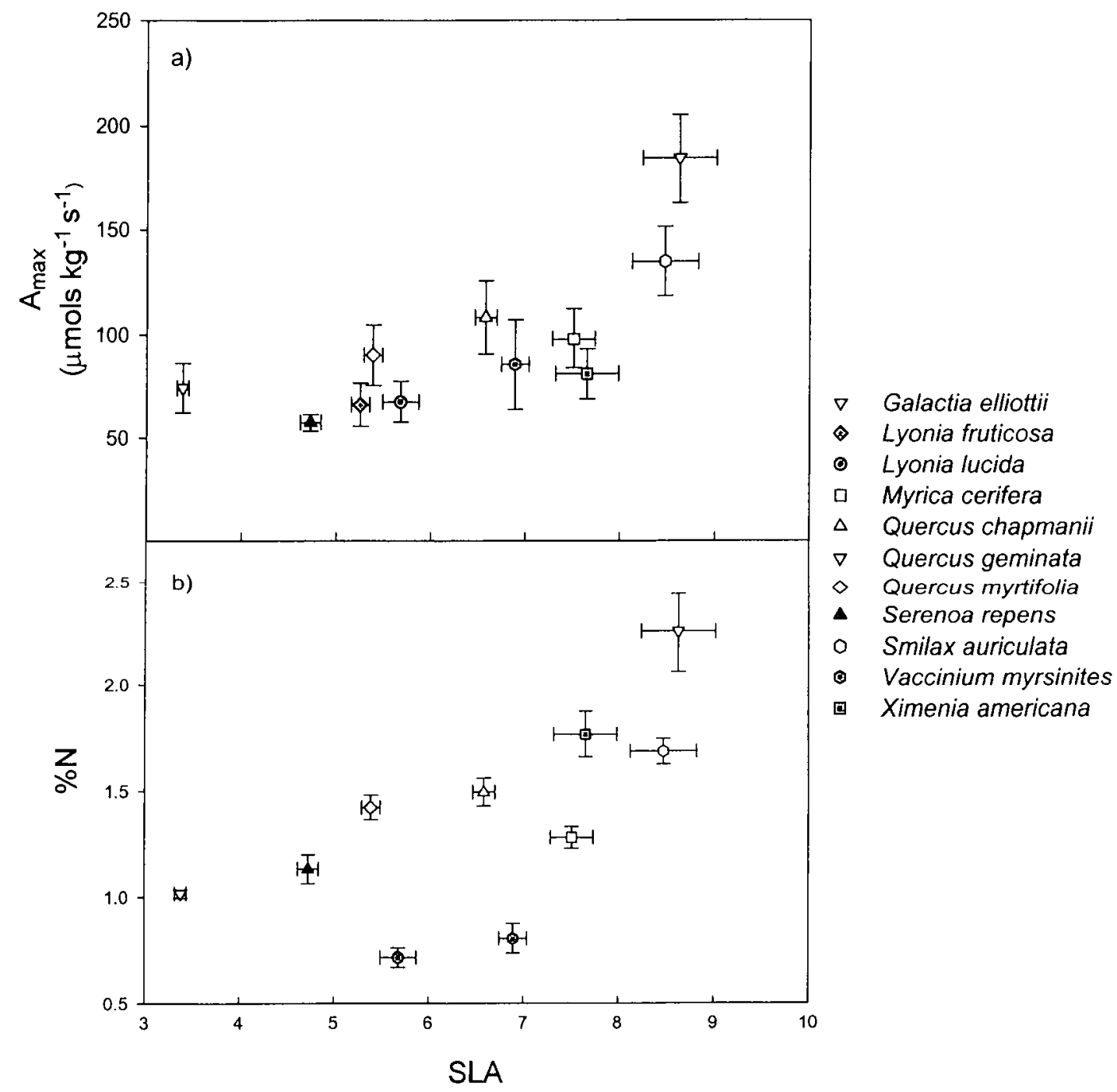




\section{Functional Groups}

The species that were the most similar in their physiological responses at the Camera Pad burn plot were Quercus geminata and Quercus myrtifolia (Figure 9). Quercus chapmanii also responded very similarly to the other two oaks. Lyonia lucida and Vaccinium myrsinites differed the most from the other eight species in the physiological responses, yet these two species responded similarly to one another. Galactia elliottii and Smilax auriculata also were quite similar in their physiological responses (Figure 9).

Five physiologically based functional groups of species (Table 6) were identified from the cluster analysis at a similarity distance of approximately 24 (Figure 9).

Galactia elliottii and Smilax auriculata were members of one functional group, while Myrica cerifera and the three oaks were members of a second functional group.

Serenoa repens and Ximenia americana were not clustered with any other species, while Lyonia lucida and Vaccinium myrsinites were members of another functional group.

Table 6: The species included in each physiological functional group based on species responses to carbon, nitrogen, and water.

\begin{tabular}{cc}
\hline Physiological Group & Species Included \\
\hline 1 & Serenoa repens \\
2 & Lyonia lucida, Vaccinium myrsinites \\
3 & Myrica cerifera, Quercus chapmanii, Quercus geminata, \\
& Quercus myrtifolia \\
5 & Galactia elliottii, Smilax auriculata \\
5 & Ximenia americana \\
\hline
\end{tabular}

Of the three morphological characteristics, only life form classifications were able to adequately depict membership in the physiologically based functional groups (Figure 9). Groupings based on specific leaf area and leaf thickness contained physiologically 
Figure 9: Dendrogram depicting physiological based functional groups and how they relate to the morphological classifications: life form, leaf thickness (LT), and specific leaf area (SLA). The physiological variables used to create the clusters included $A_{\max }, g_{\max }, R_{d}, l_{c}, \Phi, \delta{ }^{13} \mathrm{C}, \delta{ }^{15} \mathrm{~N}, \% \mathrm{~N}, \% \mathrm{C}$, and $\mathrm{C}: \mathrm{N}$. These clusters are significantly different from random $(p=0.04)$.

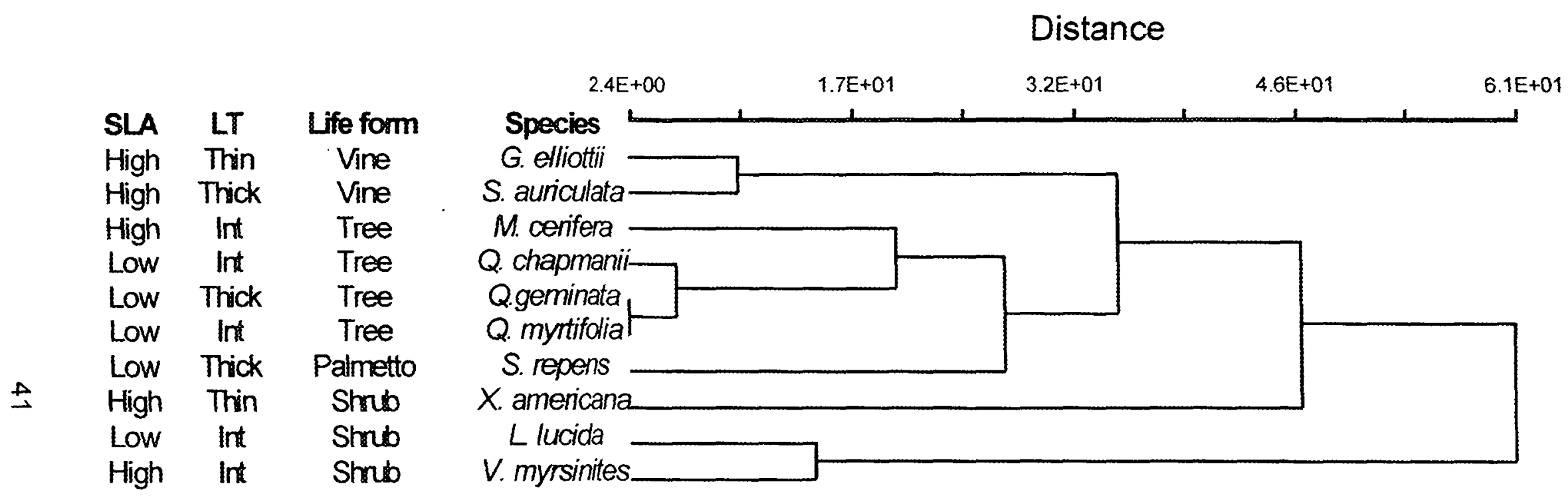


dissimilar species. For instance, specific leaf area grouped Galactia elliottii and Vaccinium myrsinites together, yet these are two of the most dissimilar species in their physiological responses. By using the four life form classifications, a summary of the expected physiological responses can be made (Tables 5 and 7).

Table 7: Comparison of the integrated physiological measures for the functional groups from 1999 data in the Camera Pad burn plot

\begin{tabular}{ccccc}
\hline & Palmetto & Shrub & Tree & Vine \\
\cline { 2 - 5 } $\mathbf{N}$ & 3 & 8 & 12 & 5 \\
$\% \mathbf{C}\left(\mathbf{g ~ g}^{-1}\right)$ & $43.60(0.42)$ & $50.07(0.71)$ & $47.73(0.39)$ & $44.37(0.12)$ \\
$\% \mathbf{N}\left(\mathbf{g ~ g}^{-1}\right)$ & $1.13(0.07)$ & $1.15(0.19)$ & $1.30(0.06)$ & $2.03(0.17)$ \\
$\mathbf{C : N}$ & $38.83(2.41)$ & $52.58(7.84)$ & $37.55(1.91)$ & $22.51(1.80)$ \\
$\delta^{15} \mathbf{N}(\%)$ & $-1.19(0.57)$ & $-2.86(0.51)$ & $-3.09(0.20)$ & $-1.15(0.36)$ \\
$\delta^{13} \mathbf{C}(\%)$ & $-26.93(0.02)$ & $-30.21(0.57)$ & $-28.19(0.29)$ & $-27.12(0.20)$ \\
\hline
\end{tabular}

Spatial Robustness

Management regime did not alter species responses in the Florida scrub. For instance, the species at the burn and mechanically treated Camera Pad plots exhibited similar physiological responses (Figure 10). Respiration varied more than photosynthesis at light saturation and the integrated measures. Galactia elliottii had a lower rate of dark respiration in the burn plot, whereas several of the other species had higher respiration rates in the burn plot. Similar trends were observed between the Camera Pad burn and fire-suppressed plots.

More important than individual species responses, was how the physiologically based functional groups responded spatially. No plot (Table 8 ) or management regime (Table 9) effects were found after accounting for the differences between the physiological functional groups. The five physiological groupings were found to be robust across plots (Table 8) and management regimes (Table 9) when accounting for spatial differences. Therefore, the five groupings continued to cluster differently based on their 
Figure 10: Robustness of the physiological responses of eleven scrub species in 2000 between two plots with varying management regimes; the Camera pad burn plot and the Camera Pad mechanically treated plot. Data points are species means and error bars indicate standard error.
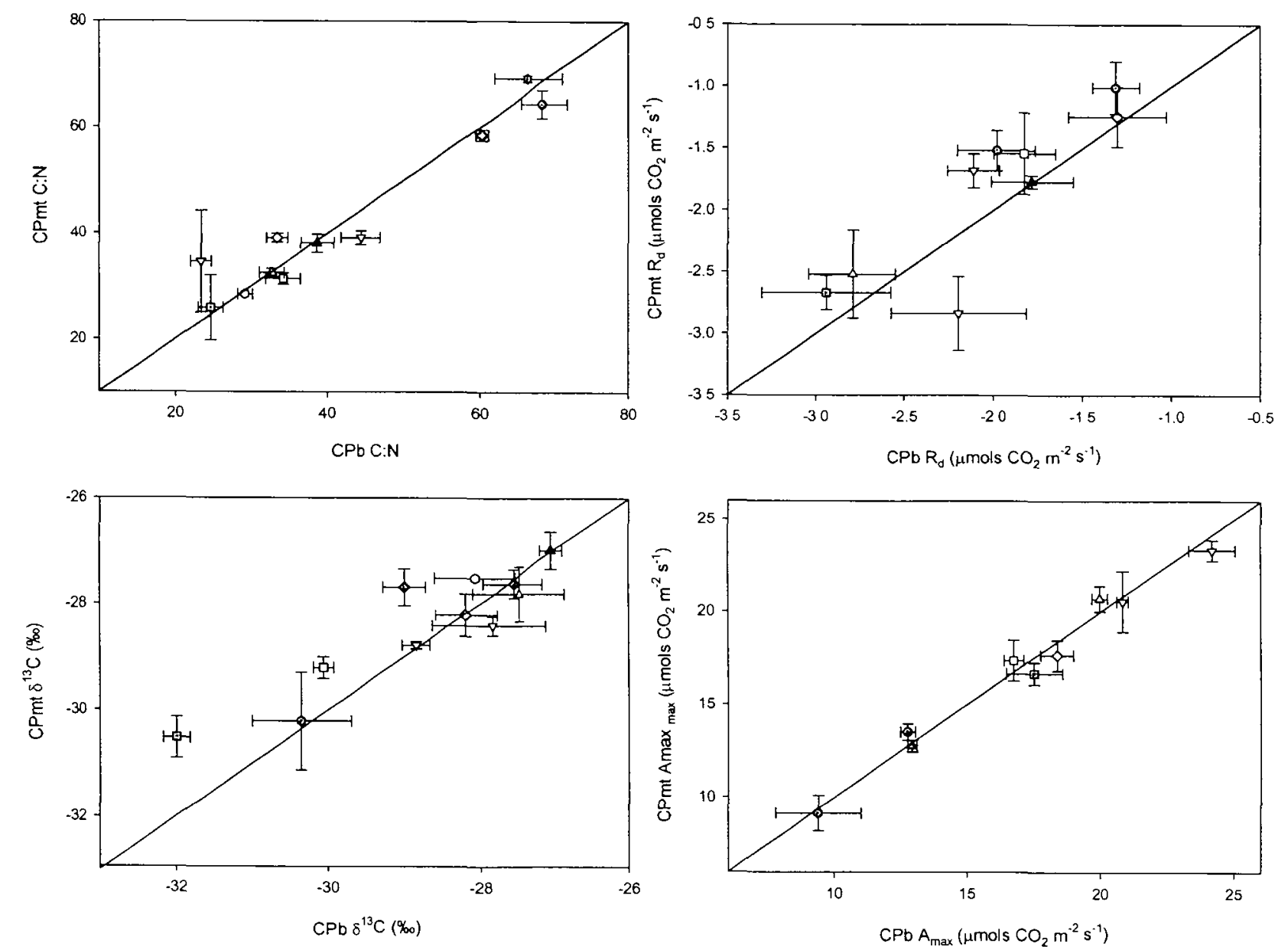

$\nabla$ Galactia elliottii

Lyonia fruticosa

Lyonia lucida Myrica cerifera Quercus chapmanii Quercus geminata

Quercus myrtifolia

Serenoa repens

Smilax auriculata

- Vaccinium myrsinites

- Ximenia americana

1:1 Line 
Table 8: Summary of analysis of similarities (ANOSIM) for determination of spatial robustness between plots of the physiologically based functional groups (PFG). \# $\mathrm{S} \times \mathrm{P}$ indicates the number of species by plot combinations included in the analysis. Pairwise comparison numbers indicate the different physiological functional groups (Table 6).

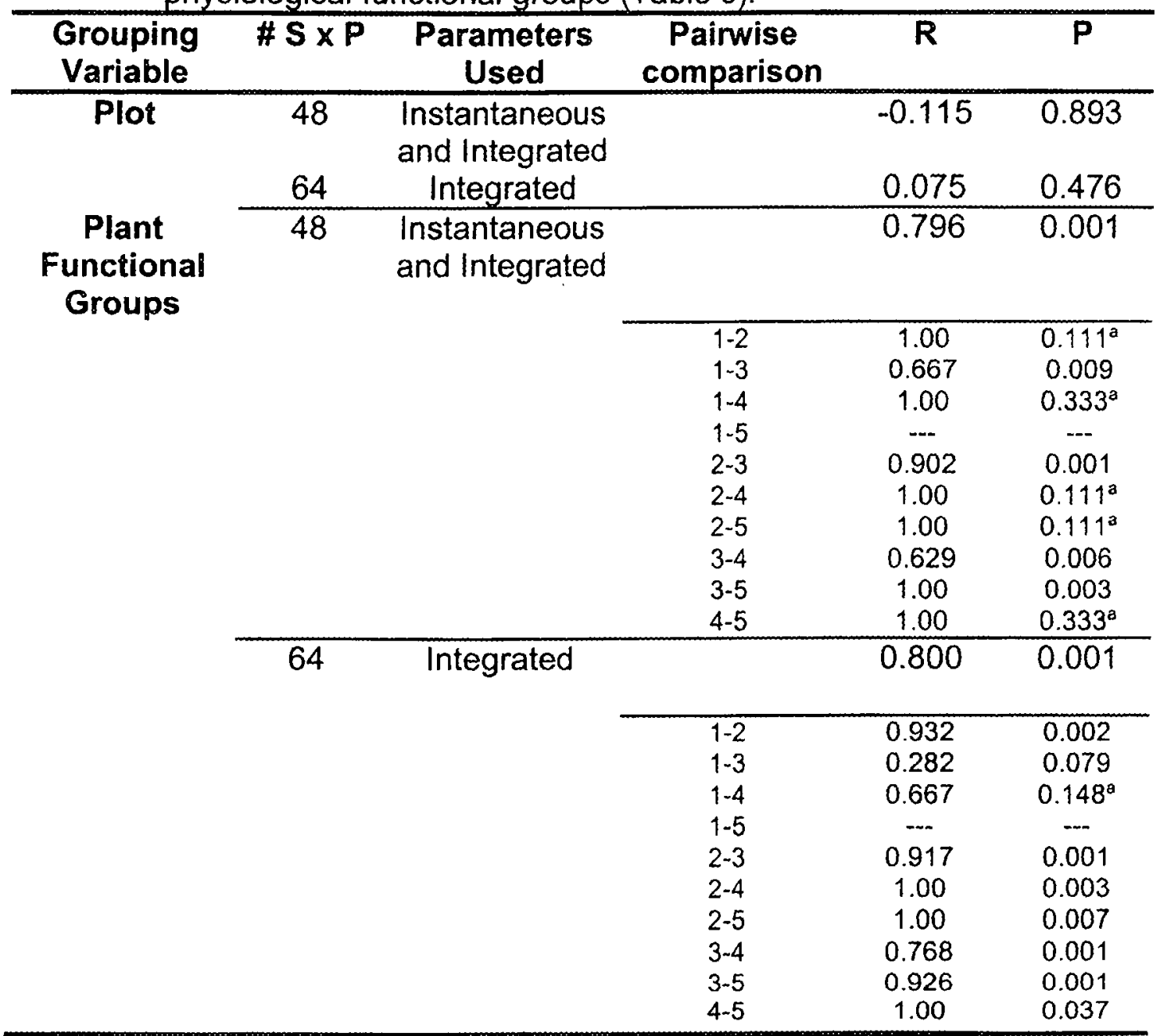

\footnotetext{
${ }^{a}=$ the sample size is too small to deliver a significant $p$ value. However the $\mathrm{R}$ statistic indicates that
} there is good separation for all the pairwise comparisons. 
Table 9: Summary of analysis of similarities (ANOSIM) for determination of spatial robustness between management regimes of the physiologically based functional groups (PFG). \# $\times$ P indicates the number of species by plot combinations included in the analysis. Pairwise comparison numbers indicate the different physiological functional groups (Table 6).

\begin{tabular}{|c|c|c|c|c|c|}
\hline $\begin{array}{l}\text { Grouping } \\
\text { Variable }\end{array}$ & \#S $\times P$ & $\begin{array}{c}\text { Parameters } \\
\text { Used }\end{array}$ & $\begin{array}{c}\text { Pairwise } \\
\text { comparison }\end{array}$ & $\mathbf{R}$ & $\mathbf{P}$ \\
\hline \multirow[t]{2}{*}{$\begin{array}{l}\text { Management } \\
\text { Regime }\end{array}$} & 48 & $\begin{array}{l}\text { Instantaneous } \\
\text { and Integrated }\end{array}$ & & 0.018 & 0.340 \\
\hline & 64 & Integrated & & 0.059 & 0.099 \\
\hline \multirow{22}{*}{$\begin{array}{c}\text { Plant } \\
\text { Functional } \\
\text { Groups }\end{array}$} & 48 & $\begin{array}{l}\text { Instantaneous } \\
\text { and Integrated }\end{array}$ & & 0.724 & 0.001 \\
\hline & & & $1-2$ & 0.876 & 0.006 \\
\hline & & & $1-3$ & 0.594 & 0.001 \\
\hline & & & 1.4 & 1.00 & 0.033 \\
\hline & & & 1.5 & 1.00 & 0.033 \\
\hline & & & $2-3$ & 0.908 & 0.001 \\
\hline & & & 2.4 & 1.00 & 0.003 \\
\hline & & & $2-5$ & 1.00 & 0.007 \\
\hline & & & $3-4$ & 0.508 & 0.001 \\
\hline & & & $3-5$ & 0.935 & 0.001 \\
\hline & & & $4-5$ & 0.690 & $0.100^{\mathrm{a}}$ \\
\hline & 64 & Integrated & & 0.816 & 0.001 \\
\hline & & & $\overline{1-2}$ & 0.900 & 0.001 \\
\hline & & & $1-3$ & 0.424 & 0.007 \\
\hline & & & $i-4$ & 0.707 & 0.005 \\
\hline & & & $1-5$ & 1.00 & 0.033 \\
\hline & & & $2-3$ & 0.902 & 0.001 \\
\hline & & & $2-4$ & 1.00 & 0.001 \\
\hline & & & $2-5$ & 1.00 & 0.001 \\
\hline & & & $3-4$ & 0.713 & 0.001 \\
\hline & & & $3-5$ & 0.907 & 0.001 \\
\hline & & & $4-5$ & 0.819 & 0.009 \\
\hline
\end{tabular}

$\bar{a}=$ the sample size is too small to deliver a significant $p$ value. However the $R$ statistic indicates that there is good separation for all the pairwise comparisons. 
physiology regardless of the plot location (Table 8) or the management regime (Table 9). One exception was groups 1 (S. repens) and 3 (Quercus group), which did not cluster separately in the plot test using only the integrated measures, but did when considering management regime.

Temporal Robustness

In general, species responses did not differ between years in the Camera Pad burn plot $(\mathrm{CPb})$ (Figure 11). The integrated measures were more robust than the instantaneous measures. This was observed for the Camera Pad mechanically treated plot as well (data not shown). For instance, dark respiration was higher in 1999 than 2000 for several species, most notably Vaccinium myrsinities and Smilax auriculata. However, there was virtually no variation in the carbon to nitrogen ratio between the two years. The carbon isotope ratio $\left({ }^{13} \mathrm{C}\right)$ was temporally robust for all plots (Figure 12). In addition, $\delta{ }^{13} \mathrm{C}$ values of the same species from different plots tended to cluster together. When all physiological variables are considered together, species responses were highly correlated between the two years; 1999 and 2000 (Table 10, Mantel test). At the Camera Pad burn plot, the physiological responses of the species present were significantly correlated between the two years $(R=0.67, p=0.001)$; as well as for the Camera Pad mechanically treated plot $(R=0.45, p=0.025)$. The integrated responses of the species present at the Kennedy Parkway mechanically treated and the Happy Creek burn plots were significantly correlated between 1999 and $2000(R=0.83, p=$ $0.001 ; R=0.76, p=0.001$ respectively). When the integrated measures were compared between 1999 and 2000 for the 64 species by plot comparisons, the data 
Figure 11: Temporal comparisons of species responses at the Camera Pad burn plot for the years 1999 and 2000. Data points are mean species values and error bars indicated standard error.
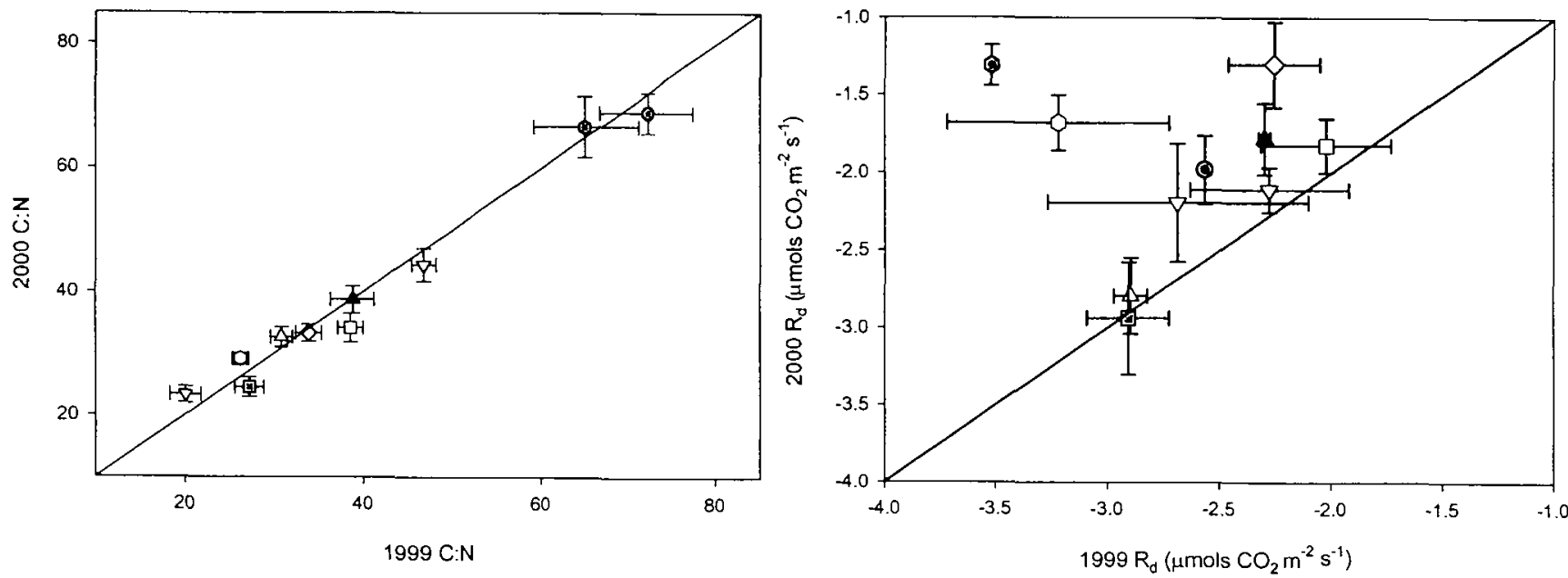

ज
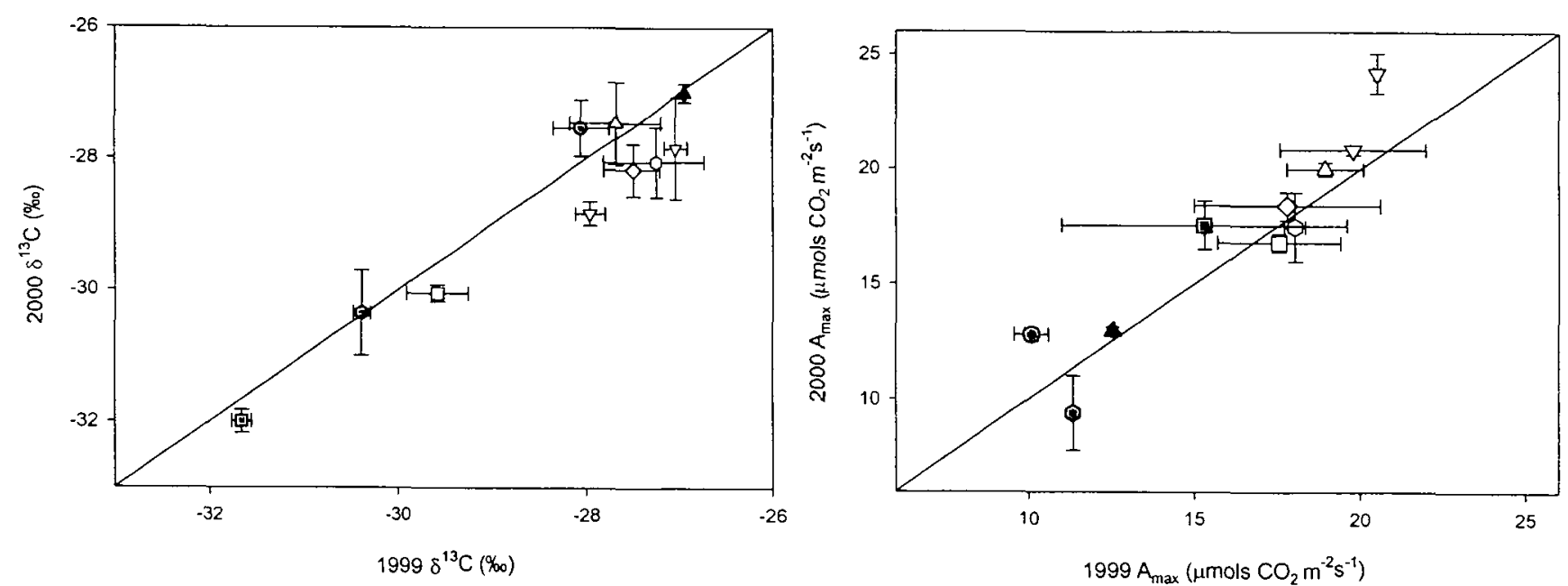

Galactia elliotti

Lyonia lucida

Myrica cerifera

$\triangle$ Quercus chapmanii

$\nabla \quad$ Quercus geminata

$\diamond \quad$ Quercus myrtifolia

- Serenoa repens

- Smilax auriculata

- Vaccinium myrsinites

a Ximenia americana

- 1:1 Line 
Figure 12: Temporal comparison of species carbon isotope values for the eight plots that were sampled in 1999 and 2000. Data points are the mean species value per plot.

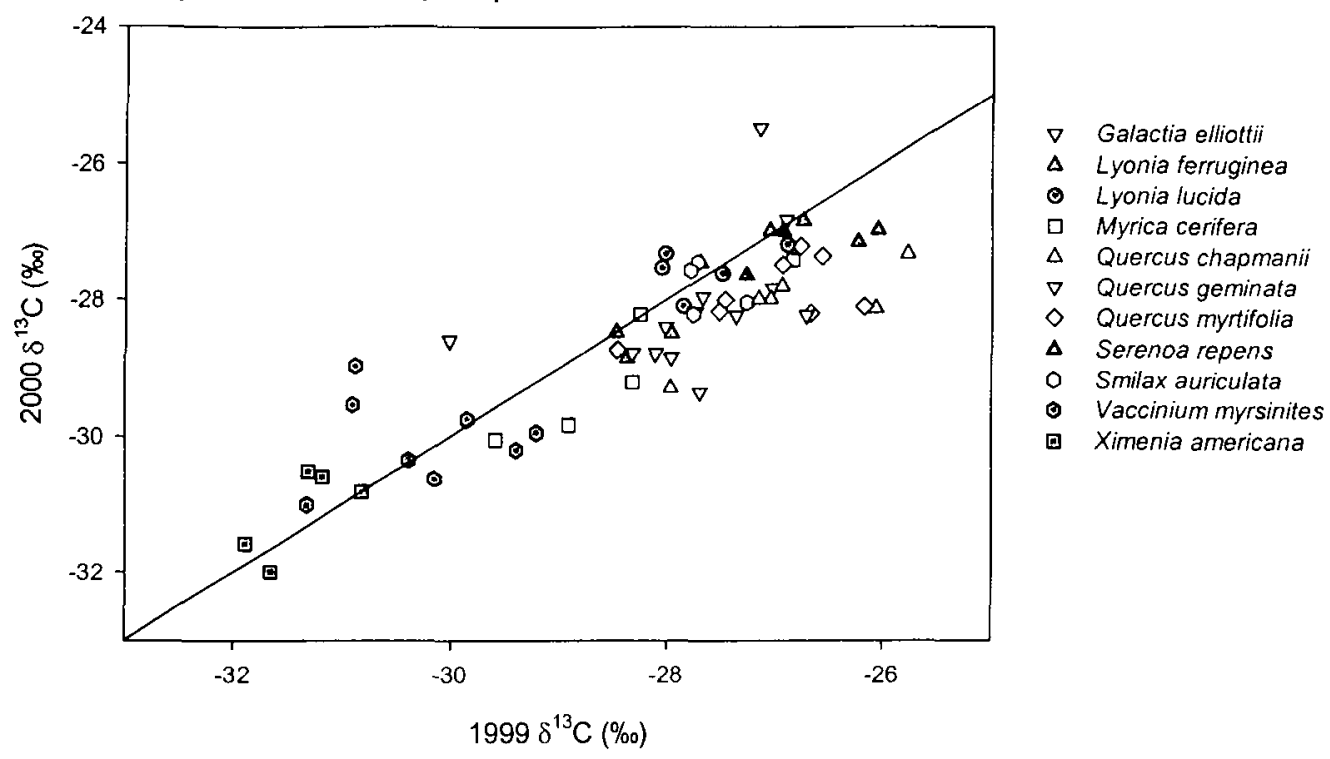

Table 10: Summary of Mantel Test results for temporal robustness. \# S $\mathrm{P}$ indicates the number of species by plot combinations included in the analysis. $R$ is the correlation between the 1999 and 2000 distance matrices, and $p$ is the significance level.

\begin{tabular}{ccccc}
\hline Plot & $\# \mathrm{~S} \times \mathrm{P}$ & Physiological parameters & $\mathrm{R}$ & $\mathrm{P}$ \\
\hline $\mathrm{CPb}$ & 10 & Instantaneous and Integrated & 0.67 & 0.001 \\
$\mathrm{CPmt}$ & 9 & Instantaneous and Integrated & 0.45 & 0.025 \\
$\mathrm{KPmt}$ & 11 & Integrated & 0.83 & 0.001 \\
$\mathrm{HCb}$ & 10 & Integrated & 0.76 & 0.001 \\
$\mathrm{All}$ & 64 & Integrated & 0.79 & 0.001 \\
\hline
\end{tabular}

from the two years were highly correlated indicating a strong temporal robustness $(R=$ $0.79, p=0.001)$

Temporal robustness of the five physiological functional groups was of more interest than species responses. No differences were identified between 1999 and 2000 when the differences in the responses of the physiological groupings were accounted for (Table 11). The physiological functional groups were found to be temporally robust. The groups did cluster differently based on their physiology when differences in years were allowed for (Table 11). 
Table 11: Summary of analysis of similarities (ANOSIM) for determination of temporal robustness of the physiologically based functional groups (PFG). \# $\mathrm{S} \times \mathrm{P}$ indicates the number of species by plot combinations included in the analysis. Pairwise comparison numbers indicate the different physiological functional groups (Table 6).

\begin{tabular}{|c|c|c|c|c|c|}
\hline $\begin{array}{l}\text { Grouping } \\
\text { Variable }\end{array}$ & $\# \mathbf{S} \times \mathbf{P}$ & $\begin{array}{c}\text { Parameters } \\
\text { Used }\end{array}$ & $\begin{array}{c}\text { Pairwise } \\
\text { comparison }\end{array}$ & $\mathbf{R}$ & $\mathbf{p}$ \\
\hline \multirow{24}{*}{$\begin{array}{c}\text { Plant } \\
\text { Functional } \\
\text { Groups }\end{array}$} & 25 & $\begin{array}{l}\text { Instantaneous } \\
\text { and Integrated }\end{array}$ & & -0.027 & 0.725 \\
\hline & 58 & Integrated & & -0.014 & 0.708 \\
\hline & 25 & $\begin{array}{l}\text { Instantaneous } \\
\text { and Integrated }\end{array}$ & & 0.682 & 0.001 \\
\hline & & & $1-2$ & 0.841 & 0.002 \\
\hline & & & $1-3$ & 0.562 & 0.002 \\
\hline & & & $1-4$ & 0.861 & 0.002 \\
\hline & & & 1.5 & 1.0 & 0.010 \\
\hline & & & $2-3$ & 0.708 & 0.001 \\
\hline & & & $2 \sim 4$ & 0.997 & 0.001 \\
\hline & & & $2-5$ & 0.985 & 0.001 \\
\hline & & & $3-4$ & 0.307 & 0.006 \\
\hline & & & $3-5$ & 0.774 & 0.001 \\
\hline & & & $4-5$ & 0.972 & 0.001 \\
\hline & 58 & Integrated & & 0.776 & 0.001 \\
\hline & & & $1-2$ & 0.895 & 0.001 \\
\hline & & & $1-3$ & 0.424 & 0.001 \\
\hline & & & $1-4$ & 0.428 & 0.001 \\
\hline & & & $1-5$ & 1.00 & 0.001 \\
\hline & & & $2-3$ & 0.875 & 0.001 \\
\hline & & & $2-4$ & 0.979 & 0.001 \\
\hline & & & $2-5$ & 0.987 & 0.001 \\
\hline & & & $3-4$ & 0.650 & 0.001 \\
\hline & & & $3-5$ & 0.946 & 0.001 \\
\hline & & & $4-5$ & 0.769 & 0.001 \\
\hline
\end{tabular}


Robustness of Morphological Indicators of Function

The physiological based functional groups of scrub species were found to be spatially and temporally robust. The focus then shifts to which morphological indicator best represents these five physiological groupings across all the plots. The life form categories were found to adequately depict the physiologically based functional groups in 2000 at all the plots as had previously been shown for 1999 in the Camera pad burn plot (Figures 13, 14, and 15). The trees, shrubs, vines, and palmettos did cluster differently based on their physiology. Interestingly, the life form classifications were able to depict the functional groups not only using both the instantaneous and integrated variables (Figure 13) but also when only the integrated variables were used (Figures 14). Spatial separation of species between the various plots did not alter the physiological functional groups or the ability of the life form classifications to depict the groupings.

The life form classifications remained the most useful morphological indicator of physiological function for the scrub species regardless of temporal and spatial differences (Figure 15). Neither specific leaf area (Figure 15a) or leaf thickness (Figure 15c) had as good of separation as did life form, although groupings were significant. In all cases the groupings were stronger using all ten physiological parameters over just the integrated measures (Table 12). The degree of separation for SLA groupings was higher than for leaf thickness (ANOSIM; $R=0.426$ and $R=0.344$ respectively). However, the degree of separation for life form was much larger than for either SLA or leaf thickness $(R=0.629)$. A high degree of separation is indicative of complete 


\section{Distance}

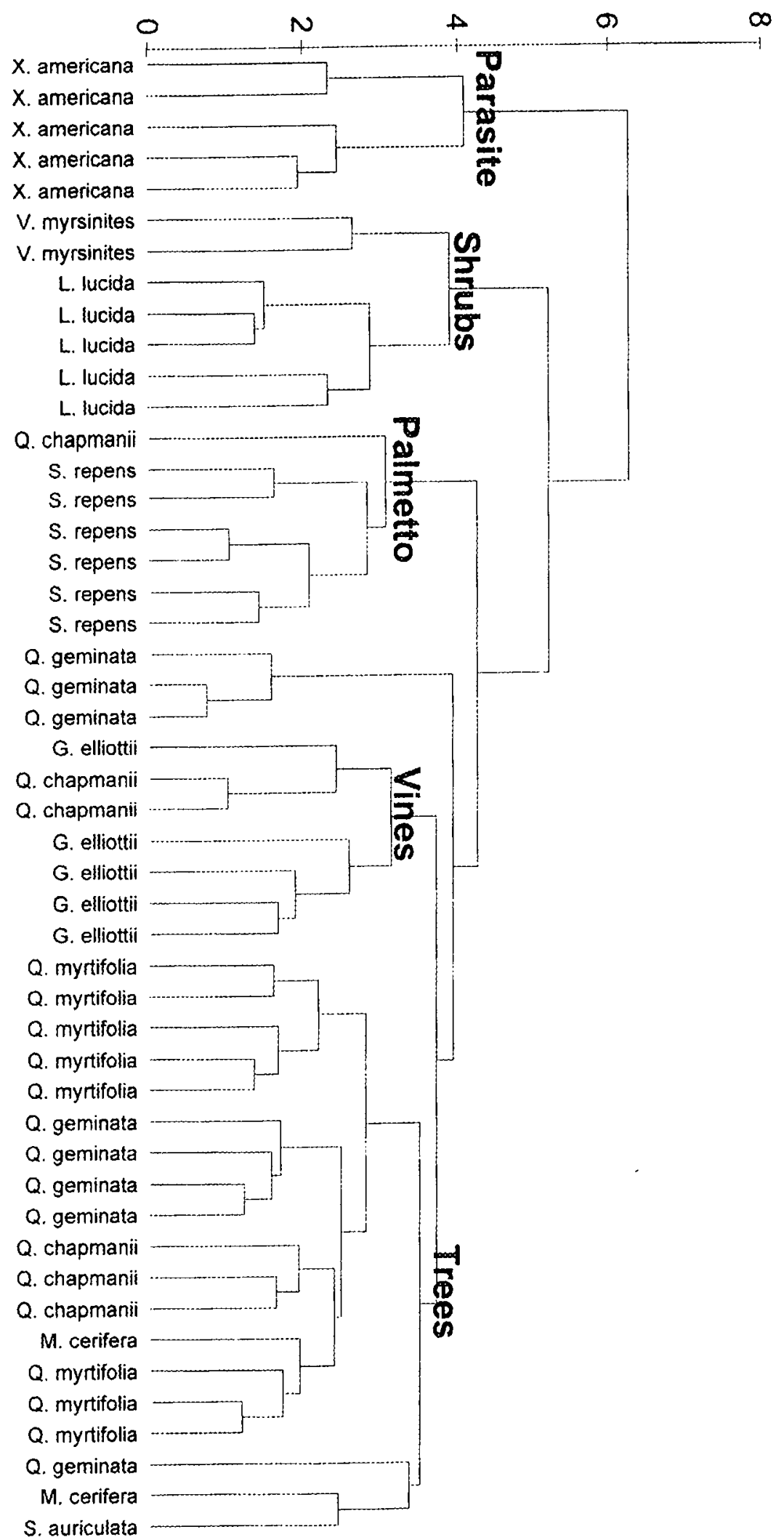

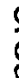

@

(D)

₹ 8

(D)

용

के 2

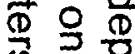

.

$\infty$

㑒

흥요 웅

口.

$>$ क

节

0 음

$3)$

@

刀

造

-

$\theta 3$

क ज

के D

$\Omega$ 긍

क

는응

웅 응

Z

- 것

ㅇํㅇㅇㅇㅇ

응ㅇㅇ

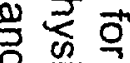

?응

Z@

윽

ธ오

글.

बू कू

몽

क

등

क

的

ธ 


\section{Distance}

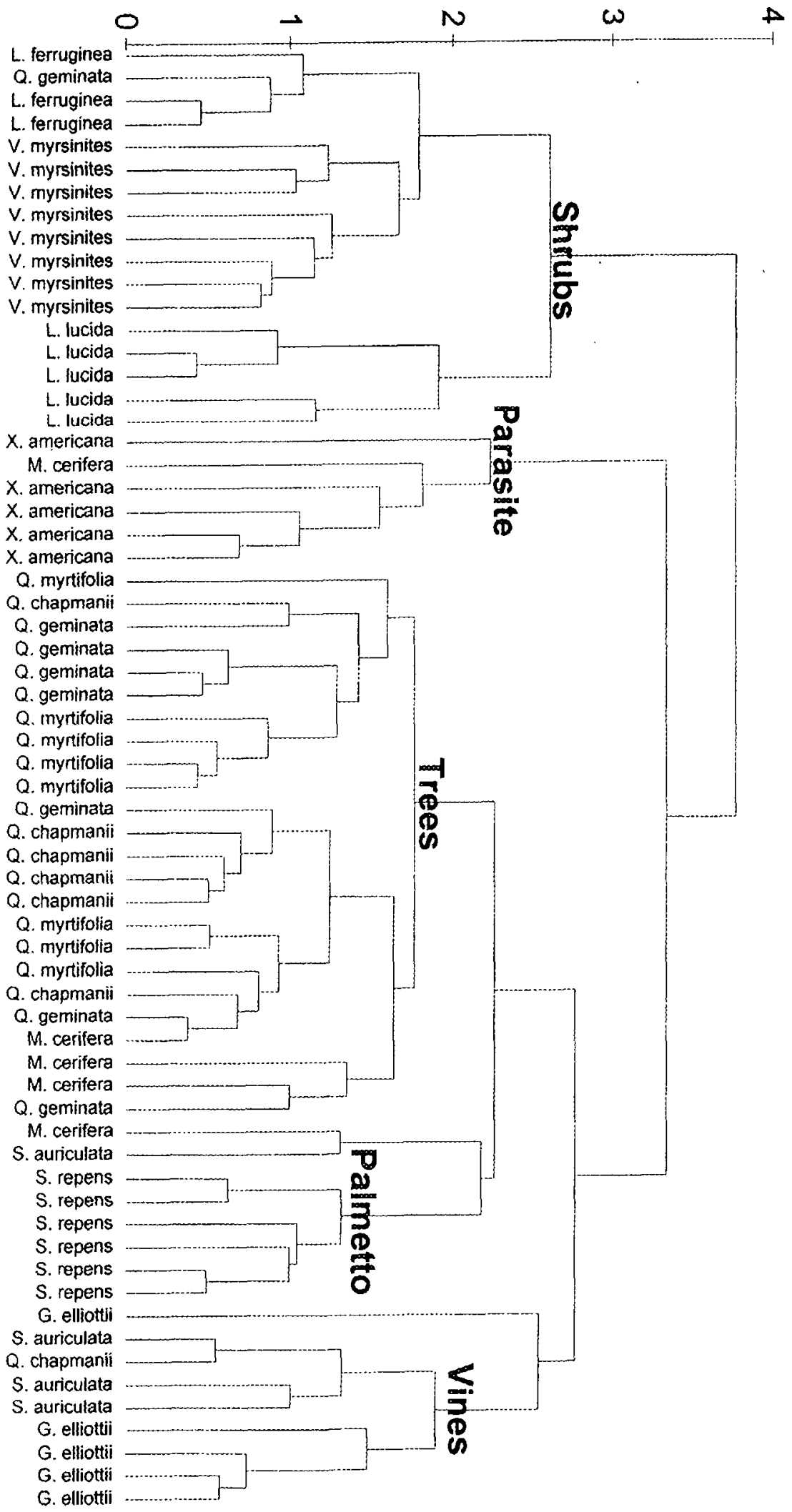

$\checkmark$. myrsinites

$V$ myrsinites

V. myrsinites

$V$. myrsinites

$\checkmark$. myrsinites

V. myrsinites

L. lucida

L. Jucida

L. lucida

$M$. cenfera

$X$ americana

$X$. americana

$X$ american

Q. myrtifolia

Q. chapmanil

Q geminata

Q. geminata

Q. myrtifolia

Q. myrtifolia

Q. chapman

Q. chapman

Q. chapman

Q. myrtifol

Q. myrtifolia

chapman

M. cerifera

auriculata

S. repens

S. repens

s. repens

S. repens

auriculata

. chapman

auriculata

G. elliotti

G. elliottii 
Figure 15: Non-metric multidimensal scaling (MDS) of the physiological functional groups (stress $=0.08$ ) depicted by (a) specific leaf area, (b) life form, (c) leaf thickness, and (d) life forms + Ximenia americana as a separate category.

a) SLA

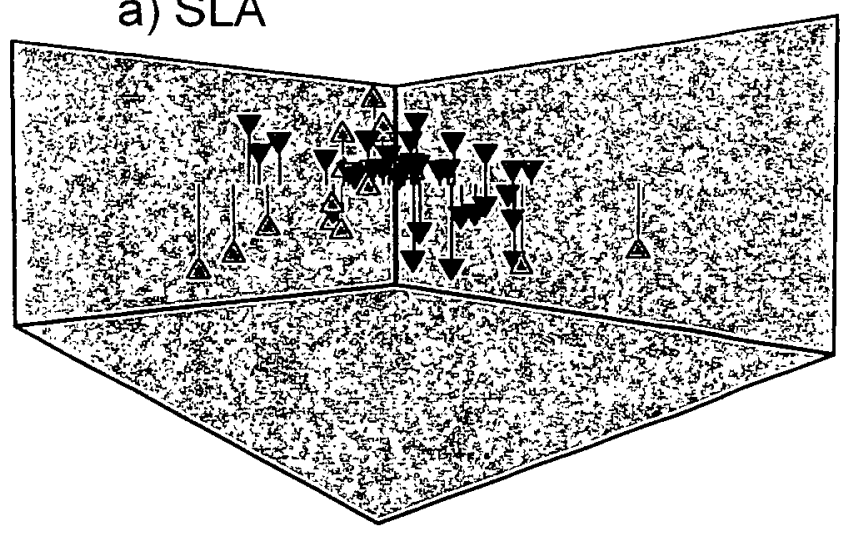

b) Life form

$\triangle$ High

$\checkmark$ Low

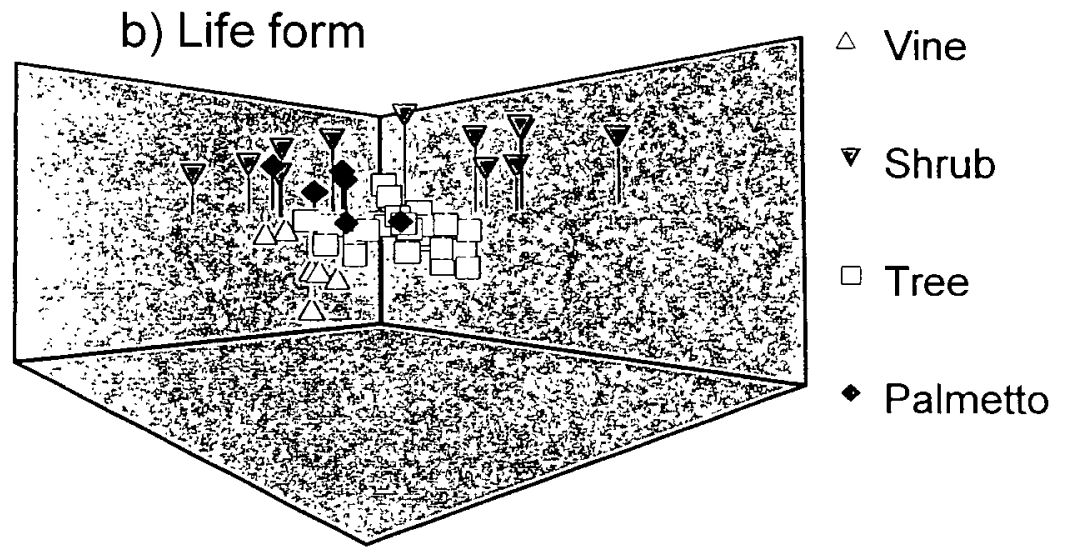

d) Life form + parasite

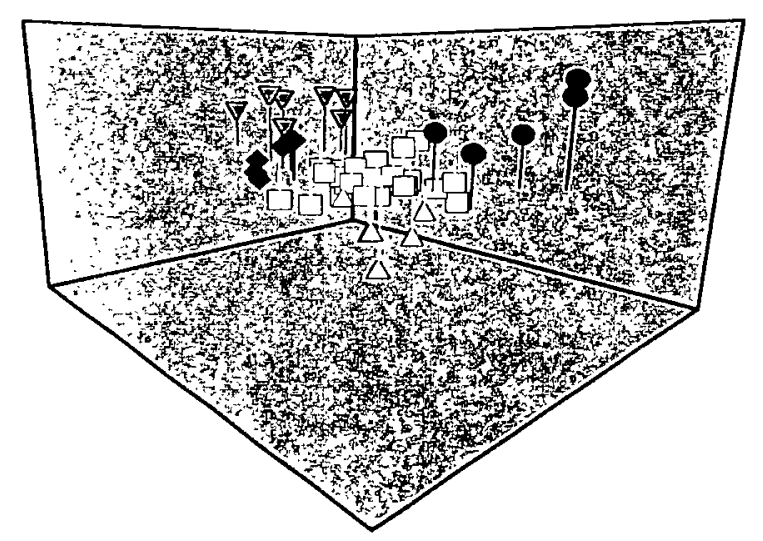

$\triangle$ Vine

$\checkmark$ Shrub

$\square$ Tree

- Palmetto

- Parasite 
Table 12: Summary of analysis of similarity (ANOSIM) to determine the acceptable morphological indicator of physiological function.

\begin{tabular}{|c|c|c|c|}
\hline Morphological Indicator & Parameters & $\mathbf{R}$ & $\mathbf{p}$ \\
\hline \multirow[t]{3}{*}{ Lifeform } & & & \\
\hline & Instantaneous \& Integrated & 0.629 & 0.001 \\
\hline & Integrated & 0.598 & 0.001 \\
\hline \multirow[t]{3}{*}{ Lifeform +Ximenia americana } & & & \\
\hline & Instantaneous \& Integrated & 0.794 & 0.001 \\
\hline & Integrated & 0.789 & 0.001 \\
\hline \multirow[t]{3}{*}{ Specific leaf area } & & & \\
\hline & Instantaneous \& Integrated & 0.426 & 0.001 \\
\hline & Integrated & 0.275 & 0.001 \\
\hline \multirow[t]{3}{*}{ Leaf thickness } & & & \\
\hline & Instantaneous \& Integrated & 0.344 & 0.001 \\
\hline & Integrated & 0.250 & 0.001 \\
\hline
\end{tabular}

separation between the groups, whereas small values imply little separation. Thus the life form groupings adequately explained the variation in the physiological parameters.

Ximenia americana differed in physiological response when compared to the other shrubs (see above for details). By removing $X$, americana from the shrubs and placing it in its own category, which might be considered a parasitic life form (Figure $15 d)$, the degree of separation between the groups increased $(R=0.794)$. Whereas under the four life form classification, the shrubs and the palmettos were not found to differ in their physiological responses (ANOSIM; $R=0.16, p=0.064$ ), by separating the $X$. americana from the shrubs all five groups differ from one another. Thus separation into trees, shrubs, vines, palmetto, and $X$. americana adequately describes physiological function.

\section{Discussion}

Distinct species differences in physiological responses to carbon, nitrogen, and water were observed in the Florida scrub. However, each species was not unique in 
physiological response, instead discreet groups responded similarly. Based on these similarities, five physiologically based functional groups were formed (Figures 9,13 and 14, Table 6). Two of these consisted of only one species. Serenoa repens is the only palmetto found in the oak - saw palmetto scrub at KSC/MINWR, but it comprises between $30-40 \%$ of the ground cover (Schmalzer and Hinkle 1992). The other single species category is the shrub Ximenia americana, which is the only parasitic plant common to this area of scrub. Each of the remaining three physiological groupings consisted of two or more species. Quercus chapmanii, Q. geminata, Q. myrtifolia, and Myrica cerifera were grouped together based on similar responses, and this group typically comprises approximately $40 \%$ of the ground cover (Schmalzer and Hinkle 1992). Lyonia lucida, L. ferruginea, L. fruticosa, and Vaccinium myrsinites were grouped together, whereas Smilax auriculata and Galactia elliottii made up the final group.

The five physiologically based groups were robust spatially and temporally (Tables $8,9,10$, and 11), so it can be expected that these groupings are representative of scrub at KSC/MINWR. This simplifies the system from twelve species to five physiological groupings. Collecting physiological data for even five groups on a large scale is still unrealistic. Instantaneous measurements are not only time consuming but also dependent on environmental conditions. For instance, during the summer in scrub the window of opportunity to achieve maximum rates of photosynthesis may be fairly short; two to three hours; before stomatal closure due to high vapor pressure deficit (VPD) or extreme temperatures occurs. Foliage samples, although easy to collect, may be time consuming to prepare and expensive to process. Therefore these 
physiologically based functional groups will be useful for scaling from leaf level to ecosystem processes only when coupled with an easy-to-measure morphological indicator.

Leaf thickness decreases and SLA increases with shady canopy positions (Sprugel et al. 1996; Ishida et al. 1999), so many studies have related physiological changes from sun or shade acclimation with changes in these parameters (Brooks et al. 1996; Ishida et al. 1999; McKee 1995). The relationship of leaf thickness and SLA with photosynthesis is due to differences in the anatomy of sun and shade leaves. Thicker leaves (sun leaves) utilize more light than thinner leaves (shade leaves) because they have more palisade and mesophyl for carbon absorption. Thinner leaves have fewer chloroplasts per unit area due to the reduction in mesophyll (Lambers et al. 1998). However, scrub does not have distinct canopy strata, instead, all species develop in high light environments. The exception to this is the fire-suppressed scrub in which the trees become the overstory and the shrubs and palmetto the understory. Therefore the leaf adaptations of scrub plants are most likely due to the xeric nature of the system. Plants in xeric conditions in order to minimize water lose often have less area for transpiring, the leaves are smaller and thicker often due to increased epidermal layers and waxy cuticles (Larcher 1995).

The measured leaf characteristics were not able to adequately depict the physiological responses of scrub species (Figures 9 and 15, Table 12). In some studies, these variables are adequate indictors of function (Reich et al. 1997; Reich et al. 1998; Reich et al. 1998; Ackerly 1999) and data from the current study also showed some of the trends expected with the leaf characteristics. Specific leaf area (SLA) and 
leaf thickness were closely related variables in that thicker leaves generally have a low SLA. For example, Galactia elliottii leaves had a high SLA $\left(8.63 \pm 0.39 \mathrm{~m}^{-2} \mathrm{~kg}^{-1}\right)$ but were thin $(0.30 \pm 0.009 \mathrm{~mm})$, whereas Quercus geminata leaves were thick $(0.65 \pm$ $0.016 \mathrm{~mm})$ with a low SLA $\left(3.38 \pm 0.06 \mathrm{~m}^{-2} \mathrm{~kg}^{-1}\right)$. A positive correlation between SLA and photosynthesis on a mass basis was found as well as between SLA and nitrogen concentration (Figure 8). Leaf thickness was found to be positively associated with photosynthesis on an area basis and the stable carbon isotope for the scrub vegetation. However no other relationships were identified between the leaf characteristics and the physiological parameters. Neither groupings based on high and low SLA or on the three leaf thickness categories agreed well with the physiologically based groupings (Figure 9). For instance Vaccinium myrsinites and Galactia elliottii both had high specific leaf areas but were very dissimilar in physiological responses. Ximenia americana and Galactia elliottii both had thin leaves yet these species were also dissimilar in physiological response. There was not good separation in the physiological responses of scrub species that possessed thin or thick leaves or had high or low SLA (Figure 15, Table 9).

Life form classifications were able to adequately depict the physiology of scrub species (Figures $9,13,14$, and 15; Table12). Previous research has shown that although life forms are based on a morphological and structural basis they serve as a good indicator of physiological processes. For instance, Chapin et al. (1996) found that in the arctic traits associated with resource acquisition and growth rate were important for separating eight growth form categories. The categories trees, shrubs, vines and palmetto agreed well (ANOSIM; $R=0.629$ ) with the physiological groupings in Florida 
scrub (Figures 9, 13, and 14). For example, the two vines Galactia elliottii and Smilax auriculata are more similar to each other in physiological response than to any other species. Separating Ximenia americana from the shrubs category makes an improvement (ANOSIM; $R=0.794$ ) on the ability of distinguishing the functional groups based on the suite of physiological parameters (Figures $9,13,14$, and 15; Table 12), and is a more accurate representation of the original five physiological groups. Separating Ximenia americana from the remaining shrubs would not be appropriate without an a priori reason for doing so. However, Ximenia is a facultative hemiparasite that attaches to the roots of its host plant, from which it obtains water and nutrients. As a hemiparasite, Ximenia would be expected to differ in function from the other shrubs. Hemiparasites generally have high stomatal conductances, high rates of transpiration and low water-use efficiencies thus maintaining a steeper water potential gradient between the roots and the leaves of the parasite than the host plant (Goldstein et al. 1989; Ducharme and Ehleringer 1996). This steep water potential gradient is responsible for the import of water and nutrients from the host plant, and may lead to a high nitrogen concentration in the leaves of the parasite (Lambers et al. 1998). Although hemiparasites are difficult to identify visually because they are diverse in taxa as well as morphology (Lambers et al. 1998) the physiological responses remain similar. Therefore a priori knowledge of parasitism suggests the species should not be included in its respective life form group, but together with other parasites.

The physiological similarities of species within a life form grouping might have been due to members being closely related taxonomically. Indeed, taxonomic relatedness within a functional group is not at all unusual. In Argentina, Diaz and 
Cabido (1997) found that a single plant family dominated some plant functional types. Hadar et al. (1999) used a combination of life forms and families as functional types in the Mediterranean to examine the effects of grazing and clearing on the community. In this study, two of the functional groups identified included species that are closely related on a taxonomic basis. The shrubs (Figures 9,13 , and 14, Table 6 ) not only include species that belong to the same genera, but all species included in this group belong to the Ericaceae family (Wunderlin 1982). This group consisted of the following four species; Lyonia ferruginea, L. fruticosa, L. lucida, and Vaccinium myrsinities. Members classified as trees (Table 6 ) were also closely related taxonomically with all species belonging to the same subclass Hamamelidae (Cronquist 1981). This group contained three oaks (Quercus chapmanii, Q. geminata, Q. myrtifolia) that belong to the same genera as well as Myrica cerifera. However, little ecological information is usually contained in the family or higher levels of taxonomy (Scholes et al. 1997).

Functional classifications based on taxonomy miss similarities between species due to convergent evolution (Bond 1997). For example, the $\mathrm{C}_{4}$ photosynthetic pathway has evolved multiple times in different taxonomic groups (Ehleringer and Monson 1993). Plant classifications based on functional attributes may cross taxonomic classifications (Woodward and Kelly 1997). In fact, the vines (Table 6) contain two species that although similar in growth form and physiology belong to different taxonomic classes. Smilax auriculata is a monocot (class Liliopsida) whereas Galactia elliottii is a dicot (class Magnoliopsida) (Cronquist 1981). The remaining two functional groups each consisted of only one species, the palmetto Serenoa repens is a monocot (Cronquist 1981) along with the parasite Ximenia americana. Interestingly, Ximenia americana and 
Galactia elliottii which were found to be extremely dissimilar on a physiological basis, are more closely related to each other taxonomically than to any of the other species; they both belong to the subclass Rosidae (Cronquist 1981). Although taxonomic relatedness could play a role in determining two of the functional groups, it does not account for the similarities between the vines. However this study was not designed to test for the importance of taxonomic relatedness in species functioning so further studies would be needed to fully address this issue.

The life form classifications, trees, shrubs, palmetto, vines, and parasite were determined to be good indicators of the physiological processes of scrub species, and would be a useful method of grouping for scaling physiological processes to the ecosystem level or above. Interestingly, these data suggest that functional groups based on life forms could have been obtained using a smaller suite of parameters (Tables $8,9,11$, and 12). Life forms adequately depicted the physiology of scrub species not only when all 10 parameters were examined, but also when only the integrated measures were examined. Therefore the integrated measures, which are less time consuming to sample, adequately separate the scrub species in terms of the carbon, nitrogen, and water dynamics. In fact, the integrated measures should be more representative of actual function for classifying species because they integrate processes over time and are not as dependent on momentary environmental conditions as the instantaneous measures are.

One important feature that varied between the three different sites was depth to the water table (Figure 2), with a difference of approximately a half-meter between the extremes; the Camera Pad and Happy Creek plots. Composition of scrub is known to 
be closely related to water table depth with oaks dominating on the more xeric sites and saw palmetto on the wetter sites (Schmalzer and Hinkle 1992). Although these plots were chosen to have similar composition, it was expected that the difference in depth to the water table might influence species responses particularly in terms of water. However, the responses of the functional groups were not altered by differences in water table between the plots (Table 8). For example, S. repens had an intrinsic wateruse efficiency of $48 \mu$ mols $\mathrm{CO}_{2} / \mathrm{mmols} \mathrm{H}_{2} \mathrm{O}$ while the WUE of trees was between 50 $60 \mu$ mols $\mathrm{CO}_{2} / \mathrm{mmols}_{2} \mathrm{O}$ at both the Camera Pad and Happy Creek burn plots. Since physiological function of these groups did not differ with a half-meter change in the water table, these groupings might be expected to remain robust across the scrub with similar species composition at KSC/MINWR. As a result, changes in ecosystem fluxes could possibly be predicted from changes in composition. Other ecosystems have also been found to be robust in function within a group, but where changes in composition of the groups altered ecosystem processes. For instance, in New Mexico a shift from grasses to shrub-dominated systems that have less total organic carbon was accompanied by $\mathrm{CO}_{2}$ being lost to the atmosphere (Reynolds et al. 1997). In the Patagonian steppe, the increase in shrub cover that accompanied increased grazing intensity reduced transpiration but increased water loss due to evaporation and drainage (Aguiar et al. 1996). Annual net primary production also decreased as the community shifted from grass to shrubs. At KSC/MINWR, as the depth to the water table decreases a shift occurs in species composition in which the trees begin to disappear and the abundance of saw palmetto doubles (Schmalzer and Hinkle 1992). This shift has little effect on the abundance of shrubs but does alter the shrub species 
composition. However total cover of plants within both the oak-saw palmetto scrub and the saw palmetto systems remains about the same (Schmalzer and Hinkle 1992). This shift in composition due to decreasing water table depth might be associated with less carbon assimilation because $S$. repens has a lower photosynthetic rate than the trees. However both the trees and S. repens are efficient in their water-use, and since total cover remains the same there would most likely be a decrease in ecosystem water flux. A change in the species composition of the shrub group would have no effect since all shrubs function similarly, unless that shrub was a parasite. Since the parasites often inhabit the drier sites, a decrease in parasitic shrubs with an increase in the water table would decrease water loss from the site since the parasites have the highest rates of transpiration and a low water-use efficiency.

In addition to depth to the water table, management regime also did not seem to affect the physiological responses of the functional groups (Table 9). Management of scrub on KSC/MINWR is done primarily to provide the appropriate habitat for the threatened Florida Scrub Jay (Aphelocoma coerulescens coerulescens). Long-term studies have been and are continuing to be conducted to determine how management regime affects species composition and structure of scrub (Schmalzer et al. 1994; Schmalzer and Boyle 1998; Schmalzer and Adrian 2001), however this was the first study to examine whether these management regimes affected a species physiology. The responses of the functional groups did not vary between the three management regimes. For example, the $\mathrm{C}: \mathrm{N}$ ratio for vines remained low (20-30) regardless of management regime, while the trees and S. repens maintained $\mathrm{C}: \mathrm{N}$ in the range of 3040. The shrubs had low leaf nitrogen concentrations $(0.7-0.8 \%)$ whereas the vines 
maintained high concentrations $(1.9-2.2 \%)$ in all three management regimes. This does not mean that management regime has no impact on the scrub system because ecosystem function (e.g. water exchange with the atmosphere) is determined by both the physiology of the different species or groups of species and the ecosystem composition of those species along with the total amount of transpiring leaf area. Although physiological responses of a particular group remain the same between the management regimes, species composition does not. In mechanically treated scrub, S. repens returns to only about $50 \%$ of its pre-burn cover (Schmalzer and Boyle 1998) whereas the regrowth of trees and shrubs is similar to that of burned scrub (Schmalzer and Adrian 2001).

Compositional changes with altered management is not unusual because management regime often acts as a disturbance on the system, and disturbance may be associated with a change in composition. In the Mediterranean, grazing was found to favor the functional groups that were made up by species small in stature, whereas clearing was a more generalized response that favored species in each functional group (Hadar et al. 1999). According to Shaver et al. (1997) the functional types (deciduous shrubs, evergreen shrubs, graminoids, forbs, mosses and lichens) are useful for predicting responses to disturbance in the tundra. For instance, graminoids initially increase in response to physical disturbance, but after several years deciduous shrubs dominate (Shaver et al. 1997). Serenoa repens is unique among the scrub species in its physiological response. Loss of a large percentage of S. repens may lower the amount of carbon gained per water lost for the system, particularly if the loss of $S$. repens is not associated with a change in cover of the other functional groups. 
Fire-suppressed scrub also differs in composition when compared to burned and mechanically treated scrub. The percent cover of the trees more than doubles in firesuppressed scrub and approaches approximately $80-90 \%$ of the cover. The percent cover of $S$. repens is about a third of that found in burned scrub. The total cover of the shrubs is about equal although species differ between the burned and fire-suppressed scrub. Total vegetation cover also doubles (Schmalzer and Hinkle 1992). This difference in composition and increase in total cover has implications for how firesuppressed scrub may function differently than fire maintained scrub. By doubling the vegetation cover, more water will be lost due to transpiration in the fire-suppressed scrub than the fire-maintained scrub. More carbon may be assimilated in the firesuppressed scrub than the fire-maintained scrub because of the increase in tree cover, which has high rates of photosynthesis when compared to $S$. repens.

The functional groups were not only robust spatially but also temporally. Physiological responses of the life form groups were consistent between 1999 and 2000 , even though precipitation during the summer of 2000 was only $43 \%$ of that in 1999 (Figures 9, 13, and 14; Table 11). For instance, the shrubs had a C:N ratio around 70 for both years. The life forms also maintained consistent $\delta^{13} \mathrm{C}$ values between the two years regardless of plots (see Figure 12, Appendix 1). For example, Serenoa repens and the trees maintained a $\delta^{13} \mathrm{C}$ of approximately $-27 \%$. This indicates that factors that influence physiology remain stable through time, so the functional groups would be expected to be useful regardless of differences in environmental conditions between years. Brooks et al. (1997) also found that life form groupings 
derived from $\delta^{13} \mathrm{C}$ remained stable between 1993 and 1994 even though weather fluctuated greatly between the two years.

These data add to the accumulating evidence that groupings based on life forms are adequate for explaining function in a variety of systems irrespective of whether physiological, phenological, physiognomic, or a combination of traits are examined. In an Australian semi-arid woodland five main functional types identified by a combination of growth form and life history attributes (perennial forbs, subshrubs, $\mathrm{C}_{4}$ grasses, trees/shrubs, and annual forbs) were derived from a combination of vegetative, life history, phenology and seed biology attributes (Westoby and Leishman 1997). Shao et al. (1996) found that the classifications of woody and non-woody more adequately described the function of 19 plant associations of coastal barrier islands than did the earlier classifications based on salt tolerance. However plant functional groups are not only useful for scaling up ecosystem processes but they may also be useful for predicting the effects of changes in composition of functional groups due to global change or land use change. Chapin et al. (1996) found that grouping species into eight growth form categories (sedges, forbs, deciduous shrubs, grasses, evergreen shrubs, non-vascular plants, deciduous trees, and evergreen trees) was useful not only for capturing regional ecosystem dynamics but also predicting the effects of vegetation on the environment and responses to climate change in the arctic. For instance, it was predicted that global warming would increase the abundance of trees that would lead to increased carbon storage, higher transpiration, and reduced albedo.

A limitation of the usefulness of life forms as functional groups in the scrub habitat as defined in this study may be in the ability to predict species distributions in 
response to global change. In order to determine distribution responses to environmental change, the regeneration phase could be important in the development of the functional groups to predict species spread and distribution by inclusion of information such as dispersal rate and spread (Hobbs 1997). Classifications based on life forms and phenology often fails to include information about the dynamics of the community (Noble and Gitay 1996). For instance, in an Australian semi-arid woodland the five main functional types identified by a combination of growth form and life history attributes (perennial forbs, subshrubs, $\mathrm{C}_{4}$ grasses, trees/shrubs, and annual forbs) do not capture the variation in seed and dispersial biology included for each species (Westoby and Leishman 1997). Information on dispersal and regeneration might need to be incorporated into the suite of parameters before determining if life forms could predict the distribution of Florida scrub in response to global change. Unfortunately there is little difference in regeneration strategies of the scrub species. All twelve scrub species included in this study revegetate by resprouting after stand replacing fires. Galactia elliottii and L. ferruginea are obligate resprouters, whereas S. repens and S. auriculata may also seed besides resprouting. The remaining seven species revegetate by a combination of resprouting and clonal spread (Menges and Kohfeldt 1995). Although resprouting after fire occurs relatively quickly (Schmalzer and Hinkle 1992) spread of scrub species into adjacent clearings occurs much more slowly. In fact, oaks and ericads slowly vegetate openings by spreading clonally from the perimeters. There is little establishment of woody species by seeding in the openings (Schmalzer and Adrian 2001). Clonal spread by $S$. repens may be incredibly slow with growth rates between 0.6 and $2.2 \mathrm{~cm} / \mathrm{yr}$ and seedling recruitment is rare (Abrahamson 1995). The 
dependence on vegetative spread and the slow rates at which these species colonize disturbed areas draws into question the ability of this system to dynamically respond to global changes. However more research is needed to determine species responses to climatic changes.

The support of life forms as useful functional groups in the Florida scrub should be viewed in this case as a method for scaling up to ecosystem processes or predicting biosphere atmospheric interactions, and should not be used to make management decisions on biodiversity. For instance, managers should not focus their efforts on a single tree species to maintain ecosystem functions. Although the functional groups describe the functional diversity in the scrub system in terms of the cycling of carbon, nitrogen and water, it was beyond the scope of this study to examine other ecosystem interactions (e.g. tropic level interactions). The data suggests that a shift in the composition of tree species would not alter the ecosystem properties studied. However it does not indicate how removal of that species would affect other species that might rely on particular trees. For instance, it has been found that species-specific relationships occur between the scrub oaks and cynipids. On KSC/MINWR 18 cynipids were found to induce galls on the oaks, however each was found to have only one host species; 8 were specific to Q. chapmanii, 5 to Q. myrtifolia, and 5 to Q. geminata (Abrahamson and Melika unpublished data). Q. geminata has very unique cynipid communities when compared to most other white oaks, and differences in cynipid communities exist between the white oaks (Q. chapmanii and Q. geminata) and the red oaks (Q. myrtifolia) (Abrahamson et al. 1998). Therefore by removing one oak species from the scrub, the biodiversity of cynipids would be decreased. 


\section{Conclusion}

Five physiologically based functional groups were identified in the Florida scrub based on species responses to parameters associated with carbon, nitrogen, and water dynamics. Although specific leaf area and leaf thickness were correlated to some of the physiological parameters, they were not able to adequately depict the physiological groupings. However life form classifications into trees, shrubs, vines, and palmetto were found to be an adequate indicator of physiological function. The ability of life forms to depict the physiological groupings was improved by separating the parasitic shrub from the shrub category. The responses of the life form groupings were not altered by spatial differences in water table depth or by management regimes. Nor were there differences in the physiological responses of the functional groups between the two years 1999 and 2000. Therefore the life form classifications including parasite were good indicators of the physiological processes of scrub species, and would be a useful method of grouping for scaling physiological processes to the ecosystem level. 


\section{References}

Abrahamson, W. G. (1995). Habitat distribution and competitive neighborhoods of two Florida palmettos. Bulletin of the Torrey Botanical Club 122(1): 1-14.

Abrahamson, W. G., G. Melika, R. Scrafford and G. Csoka (1998). Gall-inducing insects provide insights into plant systematic relationships. American Journal of Botany 85(8): 1159-1165.

Ackerly, D. D. (1999). Convergence and correlations among leaf size and function in seed plants: A comparative test using independent contrasts. American Journal of Botany 86(9): 1272-1281.

Adrian, R. W., R. C. J. Lee and J. E. Sasser (1983). Upland management plan Merritt Island National Wildlife Refuge. Titusville, FL, US-FWS/MINWR.

Aguiar, M. R., J. M. Paruelo, O. E. Sala and W. K. Lauenrothe (1996). Ecosystem responses to changes in plant functional type composition: An example from the Patagonian steppe. Journal of Vegetation Science 7: 381-390.

Bonal, D., D. Sabatier, P. Montpied, D. Tremeaux and J. M. Guehl (2000). Interspecific variability of $\delta^{13} \mathrm{C}$ among trees in rainforests of French Guiana: functional groups and canopy integration. Oecologia 124(3): 454-468.

Bond, W. J. (1997). Functional types for predicting changes in biodiversity: a case study in Cape fynbos. In Plant functional types: Their relevance to ecosystem properties and global change. T. M. Smith, H. H. Shugart and F. I. Woodward. Cambridge, Cambridge University Press: 174 - 194.

Box, E. O. (1996). Plant functional types and climate at the global scale. Journal of Vegetation Science 7: 309-320.

Brooks, J. R., L. B. Flanagan, N. Buchmann and J. R. ehleringer (1997). Carbon isotope composition of boreal plants: functional grouping of life forms. Oecologia 110: 301-311.

Brooks, J. R., D. G. Sprugel and T. M. Hinckley (1996). The effects of light acclimation during and after foliage expansion on photosynthesis of Abies amabilis foliage within the canopy. Oecologia 107: 21-32.

Chapin, F. S. (1993). Functional role of growth forms in ecosystem and global processes. In Scaling physiological processes: Leaf to globe. J. R. Ehleringer and C. B. Field. London, Academic Press: 287-312. 
Chapin, F. S. I., M. S. Bret-Harte, S. E. Hobbie and H. Zhong (1996). Plant functional types as predictors of transient responses of arctic vegetation to global change. Journal of Vegetation Science 7: 347-358.

Clarke, K. R. and R. M. Warwick (2001). Change in marine communities: An approach to statistical analysis and interpretation. Plymouth, UK, PRIMER-E Itd.

Condit, R., S. P. Hubbell and R. B. Foster (1996). Assessing the response of plant functional types to climatic change in tropical forests. Journal of Vegetation Science 7: 405-416.

Cronquist, A. (1981). An integrated system of classification of flowering plants. New York, Columbia University Press.

Diaz, S. and M. Cabido (1997). Plant functional types and ecosystem function in relation to global change. Journal of Vegetation Science 8: 463-474.

Ducharme, L. A. and J. R. Ehleringer (1996). Gas exchange, $\delta^{13} \mathrm{C}$, and heterotrophy for Castilleja linariifolia and Orthocarpus tolmiel, facultative root hemiparasites on Artemisia tridentata. Great Basin Naturalist 56: 333-340.

EG\&G Florida, I. (1994). Environmental resources document. John F. Kennedy Space Center, National Aeronautics and Space Administration.

Ehleringer, J. R., A. E. Hall and G. D. Farquhar (1993). Stable Isotopes and Plant Carbon-Water Relations. San Diego, Academic Press.

Ehleringer, J. R. and R. K. Monson (1993). Evolutionary and ecological aspects of photosynthetic pathway variation. Annu. Rev. Ecol. Syst. 24: 411-439.

Evans, J. R. (1989). Photosynthesis and nitrogen relationships in $C_{3}$ plants. Oecologia 78: $1-19$.

Farquhar, G. D., J. R. Ehleringer and K. T. Hubick (1989). Carbon isotope discrimination and photosynthesis. Ann. Rev. Plant Physiol. Mol. Biol. 40: 503-537.

Fortin, M.-J. and J. Gurevitch (2001). Mantel tests: spatial structure in field experiments. In Design and analysis of ecological experiments. S. M. Scheiner and J. Gurevitch. New York, Oxford University Press: 308-326.

Godfrey, R. K. (1988). Trees, shrubs, and woody vines of Northern Florida and adjacent Georgia and Alabama. Athens, The University of Georgia Press.

Goldstein, G., F. Rada, L. Sternberg, J. L. Burguera, A. Orozco, M. Montilla, O. Zabala, A. Azocar, M. J. Canales and A. Celis (1989). Gas exchange and water balance of a mistletoe species and its mangrove host. Oecologia 78: 176-183. 
Hadar, L., I. Noy-Meir and A. Perevolotsky (1999). The effect of shrub clearing and grazing on the composition of a Mediterranean plant community: functional groups versus species. Journal of Vegetation Science 10: 673-682.

Hobbs, R. J. (1997). Can we use plant functional types to describe and predict responses to environmental change? In Plant functional types: Their relevance to ecosystem properties and global change. T. M. Smith, H. H. Shugart and F. I. Woodward. Cambridge, Cambridge University Press: 66 - 87.

Huckle, H. F., H. D. Dollar and R. F. Pendleton (1974). Soil survey of Brevard County, Florida. Washington, D. C., U.S. Department of Agriculture, Soil Conservation Service: 123.

Ishida, A., T. Toma and Marjenah (1999). Leaf gas exchange and chlorophyll fluorescence in relation to leaf angle, azimuth, and canopy position in the tropical pioneer tree, Macaranga conifera. Tree Physiology 19: 117-124.

Jackson, P. C., J. Cavelier, G. Goldstein, F. C. Meinzer and N. M. Holbrook (1995). Partitioning of water resources among plants of a lowland tropical forest. Oecologia 101: 197-203.

Koike, T. (1988). Leaf structure and photosynthetic performanace as related to the forest succession of deciduous broad-leaved trees. Plant Sp. Biol. 3: 77-87.

Lakela, O. and R. P. Wunderlin (1980). Trees of Central Florida. Miami, FL, Banyan Books.

Lambers, H., F. S. I. Chapin and T. L. Pons (1998). Plant Physiological Ecology. New York, Springer-Verlag.

Larcher, W. (1995). Physiological Plant Ecology. New York, Springer.

McCune, B. and M. J. Mefford (1999). PC-ORD. Multivariate Analysis of Ecological Data, Version 4. Gleneden Beach, MjM Software Design.

McGarigal, K., S. Cushman and S. Stafford (2000). Multivariate statistics for wildlife and ecology research. New York, Springer.

McKee, K. L. (1995), Interspecific variation in growth, biomass partioning, and defensive characteristics of neotropical mangrove seedlings: response to light and nutrient availability. American Journal of Botany 82(3): 299-307.

Menges, E. S. and N. Kohfeldt (1995). Life history strategies of Florida scrub plants in relation to fire. Bulletin of the Torrey Botanical Club 122(4): 282-297. 
Myers, R. L. (1990). Scrub and High Pine. In Ecosystems of Florida. R. L. Myers and J. J. Ewel. Orlando, University of Central Florida Press: 150-193.

Nadelhoffer, K., G. Shaver, B. Fry, A. Giblin, L. Hohnson and R. McKane (1996). ${ }^{15 N}$ natural abundances and $N$ use by tundra plants. Oecologia 107: 386-394.

Nelson, G. (1994). The Trees of Florida: A reference and field guide. Sarasota, Pineapple Press.

Nelson, G. (1996). The Shrubs and Woody Vines of Florida: A reference and field guide. Sarasota, Pineapple Press.

Noble, I. R. and H. Gitay (1996). A functional classification for predicting the dynamics of landscapes. Journal of Vegetation Science 7: 329-336.

Pagano, R. R. (1994). Understanding statistics in the behavioral sciences. Minneapolis/St. Paul, West Publishing Company.

Reich, P. B., D. S. Ellsworth and M. B. Walters (1998). Leaf structure (specific leaf area) modulates photosynthesis-nitrogen relations: evidence from within and across species and functional groups. Functional Ecology 12: 948-958.

Reich, P. B., C. Uhl, M. B. Walters and D. S. Ellsworth (1991). Leaf lifespan as a determinant of leaf structure and function among 23 Amazonian tree species. Oecologia 86: 16-24.

Reich, P. B., M. B. Walters and D. S. Ellsworth (1997). From tropics to tundra: Global convergence in plant functioning. Proc. Natl. Acad. Sci. 94: 13730-13734.

Reich, P. B., M. B. Walters, D. S. Ellsworth and C. Uhl (1994). Photosynthesis-nitrogen relations in Amazonian tree species. Oecologia 97: 62-72.

Reich, P. B., M. B. Walters, D. S. Ellsworth, J. M. Vose, J. C. Volin, C. Gresham and W. Bowman (1998). Relationships of leaf dark respiration to leaf nitrogen, specific leaf area and leaf life-span: a test across biomes and functional groups. Oecologia 114: 471-482.

Reynolds, J. F., R. A. Virginia and W. H. Schlesinger (1997). Defining functional types for models of desertification. In Plant functional types: Their relevance to ecosystem properties and global change. T. M. Smith, H. H. Shugart and F. I. Woodward. Cambridge, Cambridge University Press: $195-216$.

Roggy, J. C., M. F. Prevost, G. Gourbiere, H. Casabianca, J. Garbaye and A. M. Domenach (1999). Leaf natural $15 \mathrm{~N}$ abundance and total $\mathrm{N}$ concentration as potential indicators of plant $\mathrm{N}$ nutrition in legumes and pioneer species in a rain forest of French Guiana. Oecologia 120: 171-182. 
Ryan, M. G. (1991). Effects of climate change on plant respiration. Ecol. Apps. 1: 157 167.

Schmalzer, P. A. and F. W. Adrian (2001). Scrub restoration on Kennedy Space Center/ Merritt Island National Wildife Refuge, 1992 - 2000. Florida Scrub Symposium, Orlando, FL, U.S. Fish and Wildlife Service.

Schmalzer, P. A. and S. R. Boyle (1998). Restoring long-unburned oak-saw palmetto scrub requires mechanical cutting and prescribed burning. Restoration and Management Notes 16(1): 96-97.

Schmalzer, P. A., S. R. Boyle and H. M. Swain (1999). Scrub ecosystems of Brevard County Florida: A regional characterization. Florida Scientist 62(1): 13-47.

Schmalzer, P. A., D. R. Breininger, F. W. Adrian, R. Schaub and B. W. Duncan (1994). Development and implementation of a scrub habitat compensation plan for Kennedy Space Center. Kennedy Space Center, NASA: 53.

Schmalzer, P. A., M. A. Hensley and C. A. Dunlevy (2001). Background characteristics of soils of Kennedy Space Center, Merritt Island, Florida: Selected elements and physical properties. Florida Scientist 64(3): 161-190.

Schmalzer, P. A. and C. R. Hinkle (1992). Recovery of oak-saw palmetto scrub after fire. Castanea 57(3): 158-173.

Schmalzer, P. A. and C. R. Hinkle (1992). Species composition and structure of oaksaw palmetto scrub vegetation. Castanea 57(4): 220-251.

Scholes, R. J., G. Pickett, W. N. Ellery and A. C. Blackmore (1997). Plant functional types in African savannas and grasslands. In Plant functional types: Their relevance to ecosystem properties and global change. T. M. Smith, H. H. Shugart and F. I. Woodward. Cambridge, Cambridge University Press: $255-268$.

Schulze, E.-D. (1982). Plant life formas and their carbon, water, and nutrient relations. In Plant Physiological Ecology II. Berlin, Springer Verlag: 615-676.

Shao, G., H. H. Shugart and B. P. Hayden (1996). Functional classifications of coastal barrier island vegetation. Journal of Vegetation Science 7: 391-396.

Shaver, G. R., A. E. Giblin, K. J. Nadelhoffer and E. B. Rastetter (1997). Plant functional types and ecosystem change in arctic tundras. In Plant functional types: Their relevance to ecosystem properties and global change. T. M. Smith, H. H. Shugart and F. I. Woodward. Cambridge, Cambridge University Press: 153-173. 
Sprugel, D. G., J. R. Brooks and T. M. Hinckley (1996). Effects of light on shoot geometry and needle morphology in Abies amabilis. Tree physiology 16(1-2): 9198.

Steffen, W. L. (1996). A periodic table for ecology? A chemist's view of plant functional types. Journal of Vegetation Science 7: 425-430.

Steffen, W. L., B. H. Walker, J. S. I. Ingram and G. W. Koch, Eds. (1992). Global change and terrestrial ecosystems: the operational plan. Stockholm, IGBP and ICSU.

Westoby, M. and M. Leishman (1997). Catagorizing plant species into functional types. In Plant Functional Types: Their relevance to ecosystem properties and global change. T. M. Smith, H. H. Shugart and F. I. Woodward. Cambridge, Cambridge University Press: $104-121$.

Woodward, F. I. and C. K. Kelly (1997). Plant functional types: towards a definition by environmental constraints. In Plant functional types: Their relevance to ecosystem properties and global change. T. M. Smith, H. H. Shugart and F. I. Woodward. Cambridge, Cambridge University Press: 47-65.

Wunderlin, R. P. (1982). Guide to the vascular plants of Central Florida. Tampa, University Presses of Florida. 
Appendices 


\section{Appendix A: Physiological parameters}

Table 13: Physiological parameters for species in the Camera Pad burn plot. ( $A_{\max }, g_{\max }, \Phi, R$, and CP obtained from light curves $n=2$ for $1999, n=3$ for 2000 ( ${ }^{*}$ indicates an exception where $n=6) ; \% N, \% C, C: N, \delta^{15} N$, and $\delta^{i 3} \mathrm{C} n=3$ for both years) ${ }^{* *} n=1$

\begin{tabular}{|c|c|c|c|c|c|c|c|c|c|c|}
\hline & $\begin{array}{c}A_{\max } \\
\left(u \operatorname{mois} \mathrm{CO}_{2} \mathrm{~m}^{-2}\right. \\
\left.\mathrm{s}^{-1}\right) \\
\end{array}$ & $\begin{array}{c}g_{\max } \\
\left(\mathrm{mmols} \mathrm{H}_{2} \mathrm{O} \mathrm{m}^{-2}\right. \\
\left.\mathrm{s}^{-1}\right)\end{array}$ & $\begin{array}{c}\Phi \\
\text { (umols } \mathrm{CO}_{2} \\
\text { lumols photons) }\end{array}$ & $\begin{array}{c}\mathbf{R}_{\mathrm{d}} \\
\left(\mu \mathrm{mols} \mathrm{CO}_{2} \mathrm{~m}^{-2}\right. \\
\mathrm{s}^{-1} \text { ) } \\
\end{array}$ & $\begin{array}{c}\mathrm{I}_{\mathrm{c}} \\
\text { (umols photons } \\
\mathrm{m}^{-2} \mathrm{~s}^{-1} \text { ) }\end{array}$ & $\begin{array}{c}\% N \\
\left(g^{-1}\right)\end{array}$ & $\begin{array}{c}\% C \\
\left(g^{-1}\right)\end{array}$ & $C: N$ & $\begin{array}{l}\delta^{15} N \\
(\%)\end{array}$ & $\begin{array}{l}\delta^{13} \mathrm{C} \\
(\%)\end{array}$ \\
\hline Species & \multicolumn{10}{|c|}{1999} \\
\hline G. elliottii & $19.80 \pm 2.20$ & $0.250 \pm 0.03$ & $0.055 \pm 0.001$ & $-2.69 \pm 0.59$ & $48.48 \pm 10.10$ & $2.25 \pm 0.19$ & $44.48 \pm 0.16$ & $20.05 \pm 1.73$ & $-1.64 \pm 0.18$ & $-27.03 \pm 0.14$ \\
\hline L. fruticosa & $14.30 \pm 0.30$ & $0.321 \pm 0.05$ & $0.039 \pm 0.006$ & $-2.82 \pm 0.25$ & $73.65 \pm 4.85$ & - & --- & - & - & $\cdots$ \\
\hline L. lucida & $10.10 \pm 0.51$ & $0.304 \pm 0.02$ & $0.039 \pm 0.001$ & $-2.57 \pm 0.01$ & $66.46 \pm 2.79$ & $0.71 \pm 0.05$ & $51.70 \pm 0.56$ & $72.05 \pm 5.45$ & $-4.03 \pm 1.23$ & $-28.06 \pm 0.30$ \\
\hline M. cerifera & $17.55 \pm 1.85$ & $0.301 \pm 0.03$ & $0.057 \pm 0.002$ & $-2.02 \pm 0.29$ & $35.44 \pm 3.78$ & $1.28 \pm 0.05$ & $49.29 \pm 0.36$ & $38.57 \pm 1.38$ & $-2.31 \pm 0.16$ & $-29.59 \pm 0.32$ \\
\hline Q. chapmanii & $18.95 \pm 1.15$ & $0.333 \pm 0.02$ & $0.052 \pm 0.004$ & $-2.90 \pm 0.07$ & $56.08 \pm 5.84$ & $1.50 \pm 0.06$ & $45.99 \pm 0.44$ & $30.83 \pm 1.28$ & $-3.10 \pm 0.16$ & $-27.70 \div 0.48$ \\
\hline Q. geminata & $20.50 \pm 0.10$ & $0.324 \pm 0.01$ & $0.041 \pm 0.002$ & $-2.28 \pm 0.35$ & $56.69 \pm 12.09$ & $1.02 \pm 0.02$ & $47.50 \pm 0.46$ & $46.82 \pm 1.33$ & $-3.26 \pm 0.41$ & $-27.96 \pm 0.16$ \\
\hline Q. myrtifolia & $17.80 \pm 2.80$ & $0.229 \pm 0.05$ & $0.047 \pm 0.002$ & $-2.26 \pm 0.21$ & $47.78 \pm 2.12$ & $1.42 \pm 0.06$ & $48.14 \pm 0.07$ & $33.96 \pm 1.47$ & $-3.69 \pm 0.40$ & $-27.52 \pm 0.30$ \\
\hline S. repens & $12.55 \pm 0.05$ & $0.344 \pm 0.00$ & $0.039 \pm 0.001$ & $-2.30 \pm 0.03$ & $58.68 \pm 0.19$ & $1.13 \pm 0.07$ & $43.60 \pm 0.42$ & $38.83 \pm 2.41$ & $-1.19 \pm 0.57$ & $-26.93 \pm 0.02$ \\
\hline S. auriculata & $18.03 \pm 0.32$ & $0.376 \pm 0.01$ & $0.051 \pm 0.003$ & $-3.22 \pm 0.50$ & $63.79 \pm 10.52$ & $1.69 \pm 0.06$ & $44.21 \pm 0.14$ & $26.20 \pm 0.89$ & $-0.42 \pm 0.55$ & $-27.27 \pm 0.55$ \\
\hline$\checkmark$. myrsinites & $11.35 \pm 0.05$ & $0.353 \pm 0.00$ & $0.049^{* *}$ & $-3.52^{\star \star}$ & $71.26^{\star \star}$ & $0.81 \pm 0.07$ & $51.53 \pm 0.41$ & $65.00 \pm 5.89$ & $-3.52 \pm 0.06$ & $-30.39 \pm 0.09$ \\
\hline \multirow[t]{2}{*}{$X$. americana } & $15.30 \pm 4.30$ & $0.566 \pm 0.14$ & $0.046 \pm 0.015$ & $-2.91 \pm 0.19$ & $68.25 \pm 17.55$ & $1.77 \pm 0.11$ & $47.82 \pm 0.57$ & $27.18 \pm 1.58$ & $-1.42 \pm 0.45$ & $-31.66 \pm 0.10$ \\
\hline & \multicolumn{10}{|c|}{2000} \\
\hline G. elliottii & $20.83 \pm 0.21^{*}$ & $0.347 \pm 0.02^{*}$ & $0.054 \pm 0.002^{\star}$ & $-2.19 \pm 0.38^{*}$ & $34.03 \pm 5.76^{*}$ & $2.17 \pm 0.12$ & $51.06 \pm 0.21$ & $21.18 \pm 2.59$ & $-1.72 \pm 0.07$ & $-27.85 \pm 0.78$ \\
\hline L. fruticosa & - & - & $\ldots$ & -- & - & $0.92 \pm 0.02$ & $55.34 \pm 1.11$ & $60.23 \div 0.77$ & $-2.77 \pm 0.10$ & $-28.99 \pm 0.27$ \\
\hline L. lucida & $12.78 \pm 0.28^{*}$ & $0.346 \pm 0.03^{*}$ & $0.043 \pm 0.001^{\star}$ & $-1.98 \pm 0.22^{*}$ & $38.03 \pm 4.75^{*}$ & $0.83 \pm 0.04$ & $58.05 \pm 0.76$ & $74.83 \div 6.57$ & $-3.05 \pm 0.49$ & $-27.54 \pm 0.43$ \\
\hline M. cenfera & $16.77 \pm 0.38$ & $0.409 \pm 0.01$ & $0.050 \pm 0.002$ & $-1.82 \pm 0.17$ & $27.49 \pm 3.91$ & $1.54 \pm 0.09$ & $52.06 \pm 0.56$ & $34.12 \pm 2.30$ & $-1.79 \pm 0.13$ & $-30.06 \pm 0.13$ \\
\hline Q. chapmanii & $19.98 \pm 0.30^{*}$ & $0.380 \pm 0.02^{*}$ & $0.047 \pm 0.001^{*}$ & $-2.79 \pm 0.25^{\star}$ & $53.55 \pm 4.70^{*}$ & $1.57 \pm 0.03$ & $51.07 \pm 1.74$ & $32.62 \pm 1.62$ & $-2.73 \pm 0.53$ & $-27.46 \pm 0.63$ \\
\hline Q. geminata & $24.18 \pm 0.88^{*}$ & $0.511 \pm 0.04^{*}$ & $0.045 \pm 0.003^{*}$ & $-2.11 \pm 0.14^{*}$ & $42.74 \pm 1.91^{\star}$ & $1.24 \pm 0.06$ & $54.69 \pm 0.51$ & $44.31 \pm 2.63$ & $-1.82 \pm 0.55$ & $-28.84 \pm 0.18$ \\
\hline Q. myrifolia & $18.38 \pm 0.60^{*}$ & $0.361 \pm 0.04^{*}$ & $0.044 \pm 0.001^{*}$ & $-1.30 \pm 0.27^{\star}$ & $25.62 \pm 5.74^{*}$ & $1.62 \pm 0.07$ & $53.87 \pm 0.66$ & $33.27 \pm 1.40$ & $-2.72 \pm 0.18$ & $-28.18 \pm 0.40$ \\
\hline S. repens & $12.95 \pm 0.17^{\star}$ & $0.355 \pm 0.02^{*}$ & $0.036 \pm 0.000^{*}$ & $-1.78 \pm 0.23^{*}$ & $43.67 \pm 6.17^{*}$ & $1.36 \pm 0.07$ & $52.15 \pm 0.41$ & $38.67 \pm 2.19$ & $-1.05 \pm 0.19$ & $-27.00 \pm 0.14$ \\
\hline S. auriculata & $17.47 \pm 1.51$ & $0.462 \pm 0.07$ & $0.048 \pm 0.005$ & $-1.68 \pm 0.18$ & $27.97 \pm 3.34$ & $1.73 \pm 0.05$ & $50.38 \pm 0.48$ & $29.12 \pm 0.99$ & $-0.78 \pm 0.77$ & $-28.06 \pm 0.53$ \\
\hline V. myrsinites & $9.41 \pm 1.60$ & $0.232 \pm 0.08$ & $0.031 \pm 0.002$ & $-1.31 \pm 0.13$ & $33.43 \pm 2.63$ & $0.85 \pm 0.05$ & $56.12 \pm 0.88$ & $66.65 \pm 4.86$ & $-2.38 \pm 0.38$ & $-30.34 \pm 0.64$ \\
\hline$X$ americana & $17.53 \pm 1.05^{\star}$ & $0.815 \pm 0.05^{*}$ & $0.047 \pm 0.001^{*}$ & $-2.94 \pm 0.36^{*}$ & $57.38 \pm 6.13^{*}$ & $2.26 \pm 0.16$ & $54.82 \pm 0.39$ & $24.50 \pm 1.60$ & $-2.59 \pm 0.16$ & $-32.00 \pm 0.18$ \\
\hline
\end{tabular}




\section{Appendix A (Continued)}

Table 14: Physiological parameters for species in the Camera Pad fire suppressed plot. ( $A_{\max }, g_{\max }, \Phi, R$, and $C P$ obtained from light curves $n=2$ for $1999, n=3$ for 2000 ( ${ }^{*}$ indicates an exception where $n=6$ ); where $n=6 ; \% N, \% C, C: N, \delta^{15} N$, and $\delta^{13} \mathrm{C} n=3$ for both years) ${ }^{* *} n=1$

\begin{tabular}{|c|c|c|c|c|c|c|c|c|c|c|}
\hline & $\begin{array}{c}A_{\max } \\
\left(\mu \operatorname{mols~} \mathrm{CO}_{2} \mathrm{~m}^{-2}\right. \\
\left.\mathrm{s}^{-1}\right)\end{array}$ & $\begin{array}{c}9 \max \\
\text { (mmois } \mathrm{H}_{2} \mathrm{O} \mathrm{m} \mathrm{m}^{-2} \\
\left.\mathrm{~s}^{-1}\right)^{2}\end{array}$ & $\begin{array}{c}\Phi \\
\text { (umols } \mathrm{CO}_{2} \\
\text { lumois photons) }\end{array}$ & $\begin{array}{c}\mathbf{R}_{\mathrm{d}} \\
\left(\mu \mathrm{mols} \mathrm{CO}_{2} \mathrm{~m}^{-2}\right. \\
\left.\mathrm{s}^{-1}\right)\end{array}$ & $\begin{array}{c}I_{c} \\
\text { (umois photons } \\
\mathrm{m}^{-2} \mathrm{~s}^{-1} \text { ) }\end{array}$ & $\begin{array}{c}\% N \\
\left(\mathrm{~g} \mathrm{~g}^{-1}\right)\end{array}$ & $\begin{array}{l}\% C \\
\left(g g^{-1}\right)\end{array}$ & $C: N$ & $\begin{array}{l}\delta^{15} N \\
\left(\%_{00}\right)\end{array}$ & $\begin{array}{c}\delta^{13} \mathrm{C} \\
\left(\%_{\infty}\right)\end{array}$ \\
\hline Species & \multicolumn{10}{|c|}{1999} \\
\hline G. elliottii & -- & - & - & - & - & $-\ldots$ & - & - & -- & $\cdots$ \\
\hline L. ferruginea & $\ldots$ & - & - & - & - & $0.99 \pm 0.03$ & $54.10 \pm 0.67$ & $54.83 \pm 2.11$ & $-2.14 \pm 0.32$ & $-28.37 \pm 0.17$ \\
\hline M. cerifera & - & - & - & -- & - & -- & - & - & - & - \\
\hline Q. chapmanii & $17.75 \pm 2.08$ & $0.196 \pm 0.05$ & $0.035 \pm 0.014$ & $-2.39 \pm 0.19$ & $98.88 \pm 11.11$ & $1.61 \pm 0.09$ & $47.12 \pm 1.41$ & $29.34 \pm 1.09$ & $-3.39 \pm 0.25$ & $-25.77 \pm 0.25$ \\
\hline Q. geminata & $24.15 \pm 0.75$ & $0.363 \pm 0.04$ & $0.045 \pm 0.005$ & $-2.44 \pm 0.09$ & $52.01 \pm 4.06$ & $1.11 \pm 0.03$ & $46.83 \pm 0.36$ & $42.41 \pm 1.23$ & $-3.68 \pm 0.21$ & $-28.11 \pm 0.42$ \\
\hline Q. myrtifolia & $10.26 \pm 2.81$ & $0.117 \pm 0.04$ & $0.027 \pm 0.006$ & $-1.78 \pm 0.15$ & $59.77 \pm 13.73$ & $1.53 \pm 0.05$ & $49.75 \pm 0.67$ & $32.66 \pm 0.71$ & $-4.81 \pm 0.24$ & $-26.77 \pm 0.49$ \\
\hline S. repens & $11.27 \pm 0.64$ & $0.234 \pm 0.02$ & $0.036 \pm 0.001$ & $-1.73 \pm 0.04$ & $39.48 \pm 1.15$ & $1.18 \pm 0.03$ & $45.94 \pm 0.84$ & $39.07 \pm 1.12$ & $-1.94 \pm 0.01$ & $-27.27 \pm 0.33$ \\
\hline \multirow[t]{2}{*}{$V$. myrsinites } & $4.24 \pm 1.28$ & $0.045 \pm 0.01$ & $0.017 \pm 0.007$ & $-1.57 \pm 0.08$ & $82.86 \pm 26.17$ & $0.90 \pm 0.09$ & $53.41 \pm 0.92$ & $59.23 \pm 4.52$ & $-2.80 \pm 0.62$ & $-30.15 \pm 0.15$ \\
\hline & \multicolumn{10}{|c|}{2000} \\
\hline G. elliottii & $17.20 \pm 0.90$ & $0.297 \pm 0.05$ & $0.049 \pm 0.004$ & $-2.30 \pm 0.80$ & $40.72 \pm 15.92$ & $2.30 \pm 0.10$ & $50.84 \pm 0.53$ & $22.21 \pm 1.23$ & $-1.98 \pm 0.01$ & $-28.46 \pm 0.79$ \\
\hline L. ferruginea & $\cdots$ & $-\ldots$ & - & -- & - & $0.90 \pm 0.04$ & $55.56 \pm 0.24$ & $61.89 \pm 2.79$ & $-1.36 \pm 0.15$ & $-28.85 \pm 0.29$ \\
\hline M. cerifera & --- & $\cdots$ & -- & -- & - & $1.65^{* *}$ & $55.67^{\star \star}$ & $33.72^{\star \star}$ & $-1.49^{\star *}$ & $-28.56^{\star \star}$ \\
\hline Q. chapmanii & $16.97 \pm 0.86$ & $0.234 \pm 0.04$ & $0.037 \pm 0.003$ & $-1.92 \pm 0.38$ & $47.23=11.25$ & $1.51 \pm 0.10$ & $51.22 \pm 0.09$ & $34.32 \pm 2.22$ & $-2.33 \pm 0.73$ & $-27.33 \pm 0.13$ \\
\hline Q. geminata & $27.00 \pm 1.62$ & $0.511 \pm 0.03$ & $0.053 \pm 0.001$ & $-1.39 \pm 0.27$ & $26.05 \div 4.73$ & $1.26 \pm 0.03$ & $51.55 \pm 0.19$ & $40.90 \pm 0.81$ & $-3.13 \pm 0.45$ & $-28.79 \pm 0.23$ \\
\hline Q. myrtifolia & $16.47 \pm 1.26$ & $0.240 \pm 0.01$ & $0.041 \pm 0.004$ & $-1.38 \pm 0.22$ & $28.87 \pm 4.85$ & $1.53 \pm 0.03$ & $52.89 \pm 0.29$ & $34.69 \pm 0.47$ & $-4.30 \pm 0.39$ & $-27.22 \pm 0.39$ \\
\hline S. repens & $12.70 \pm 0.40$ & $0.268 \pm 0.02$ & $0.034 \pm 0.000$ & $-1.16 \pm 0.20$ & $26.27 \pm 5.28$ & $1.25 \pm 0.03$ & $49.54 \pm 0.63$ & $39.76 \pm 1.24$ & $-1.27 \pm 0.18$ & $-27.65 \pm 0.35$ \\
\hline$V$. myrsinites & $\ldots$ & -- & - & - & $\ldots$ & $0.83 \pm 0.05$ & $54.86 \pm 0.53$ & $66.81 \pm 3.97$ & $-1.12 \pm 1.52$ & $-30.64 \pm 0.44$ \\
\hline
\end{tabular}




\section{Appendix A (Continued)}

Table 15: Physiological parameters for species in the Camera Pad mechanical treated plot. $\left(A_{\max }, g_{\max }, \Phi, R\right.$, and $C P$ obtained from light curves $n=2$ for 1999 . $n=3$ for 2000 ( $^{*}$ indicates an exception where $\left.n=6\right): \% N, \% C, C: N, \delta^{15} N$, and $\delta^{13} C n=3$ for both years) ${ }^{*} n=6$, ${ }^{*} n=1$

\begin{tabular}{|c|c|c|c|c|c|c|c|c|c|c|}
\hline & $\begin{array}{c}A_{\max } \\
\text { (umols } \mathrm{CO}_{2} \mathrm{~m}^{-2} \\
\mathrm{~s}^{-1} \text { ) }\end{array}$ & $\begin{array}{c}g_{\max } \\
\text { mmois } \mathrm{H}_{2} \mathrm{O} \mathrm{m}^{-2} \\
\left.\mathrm{~s}^{-1}\right) \\
\end{array}$ & 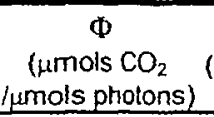 & $\begin{array}{c}\mathbf{R}_{\mathbf{d}} \\
\left(\mu \mathrm{mols} \mathrm{CO}_{2} \mathrm{~m}^{-2}\right. \\
\left.\mathrm{s}^{-1}\right) \\
\end{array}$ & $\begin{array}{c}I_{c} \\
\text { (umols photons } \\
\mathrm{m}^{-2} \mathrm{~s}^{-1} \text { ) }\end{array}$ & $\begin{array}{l}\% N \\
\left(g g^{-1}\right)\end{array}$ & $\begin{array}{l}\% C \\
\left(g g^{-1}\right)\end{array}$ & $C: N$ & $\begin{array}{l}\delta^{15} \mathrm{~N} \\
(\%) 0)\end{array}$ & $\begin{array}{l}\delta^{13} \mathrm{C} \\
(\%)\end{array}$ \\
\hline Species & \multicolumn{10}{|c|}{1999} \\
\hline G. elliottii & $16.25 \pm 1.85$ & $0.232 \pm 0.02$ & $0.037 \pm 0.004$ & $-3.75 \pm 0.55$ & $98.37 \pm 1.75$ & $2.27 \pm 0.05$ & $45.77 \pm 0.16$ & $20.15 \pm 0.37$ & $-1.57 \pm 0.20$ & $-28.02 \pm 0.36$ \\
\hline L. fernuginea & - & - & - & - & $\ldots$ & $0.93 \pm 0.04$ & $49.86 \pm 0.39$ & $53.61 \pm 1.85$ & $-2.37 \pm 0.27$ & $-27.96 \pm 0.18$ \\
\hline L. fruticosa & -- & - & $\cdots$ & - & -- & -. & $\cdots$ & - & - & - \\
\hline L. fucida & $12.60 \pm 1.70$ & $0.253 \pm 0.00$ & $0.042 \div 0.004$ & $-2.41 \pm 0.39$ & $52.51 \pm 13.98$ & $0.71 \pm 0.02$ & $50.75 \pm 0.42$ & $72.12 \pm 2.57$ & $-2.59 \pm 0.90$ & $-27.49 \pm 0.47$ \\
\hline M. cerifera & $16.40 \pm 4.00$ & $0.350 \pm 0.11$ & $0.048 \pm 0.005$ & $-3.81 \pm 0.15$ & $72.10 \pm 6.29$ & $1.46 \pm 0.03$ & $49.92 \pm 0.30$ & $34.26 \pm 0.61$ & $-2.05 \pm 0.13$ & $-28.32 \pm 0.23$ \\
\hline Q. chapmanii & $16.35 \pm 6.65$ & $0.247 \pm 0.13$ & $0.047 \pm 0.011$ & $-1.93 \pm 0.43$ & $33.65 \pm 0.78$ & $1.42 \pm 0.13$ & $45.70 \pm 1.12$ & $32.58 \pm 2.24$ & $-2.51 \pm 0.34$ & $-26.94 \pm 0.51$ \\
\hline Q. geminata & $23.75 \pm 1.35$ & $0.340 \pm 0.01$ & $0.039 \pm 0.001$ & $-1.59 \pm 0.13$ & $41.33 \pm 4.60$ & $1.14 \pm 0.03$ & $46.91 \pm 0.12$ & $41.21 \pm 1.33$ & $-3.71 \pm 0.33$ & $-28.32 \pm 0.27$ \\
\hline Q. myrtifolia & $16.75 \pm 0.45$ & $0.260 \pm 0.02$ & $0.036 \pm 0.001$ & $-1.44 \pm 0.56$ & $21.91 \pm 15.49$ & $1.37 \pm 0.05$ & $46.83 \doteq 0.49$ & $34.23 \pm 1.47$ & $-3.52 \pm 0.13$ & $-26.67 \pm 0.12$ \\
\hline S. repens & $13.45 \pm 0.05$ & $0.328 \pm 0.01$ & $0.035 \pm 0.001$ & $-2.06 \pm 0.04$ & $53.57 \pm 3.71$ & $1.26 \pm 0.03$ & $44.70 \pm 0.64$ & $35.37 \pm 0.30$ & $-0.57 \pm 0.11$ & $-26.05 \pm 0.16$ \\
\hline S. auriculata & - & - & - & - & $\cdots$ & -- & $\cdots$ & --- & $\cdots$ & -- \\
\hline V. myrsinites & $11.10 \pm 0.40$ & $0.266 \pm 0.02$ & $0.042 \pm 0.006$ & $-1.97 \pm 0.17$ & $38.09 \pm 3.77$ & $0.78 \pm 0.02$ & $51.03 \pm 0.49$ & $65.58 \pm 2.19$ & $-1.47 \pm 0.72$ & $-29.40 \pm 0.07$ \\
\hline \multirow[t]{2}{*}{$X$. americana } & $.15 \pm 0.25$ & $0.648 \pm 0.02$ & $0.046 \pm 0.003$ & $-2.935 \pm 0.03$ & $57.09 \pm 5.42$ & $2.14 \pm 0.06$ & $47.61 \pm 0.59$ & $22.30 \pm 0.73$ & $-1.65 \pm 0.17$ & $-31.32 \pm 0.31$ \\
\hline & \multicolumn{10}{|c|}{2000} \\
\hline G. elliottii & $20.55 \pm 1.64^{*}$ & $0.399 \pm 0.05^{*}$ & $0.049 \pm 0.003^{*}$ & $-2.84 \pm 0.30^{*}$ & $51.88 \pm 5.59^{\star}$ & $1.69 \pm 0.37$ & $51.49 \pm 0.16$ & $34.64 \pm 9.63$ & $-1.85 \pm 0.08$ & $-28.42 \pm 0.18$ \\
\hline L. ferruginea & $\cdots$ & - & - & $\cdots$ & - & $0.97 \pm 0.01$ & $56.36 \pm 0.15$ & $57.96 \pm 0.94$ & $-1.25 \pm 0.30$ & $-28.50 \pm 0.42$ \\
\hline L. fruticosa & $\cdots$ & - & - & $-\cdots$ & - & $0.94 \pm 0.02$ & $54.70 \pm 0.25$ & $58.50 \pm 1.06$ & $-2.39 \pm 0.44$ & $-27.69 \pm 0.35$ \\
\hline L. lucida & $13.50 \pm 0.44^{\star}$ & $0.300 \pm 0.03^{\star}$ & $0.044 \pm 0.001^{\star}$ & $-1.52 \pm 0.16^{\star}$ & $27.94 \pm 3.55^{\star}$ & $0.87 \pm 0.03$ & $55.96 \pm 0.60$ & $64.40 \pm 2.63$ & $-3.23 \pm 0.56$ & $-27.63 \pm 0.27$ \\
\hline M. cerifera & $17.37 \pm\{.11$ & $0.296 \pm 0.3$ & $0.050 \pm 0.003$ & $-1.54 \pm 0.33$ & $26.82 \pm 6.17$ & $1.73 \pm 0.05$ & $54.19 \pm 0.55$ & $31.31 \pm 1.07$ & $-1.48 \pm 0.19$ & $-29.21 \pm 0.20$ \\
\hline Q. chapmanii & $20.70 \pm 0.69^{\star}$ & $0.417 \pm 0.04^{\star}$ & $0.048 \pm 0.002^{*}$ & $-2.52 \pm 0.36^{\star}$ & $46.13 \pm 5.82^{*}$ & $1.55 \pm 0.04$ & $50.14 \pm 0.32$ & $32.47 \pm 0.84$ & $-2.75 \pm 0.81$ & $-27.82 \div 0.52$ \\
\hline Q. geminata & $23.33 \pm 0.57^{\star}$ & $0.409 \pm 0.03^{*}$ & $0.044 \pm 0.001^{\star}$ & $-1.68 \pm 0.14^{*}$ & $34.92 \pm 3.12^{\star}$ & $1.31 \pm 0.03$ & $51.06 \pm 0.46$ & $39.09 \pm 1.28$ & $-3.57 \pm 0.36$ & $-28.79 \pm 0.07$ \\
\hline Q. myrtifolia & $17.63 \pm 0.82^{*}$ & $0.249 \pm 0.02^{*}$ & $0.041 \pm 0.003^{*}$ & $-1.25 \pm 0.24^{\star}$ & $26.97 \pm 4.08^{\star}$ & $1.38 \pm 0.00$ & $53.79 \pm 1.26$ & $39.05 \pm 0.84$ & $-3.52 \pm 0.31$ & $-28.21 \pm 0.40$ \\
\hline S. repens & $12.75 \pm 0.33^{*}$ & $0.322 \pm 0.04^{*}$ & $0.035 \pm 0.001^{*}$ & $-1.77 \pm 0.05^{*}$ & $45.60 \pm 1.29^{\star}$ & $1.33 \pm 0.03$ & $50.72 \pm 1.89$ & $38.09 \pm 1.74$ & $-0.52 \pm 1.02$ & $-26.98 \pm 0.35$ \\
\hline S. auriculata & -- & $\cdots$ & $\cdots$ & - & - & $1.78^{* *}$ & $50.67^{* *}$ & $28.42^{* *}$ & $1.02^{* *}$ & $-27.52^{\star \star}$ \\
\hline V. myrsinites & $9.15 \pm 0.95$ & $0.148 \pm 0.01$ & $0.031 \pm 0.001$ & $-1.01 \pm 0.21$ & $21.53 \pm 6.16$ & $0.84 \pm 0.01$ & $58.22 \pm 0.93$ & $69.22 \pm 0.58$ & $-0.84 \pm 0.71$ & $-30.21 \pm 0.92$ \\
\hline$X$. americana & $16.65 \pm 0.60^{*}$ & $0.694 \pm 0.06^{*}$ & $0.048 \pm 0.003^{*}$ & $-2.67 \pm 0.14^{*}$ & $51.19 \pm 2.86^{*}$ & $2.29 \pm 0.45$ & $53.79 \pm 0.30$ & $25.86 \pm 6.16$ & $-2.17 \pm 0.14$ & $-30.52 \pm 0.39$ \\
\hline
\end{tabular}




\section{Appendix A (Continued)}

Table 16: Physiological parameters for species in the Happy Creek burn plot. ( $A_{\max }, g_{\text {max }}, \Phi, R$, and $C P$ obtained from light curves $n=2$ for $1999, n=3$ for 2000;

\begin{tabular}{|c|c|c|c|c|c|c|c|c|c|c|}
\hline & $\begin{array}{c}\mathbf{A}_{\max } \\
\left(\mu \mathrm{mols} \mathrm{CO}_{2} \mathrm{~m}^{-2}\right. \\
\left.\mathrm{s}^{-1}\right) \\
\end{array}$ & $\begin{array}{c}g_{\max } \\
\left(\mathrm{mmols} \mathrm{H}_{2} \mathrm{O} \mathrm{m}^{-2}\right. \\
\left.\mathrm{s}^{-1}\right)\end{array}$ & $\begin{array}{c}\Phi \\
\text { ( } \mu \text { mols } \mathrm{CO}_{2} \\
\text { Jumols photons) }\end{array}$ & $\begin{array}{c}\mathbf{R}_{\mathrm{d}} \\
\text { (umols } \mathrm{CO}_{2} \mathrm{~m}^{-2} \\
\mathrm{~s}^{-1} \text { ) } \\
\end{array}$ & $\begin{array}{c}I_{c} \\
\text { (umols photons } \\
m^{-2} s^{-1} \text { ) }\end{array}$ & $\begin{array}{c}\% N \\
\left(g g^{-1}\right)\end{array}$ & $\begin{array}{c}\% C \\
\left(g g^{-1}\right)\end{array}$ & $C: N$ & $\begin{array}{c}\delta^{15} N \\
(\%(\infty))\end{array}$ & $\begin{array}{l}\delta^{13} \mathrm{C} \\
(\%)\end{array}$ \\
\hline Species & \multicolumn{10}{|c|}{1999} \\
\hline G. elliottii & $15.6 \pm 0.90$ & $0.272 \pm 0.04$ & $0.048 \pm 0.001$ & $-3.46 \pm 0.38$ & $73.19 \pm 6.95$ & $1.97 \pm 0.20$ & $45.44 \pm 0.23$ & $23.59 \pm 2.28$ & $-1.75 \pm 0.06$ & $-26.90 \pm 0.79$ \\
\hline L. lucida & $6.57 \pm 1.98$ & $0.077 \pm 0.02$ & $0.024 \pm 0.004$ & $-2.10 \pm 0.30$ & $88.03 \pm 3.51$ & $0.74 \pm 0.02$ & $51.48 \pm 0.40$ & $69.35 \pm 2.44$ & $-2.51 \pm 0.09$ & $-26.89 \pm 0.31$ \\
\hline M. cerifera & -- & - & $\cdots$ & -- & - & $1.39 \pm 0.09$ & $48.50 \pm 0.53$ & $35.02 \pm 1.96$ & $-2.70 \pm 0.11$ & $-26.84 \pm 0.21$ \\
\hline Q. chapmanii & $8.68 \pm 0.86$ & $0.207 \pm 0.03$ & $0.036 \pm 0.009$ & $-5.17 \pm 1.25$ & $142.85 \pm 3.86$ & $1.43 \pm 0.01$ & $46.47 \pm 0.61$ & $32.56 \pm 0.49$ & $-1.36 \pm 0.66$ & $-27.05 \pm 0.40$ \\
\hline Q. geminata & $19.8 \pm 0.80$ & $0.262 \pm 0.03$ & $0.044 \pm 0.013$ & $-3.63 \pm 0.08$ & $92.05 \div 29.59$ & $1.25 \pm 0.02$ & $45.47 \pm 0.22$ & $36.43 \pm 0.56$ & $-1.98 \pm 0.4$ & $-26.71 \pm 0.59$ \\
\hline Q. myrtifolia & $9.76 \pm 1.14$ & $0.176 \pm 0.02$ & $0.049 \pm 0.012$ & $-5.66 \pm 1.40$ & $131.88 \pm 15.07$ & $1.28 \pm 0.05$ & $47.46 \pm 0.64$ & $37.20 \pm 1.57$ & $-1.51 \pm 0.28$ & $-26.56 \pm 0.35$ \\
\hline S. repens & $12.2 \pm 0.00$ & $0.218 \pm 0.01$ & $0.035 \pm 0.002$ & $-2.13 \pm 0.51$ & $60.47 \pm 11.61$ & $1.32 \pm 0.01$ & $44.30 \pm 0.93$ & $33.63 \pm 0.79$ & $-0.57 \pm 0.26$ & $-27.05 \pm 0.11$ \\
\hline S. auriculata & $14.1 \pm 0.57$ & $0.196 \pm 0.01$ & $0.039 \pm 0.006$ & $-2.44 \pm 0.27$ & $68.22 \pm 18.33$ & $1.87 \pm 0.10$ & $44.34 \pm 0.66$ & $23.89 \pm 1.18$ & $0.73 \pm 0.48$ & $-27.72 \pm 0.64$ \\
\hline V. myrsinites & $16.8^{\star \star}$ & $0.284^{\star \star}$ & $0.048^{* *}$ & $-5.68 \pm 0.12$ & $117.10^{* *}$ & $0.73 \pm 0.00$ & $51.67 \pm 0.25$ & $70.77 \pm 0.85$ & $-1.66 \pm 0.64$ & $-29.21 \pm 0.79$ \\
\hline \multirow[t]{2}{*}{$X$. americana } & $11.05 \pm 0.25$ & $0.400 \pm 0.04$ & $0.036 \pm 0.002$ & $-3.93 \div 0.66$ & $122.50 \pm 12.43$ & $1.66 \pm 0.17$ & $47.89 \pm 0.59$ & $29.31 \pm 2.59$ & $-0.91 \pm 0.68$ & $-31.89 \pm 0.26$ \\
\hline & \multicolumn{10}{|c|}{2000} \\
\hline G. elliottii & $20.00 \pm 1.15$ & $0.294 \pm 0.06$ & $0.050 \pm 0.005$ & $-2.05 \pm 0.37$ & $38.33 \pm 15.20$ & $2.27 \pm 0.03$ & $49.43 \pm 0.24$ & $21.79 \pm 0.37$ & $-2.30 \pm 0.04$ & $-26.84 \pm 0.40$ \\
\hline L. lucida & $13.63 \pm 0.89$ & $0.212 \pm 0.01$ & $0.037 \pm 0.002$ & $-1.65 \pm 0.06$ & $36.61 \pm 0.81$ & $0.74 \pm 0.01$ & $55.78 \pm 0.29$ & $74.98 \pm 1.32$ & $-1.84 \pm 0.70$ & $-27.20 \pm 0.30$ \\
\hline M. cerifera & - & - & - & $\ldots$ & $\ldots$ & $.1 .26^{* \star}$ & $45.99^{\star \star}$ & $36.37^{\star \star}$ & $-2.13^{\star \star}$ & $-27.43^{* *}$ \\
\hline Q. chapmanii & $20.30 \pm 0.72$ & $0.288 \div 0.01$ & $0.047 \pm 0.002$ & $-2.25 \pm 0.19$ & $42.25 \pm 4.08$ & $1.46 \pm 0.08$ & $52.17 \pm 0.61$ & $35.97 \pm 1.68$ & $-1.91 \pm 0.56$ & $-27.97 \pm 0.37$ \\
\hline Q. geminata & $22.30 \pm 2.54$ & $0.377 \pm 0.05$ & $0.045 \pm 0.007$ & $-1.77 \pm 0.05$ & $37.74 \pm 6.43$ & $1.23 \pm 0.04$ & $52.73 \pm 0.26$ & $42.85 \pm 1.39$ & $-2.05 \pm 0.51$ & $-28.25 \pm 0.25$ \\
\hline Q. myrtifolia & $18.27 \pm 0.49$ & $0.276 \div 0.01$ & $0.044 \pm 0.002$ & $-1.64 \pm 0.05$ & $30.75 \pm 1.56$ & $1.37 \pm 0.06$ & $54.00 \pm 0.46$ & $39.64 \pm 1.77$ & $-1.99 \pm 0.17$ & $-27.37 \pm 0.52$ \\
\hline S. repens & $13.97 \pm 0.46$ & $0.273 \pm 0.01$ & $0.036 \pm 0.00\}$ & $-1.47 \pm 0.05$ & $34.99 \pm 2.07$ & $0.99 \pm 0.16$ & $49.57 \pm 0.69$ & $52.80 \pm 8.26$ & $-0.66 \pm 0.43$ & $-27.00 \pm 0.28$ \\
\hline S. aunculata & $\cdots$ & . - & -- & $\cdots$ & - & $1.71 \pm 0.09$ & $48.83 \pm 0.74$ & $28.69 \pm 1.64$ & $-0.12 \pm 0.67$ & $-27.46 \pm 0.32$ \\
\hline V. myrsinites & -- & - & -- & $\cdots$ & - & $0.80 \pm 0.07$ & $55.85 \pm 0.54$ & $70.36 \pm 4.76$ & $-0.99 \pm 0.59$ & $-29.96 \pm 0.23$ \\
\hline X. americana & $18.07 \pm 1.73$ & $0.831 \pm 0.11$ & $0.050 \pm 0.003$ & $-2.68 \pm 0.58$ & $48.11 \pm 9.44$ & $1.62 \pm 0.05$ & $58.76 \pm 0.10$ & $36.39 \pm 1.00$ & $-2.94 \pm 0.05$ & $-31.57 \pm 0.14$ \\
\hline
\end{tabular}




\section{Appendix A (Continued)}

Table 17: Physiological parameters for species in the Happy Creek fire suppressed plot. $\left(A_{\max } g_{\max }, \Phi, R\right.$, and $C P$ obtained from light curves $n=2$ for $1999, n=3$ for $2000 ; \% N, \% \mathrm{C}, \mathrm{C}: \mathrm{N}, \delta^{15} \mathrm{~N}$, and $\delta^{13} \mathrm{C} n=3$ for both years) ${ }^{* *} \mathrm{n}=1$

\begin{tabular}{|c|c|c|c|c|c|c|c|c|c|c|}
\hline & $\begin{array}{c}A_{\max } \\
\left(\mu \operatorname{mols} \mathrm{CO}_{2} \mathrm{~m}^{-2}\right. \\
\left.\mathrm{s}^{-1}\right\}\end{array}$ & $\begin{array}{c}g_{\max } \\
\text { (mmols } \mathrm{H}_{2} \mathrm{O} \mathrm{m} \\
\mathrm{s}^{-1} \text { ) }\end{array}$ & 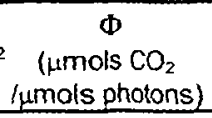 & $\begin{array}{c}\mathbf{R}_{\mathrm{d}} \\
\text { (umols } \mathrm{CO}_{2} \mathrm{~m}^{-2} \\
\mathrm{~s}^{-1} \text { \} }\end{array}$ & $\begin{array}{c}I_{c} \\
(\mu \text { mols photons } \\
\mathrm{m}^{-2} \mathrm{~s}^{-1} \text { ) }\end{array}$ & $\begin{array}{c}\% N \\
\left(\mathrm{~g} \mathrm{~g}^{-1}\right)\end{array}$ & $\begin{array}{c}\% C \\
\left(g g^{-1}\right)\end{array}$ & $C: N$ & $\begin{array}{r}\delta^{15} N \\
(\%+\infty)\end{array}$ & $\begin{array}{l}\delta^{13} \mathrm{C} \\
\left(\%_{\infty}\right)\end{array}$ \\
\hline Species & \multicolumn{10}{|c|}{1999} \\
\hline G. elfiottii & - & - & - & -- & $\cdots$ & $2.17 \pm 0.11$ & $46.09 \pm 0.49$ & $21.35 \pm 0.95$ & $-1.89 \pm 0.10$ & $-30.02 \pm 0.26$ \\
\hline L. fruticosa & $-\cdots$ & -- & -- & - &.- & -- & $\ldots$ & -- & -- & $\ldots$ \\
\hline L. Lucida & $\ldots$ & - & $-\cdots$ & - & $\ldots$ & $\cdots$ & $\sim-$ & $\cdots$ & -- & $\cdots$ \\
\hline M. cerifera & $\ldots$ & $\ldots$ & -.. & - & - & -- & $\ldots$ & -- & - & $\ldots$ \\
\hline Q. chapmanii & $10.54 \pm 0.97$ & $0.131 \pm 0.02$ & $0.025 \pm 0.006$ & $-2.38 \pm 0.47$ & $85.11 \pm 9.51$ & $1.53 \pm 0.10$ & $46.12 \pm 0.19$ & $30.50 \pm 2.29$ & $-3.03 \pm 0.32$ & $-26.07 \pm 0.18$ \\
\hline Q. geminata & $19.70 \pm 4.32$ & $0.253 \pm 0.09$ & $0.039 \pm 0.008$ & $-1.68 \pm 0.25$ & $44.47 \pm 8.47$ & $1.30 \pm 0.05$ & $46.57 \pm 0.14$ & $35.93 \pm 1.53$ & $-2.65 \pm 0.38$ & $-27.70 \pm 0.33$ \\
\hline Q. myrtifolia & $13.27 \pm 1.29$ & $0.141=0.03$ & $0.034 \pm 0.005$ & $-1.34 \pm 0.27$ & $30.76 \pm 8.21$ & $1.28 \pm 0.02$ & $47.86 \pm 0.03$ & $37.53 \pm 0.49$ & $-3.44 \pm 0.21$ & $-26.17 \pm 0.47$ \\
\hline S. repens & $11.40 \pm 0.30$ & $0.187 \pm 0.01$ & $0.032 \pm 0.001$ & $-0.731 \pm 0.19$ & $11.39 \pm 6.56$ & -- & $\cdots$ & $\ldots$ & - & -- \\
\hline S. auriculata & - & - & - & -.- & -- & - & - & $\cdots$ & $\cdots$ & -- \\
\hline \multirow[t]{2}{*}{ V. myrsinites } & $4.52 \pm 0.61$ & $0.065 \pm 0.01$ & $0.022 \pm 0.002$ & $-1.63 \pm 0.44$ & $57.86 \pm 15.37$ & $0.81^{* *}$ & $50.01 \pm 0.60$ & $60.51^{* *}$ & $-1.63^{* *}$ & $-30.91 \pm 0.44$ \\
\hline & \multicolumn{10}{|c|}{2000} \\
\hline G. elliottii & $18.00 \pm 1.75$ & $0.249 \pm 0.05$ & $0.048 \pm 0.002$ & $-2.19 \pm 0.32$ & $38.24 \pm 7.01$ & $2.14 \pm 0.11$ & $50.62 \pm 0.51$ & $23.86 \pm 1.48$ & $-2.19 \pm 0.27$ & $-28.60 \pm 0.24$ \\
\hline L. fruticosa & - & - & - & - & - & $1.05^{* \star}$ & $55.98^{\star \star}$ & $53.40^{* *}$ & $-0.66^{* *}$ & $-28.65^{* *}$ \\
\hline L. lucida & $10.20 \pm 0.47$ & $0.211 \pm 0.02$ & $0.033 \pm 0.001$ & $-1.07 \pm 0.18$ & $22.47 \pm 6.05$ & $0.83 \pm 0.04$ & $55.73 \pm 0.40$ & $67.73 \pm 4.24$ & $-1.88 \pm 1.14$ & $-28.84 \pm 0.44$ \\
\hline$M$. cerifera & - & - & - & - & $\cdots$ & $1.82 \pm 0.02$ & $52.57 \pm 0.80$ & $28.83 \pm 0.70$ & $-2.12 \pm 0.10$ & $-29.60 \pm 0.53$ \\
\hline Q. chapmanii & $17.63 \pm 0.26$ & $0.288 \pm 0.01$ & $0.042 \pm 0.003$ & $-1.95 \pm 0.42$ & $40.41 \pm 6.33$ & $1.85 \pm 0.07$ & $51.40 \pm 0.37$ & $27.81 \pm 1.08$ & $-2.61 \pm 0.30$ & $-28.14 \pm 0.36$ \\
\hline Q. geminata & $22.37 \pm 0.90$ & $0.398 \pm 0.03$ & $0.043 \pm 0.002$ & $-1.85 \pm 0.36$ & $39.31 \pm 9.84$ & $1.33 \pm 0.07$ & $51.64 \pm 0.20$ & $39.17 \pm 2.15$ & $-2.59 \pm 0.73$ & $-29.36 \pm 0.24$ \\
\hline Q. myrtifolia & $14.17 \pm 0.27$ & $0.229 \pm 0.02$ & $0.037 \pm 0.002$ & $-1.59 \pm 0.19$ & $35.20 \div 3.13$ & $1.46 \pm 0.05$ & $53.03 \pm 0.39$ & $36.42 \pm 1.43$ & $-3.49 \pm 0.24$ & $-28.12 \pm 0.28$ \\
\hline S. repens & $12.17 \pm 0.79$ & $0.257 \pm 0.02$ & $0.036 \pm 0.001$ & $-0.76 \pm 0.02$ & $11.65 \pm 0.59$ & $1.30 \pm 0.05$ & $51.04 \pm 0.42$ & $39.46 \pm 1.53$ & $-0.68 \pm 0.17$ & $-28.63 \pm 0.38$ \\
\hline S. auriculata & - & - & $\cdots$ & $\cdots$ & $\cdots$ & $1.92^{\star \star}$ & $49.51^{\star \star}$ & $25.82^{\star \star}$ & 0.44 & $-27.80^{\star \star}$ \\
\hline V. myrsinites & - & - & - & - & - & $0.95 \pm 0.07$ & $55.14 \pm 0.19$ & $58.66 \pm 4.78$ & $-1.28 \pm 0.65$ & $-29.55 \pm 0.13$ \\
\hline
\end{tabular}




\section{Appendix A (Continued)}

Table 18: Physiological parameters for species in the Happy Creek mechanically treated plot $(n=3)$.

\begin{tabular}{|c|c|c|c|c|c|c|c|c|c|c|}
\hline & $\begin{array}{c}A_{\max } \\
\left(\mu \text { mols } \mathrm{CO}_{2} \mathrm{~m}^{-2}\right. \\
\left.\mathrm{s}^{-1}\right)\end{array}$ & $\begin{array}{c}g_{\max } \\
\left(\mathrm{mmols} \mathrm{H}_{2} \mathrm{O} \mathrm{m}^{-2}\right. \\
\left.\mathrm{s}^{-1}\right)\end{array}$ & $\begin{array}{c}\Phi \\
\text { (umols } \mathrm{CO}_{2} \\
\text { (umols photons) }\end{array}$ & $\begin{array}{c}\mathbf{R}_{\mathbf{d}} \\
\left(\mu \mathrm{mols} \mathrm{CO}_{2} \mathrm{~m}^{-2}\right. \\
\left(\mathrm{s}^{-1}\right) \\
\end{array}$ & $\begin{array}{c}\mathbf{I}_{\mathrm{c}} \\
\text { (umols photons } \\
\mathrm{m}^{-2} \mathrm{~s}^{-1} \text { ) } \\
\end{array}$ & $\begin{array}{c}\% N \\
\left(g g^{-1}\right)\end{array}$ & $\begin{array}{l}\% C \\
\left(g g^{-1}\right)\end{array}$ & $C: N$ & $\begin{array}{l}\delta^{15} N \\
(\%)\end{array}$ & $\begin{array}{c}\delta^{13} \mathrm{C} \\
(\%)=\end{array}$ \\
\hline Species & \multicolumn{10}{|c|}{2000} \\
\hline G. elliottii & $23.33 \pm 0.52$ & $0.321 \pm 0.03$ & $0.055 \pm 0.005$ & $-3.21 \pm 0.51$ & $51.94 \pm 7.59$ & $2.02 \pm 0.09$ & $57.53 \pm 0.55$ & $28.63 \pm 1.10$ & $-2.29 \pm 0.24$ & $-28.22 \pm 0.84$ \\
\hline L. lucida & $12.73 \pm 0.49$ & $0.266 \pm 0.02$ & $0.040 \pm 0.002$ & $-1.57 \pm 0.25$ & $31.38 \pm 5.69$ & $0.67 \pm 0.02$ & $59.23 \pm 0.21$ & $88.77 \pm 2.56$ & $-2.42 \pm 0.67$ & $-26.88 \pm 0.46$ \\
\hline M. cerifera & -- & - & - & -- & $\ldots$ & $1.33 \pm 0.08$ & $54.14 \pm 1.00$ & $41.05 \pm 3.48$ & $-1.87 \pm 0.09$ & $-29.24 \pm 0.28$ \\
\hline Q. chapmanii & $19.80 \pm 1.08$ & $0.334 \pm 0.04$ & $0.042 \pm 0.003$ & $-2.01 \pm 0.03$ & $43.16 \pm 3.06$ & $1.73 \pm 0.09$ & $51.77 \pm 0.25$ & $30.14 \pm 1.39$ & $-1.76 \pm 0.64$ & $-27.31 \pm 0.16$ \\
\hline Q. geminata & $27.63 \pm 2.10$ & $0.538 \pm 0.05$ & $0.055 \pm 0.003$ & $-3.21 \pm 0.96$ & $53.78 \pm 14.34$ & $1.37 \pm 0.00$ & $52.17 \pm 0.13$ & $37.97 \pm 0.20$ & $-3.05 \pm 0.55$ & $-28.14 \pm 0.31$ \\
\hline Q. myrtifolia & $17.33 \pm 1.35$ & $0.311 \pm 0.04$ & $0.043 \pm 0.004$ & $-1.78 \pm 0.29$ & $34.01 \pm 4.91$ & $1.66 \pm 0.06$ & $50.56 \pm 0.76$ & $30.49 \pm 1.47$ & $-3.16 \pm 0.30$ & $-27.18 \pm 0.12$ \\
\hline S. repens & $13.70 \pm 0.75$ & $0.327 \pm 0.04$ & $0.037 \pm 0.002$ & $-1.79 \pm 0.41$ & $42.73 \pm 8.78$ & $1.29 \pm 0.11$ & $50.52 \pm 0.42$ & $39.91 \pm 3.67$ & $-0.55 \pm 0.40$ & $-27.02 \pm 0.40$ \\
\hline S. auriculata & - & $\cdots$ & - & - & -- & $2.17 \pm 0.05$ & $48.47 \pm 0.29$ & $22.34 \pm 0.60$ & $-0.22 \pm 0.48$ & $-27.5 \pm 1.15$ \\
\hline V. myrsinites & - & $\cdots$ & - & - & - & $0.84 \pm 0.01$ & $55.65 \pm 0.73$ & $66.25 \pm 0.25$ & $-1.76 \pm 0.10$ & $-29.96 \pm 0.71$ \\
\hline$X$ americana & $17.13 \pm 0.57$ & $0.769 \pm 0.05$ & $0.053 \pm 0.005$ & $-4.35 \pm 0.21$ & $75.31 \pm 4.61$ & $1.89 \pm 0.28$ & $51.07 \pm 0.80$ & $28.10 \pm 3.53$ & $-3.41 \pm 0.40$ & $-31.23 \pm 0.51$ \\
\hline
\end{tabular}




\section{Appendix A (Continued)}

Table 19: Physiological parameters for species in the Kennedy Parkway burn plot. ( $A_{\max }, g_{\max }, \Phi, R$, and $C P n=2$ for $1999, n=3$ for $2000 ; \% N, \% C, C: N, \delta^{15} N$, and $\delta^{13} \mathrm{C} n=3$ for both years). ${ }^{* *} n=1$

\begin{tabular}{|c|c|c|c|c|c|c|c|c|c|c|}
\hline & $\begin{array}{c}A_{\max } \\
\left(\mu \text { mols } \mathrm{CO}_{2} \mathrm{~m}^{-2}\right. \\
\left.\mathrm{s}^{-1}\right) \\
\end{array}$ & $\begin{array}{c}g_{\max } \\
\text { mmols } \mathrm{H}_{2} \mathrm{O} \mathrm{m} \mathrm{m}^{-2} \\
\mathrm{~s}^{-1} \text { ) }\end{array}$ & $\begin{array}{c}\Phi \\
\text { (umols } \mathrm{CO}_{2} \\
\text { lumols photons) }\end{array}$ & $\begin{array}{c}\mathbf{R}_{\mathbf{d}} \\
\text { (umols } \mathrm{CO}_{2} \mathrm{~m}^{-2} \\
\mathrm{~s}^{-1} \text { ) } \\
\end{array}$ & $\begin{array}{c}l_{c} \\
\text { (umols photons } \\
\mathrm{m}^{-2} \mathrm{~s}^{-1} \text { ) } \\
\end{array}$ & $\begin{array}{c}\% N \\
\left(g \mathrm{~g}^{-1}\right)\end{array}$ & $\begin{array}{l}\% C \\
\left(g g^{-1}\right)\end{array}$ & $C: N$ & $\begin{array}{l}\delta^{15} \mathrm{~N} \\
(\%) 0\end{array}$ & $\begin{array}{l}\delta^{13} \mathrm{C} \\
(\%)\end{array}$ \\
\hline Species & \multicolumn{10}{|c|}{$\begin{array}{rr}1999 \\
\end{array}$} \\
\hline L. fruticosa & -- & - & $\cdots$ & - & - & $-\cdots$ & $\cdots$ & -- & -- & - \\
\hline L. lucida & $6.82^{\star \pm}$ & $0.123^{* *}$ & $0.023 \pm 0.001$ & $-2.21^{\star *}$ & $98.82 \pm 28.14$ & $0.63 \pm 0.03$ & $51.18 \pm 0.48$ & $81.30 \pm 3.58$ & $-3.78 \pm 0.19$ & $-27.85 \pm 0.32$ \\
\hline M. cerifera & -- & - & -.. & $-\cdots$ & - & $1.53 \pm 0.04$ & $50.45 \pm 1.03$ & $32.96 \pm 0.92$ & $-1.92 \pm 0.20$ & $-28.91 \pm 0.28$ \\
\hline Q. chapmanii &.- & - & -- & -- & -- & -- & - & - & $\ldots$ & -- \\
\hline Q. geminata & $12.55 \pm 0.45$ & $0.160 \pm 0.01$ & $0.020^{* *}$ & $-2.18^{* *}$ & $99.95^{* *}$ & $1.06 \pm 0.04$ & $46.10 \pm 1.83$ & $43.63 \pm 1.97$ & $-2.05 \pm 0.36$ & $-27.36 \pm 0.36$ \\
\hline Q. myrtifolia & - & - & $\cdots$ & - & - & $1.22 \pm 0.06$ & $48.52 \pm 0.25$ & $39.79 \pm 1.78$ & $-1.15 \pm 0.57$ & $-28.47 \pm 0.24$ \\
\hline S. repens & $13.23 \pm 1.72$ & $0.295 \pm 0.06$ & $0.031 \pm 0.005$ & $-2.79 \pm 0.42$ & $93.01 \pm 21.52$ & $1.03 \pm 0.14$ & $44.49 \pm 0.28$ & $44.87 \pm 5.52$ & $-3.36 \pm 0.23$ & $-26.23 \pm 0.51$ \\
\hline \multirow[t]{2}{*}{ V. myrsinites } & $9.78 \pm 0.22$ & $0.198 \pm 0.00$ & $0.034 \pm 0.005$ & $-2.93 \pm 0.41$ & $77.29 \pm 3.20$ & $0.74 \pm 0.05$ & $50.09 \pm 0.46$ & $68.42 \pm 5.34$ & $-3.99 \pm 0.30$ & $-30.88 \pm 0.13$ \\
\hline & \multicolumn{10}{|c|}{2000} \\
\hline L. fruticosa & --- & -- & - & - & $\cdots$ & $0.93 \pm 0.04$ & $55.20 \pm 0.62$ & $59.30 \pm 2.11$ & $-2.77 \pm 0.17$ & $-28.64 \pm 0.68$ \\
\hline L. lucida & $12.17 \pm 0.12$ & $0.275 \pm 0.03$ & $0.039 \pm 0.002$ & $-1.69 \pm 0.59$ & $36.10 \pm 17.19$ & $0.70 \pm 0.03$ & $57.60 \pm 0.40$ & $82.84 \pm 3.91$ & $-2.83 \pm 1.24$ & $-28.11 \pm 0.55$ \\
\hline M. cerifera & - & - & -- & -- & - & $\{.36 \pm 0.07$ & $55.16 \pm 0.14$ & $40.86 \pm 2.15$ & $-3.07 \pm 0.61$ & $-29.84 \pm 0.46$ \\
\hline Q. chapmanii & $20.83 \pm 1.02$ & $0.348 \pm 0.01$ & $0.048 \pm 0.003$ & $-2.71 \pm 0.21$ & $50.81 \pm 3.89$ & $1.25 \pm 0.02$ & $51.89 \pm 0.86$ & $41.35 \pm 0.14$ & $-2.30 \pm 0.55$ & $-28.66 \pm 0.21$ \\
\hline Q. geminata & $27.53 \pm 2.01$ & $0.474 \pm 0.04$ & $0.051 \pm 0.003$ & $-1.42 \pm 0.13$ & $24.58 \pm 2.06$ & $1.17 \pm 0.04$ & $51.44 \pm 0.23$ & $44 .\{3 \pm 1.52$ & $-3.06 \pm 0.24$ & $-28.24 \pm 0.28$ \\
\hline Q. myrtifolia & $15.37 \pm 1.45$ & $0.242 \pm 0.05$ & $0.042 \pm 0.002$ & $-1.56 \pm 0.21$ & $31.44 \pm 3.57$ & $1.37 \pm 0.04$ & $51.85 \pm 0.59$ & $38.02 \pm 1.43$ & $-1.77 \pm 0.48$ & $-28.73 \pm 0.34$ \\
\hline S. repens & $13.27 \pm 0.09$ & $0.307 \pm 0.01$ & $0.034 \pm 0.001$ & $-1.99 \pm 0.09$ & $54.26 \pm 2.51$ & $1.23 \pm 0.08$ & $51.23 \pm 2.67$ & $42.01 \pm 2.99$ & $-1.97 \pm 0.23$ & $-26.85 \pm 0.43$ \\
\hline$V$ myrsinites & $\ldots$ & $\ldots$ & -- & - & $\ldots$ & $0.71 \pm 0.02$ & $56.32 \pm 0.27$ & $79.53 \pm 3.00$ & $-0.83 \pm 0.27$ & $-28.99 \pm 0.21$ \\
\hline
\end{tabular}




\section{Appendix A (Continued)}

Table 20: Physiological parameters for species in the Kennedy Parkway fire suppressed plot. ( $A_{\max }, g_{\max }, \Phi, R$, and $C P$ obtained from light curves $n=2$ for 1999 ,

\begin{tabular}{|c|c|c|c|c|c|c|c|c|c|c|}
\hline & $\begin{array}{c}\mathbf{A}_{\max } \\
\left(\mu \mathrm{mols} \mathrm{CO}_{2} \mathrm{~m}^{-2}\right. \\
\left.\mathrm{s}^{-1}\right) \\
\end{array}$ & $\begin{array}{c}g_{\max } \\
\text { mmols } \mathrm{H}_{2} \mathrm{O} \mathrm{m}^{-2} \\
\mathrm{~s}^{-1} \mathbf{3}\end{array}$ & $\begin{array}{c}\Phi \\
\text { ( } \mu \text { mols } \mathrm{CO}_{2} \\
\text { umols photons) }\end{array}$ & 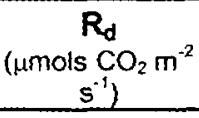 & $\begin{array}{c}I_{c} \\
\text { (umols photons } \\
\mathrm{m}^{-2} \mathrm{~s}^{-1} \text { ) }\end{array}$ & $\begin{array}{c}\% N \\
\left(g g^{-1}\right)\end{array}$ & $\begin{array}{l}\% \mathrm{C} \\
\left(g g^{-1}\right)\end{array}$ & $C: N$ & $\begin{array}{c}\delta^{15} N \\
(\%)\end{array}$ & $\begin{array}{c}\delta^{13} \mathrm{C} \\
\left(\%_{\infty}\right)\end{array}$ \\
\hline Species & \multicolumn{10}{|c|}{1999} \\
\hline G. elliottii & - & $\cdots$ & $\cdots$ & -- & - & $\cdots$ & -- & - & --- & --- \\
\hline L. ferruginea & $\cdots$ & - & -- & $\cdots$ & - & $\cdots$ & - & - & -- & - \\
\hline M. cerifera & -- & - & - & $\cdots$ & - & - & - & - & - & - \\
\hline Q. chapmanii & $14.07 \pm 1.09$ & $0.249 \div 0.05$ & $0.034 \pm 0.004$ & $-3.10 \pm 0.27$ & $85.93 \pm 14.62$ & $1.42 \pm 0.06$ & $45.81 \pm 0.31$ & $32.32 \pm 1.41$ & $-3.11 \pm 0.44$ & $-27.97 \pm 0.39$ \\
\hline Q. geminata & $24.67 \pm 1.70$ & $0.399 \pm 0.03$ & $0.050 \pm 0.002$ & $-3.22 \pm 0.67$ & $61.99 \pm 11.64$ & $1.34 \pm 0.03$ & $47.22 \pm 0.16$ & $35.32 \pm 0.79$ & $-4.22 \pm 0.16$ & $-27.74 \pm 0.14$ \\
\hline Q. myrtifolia & $20.25 \pm 2.85$ & $0.318 \pm 0.02$ & $0.045 \pm 0.007$ & $-2.28 \pm 1.12$ & $66.45 \pm 7.06$ & $1.49 \pm 0.03$ & $48.30 \pm 0.59$ & $32.34 \pm 0.72$ & $-3.21 \pm 0.23$ & $-27.46 \pm 0.06$ \\
\hline S. auriculata & -- & - & $\ldots$ & - & -- & $1.30 \pm 0.06$ & $45.09 \pm 0.74$ & $34.85 \pm 1.31$ & $-3.38 \pm 0.46$ & $-27.76 \pm 0.27$ \\
\hline V. myrsinites & $7.40 \pm 1.13$ & $0.210 \pm 0.01$ & $0.034 \pm 0.00$ & $-2.52 \pm 0.24$ & $68.06 \pm 6.45$ & $0.85 \pm 0.09$ & $50.48 \pm 0.21$ & $61.01 \pm 6.64$ & $-2.06 \pm 0.93$ & $-31.33 \pm 0.29$ \\
\hline \multirow[t]{2}{*}{$x$. americana } & $17.75 \pm 1.45$ & $0.636 \pm 0.20$ & $0.046 \pm 0.004$ & $-3.84 \pm 0.62$ & $80.09 \pm 19.84$ & $1.98 \pm 0.65$ & $47.92 \pm 0.79$ & $29.09 \pm 7.47$ & $-3.42 \pm 0.45$ & $-30.83 \pm 0.74$ \\
\hline & \multicolumn{10}{|c|}{2000} \\
\hline G. elliottii & $18.17 \pm 1.27$ & $0.372 \pm 0.07$ & $0.055 \pm 0.001$ & $-2.36 \pm 0.41$ & $35.59 \pm 5.42$ & $2.59 \pm 0.04$ & $50.05 \pm 0.73$ & $19.31 \pm 0.22$ & $-2.20 \pm 0.11$ & $-30.65 \pm 0.33$ \\
\hline L. fernuginea & --- & - & $\cdots$ & -- & $\cdots$ & $1.05 \pm 0.03$ & $54.06 \pm 0.44$ & $51.37 \pm 1.48$ & $-4.28 \pm 0.47$ & $-28.93 \pm 0.06$ \\
\hline M. cerifera & $\cdots$ & -- & - & - & $\cdots$ & $1.66 \pm 0.03$ & $51.56 \pm 0.36$ & $31.03 \pm 0.55$ & $-2.01 \pm 0.13$ & $-30.13 \pm 0.28$ \\
\hline Q. chapmanii & - & - & -- & -- & $\ldots$ & $1.77^{\star \star}$ & $50.32^{\star *}$ & $28.46^{* *}$ & $-3.91^{\star *}$ & $-29.30^{* *}$ \\
\hline Q. geminata & $27.40 \pm 1.38$ & $0.507 \pm 0.08$ & $0.052 \pm 0.004$ & $-1.39 \pm 0.15$ & $22.29 \pm 2.36$ & $1.32 \pm 0.01$ & $51.00 \pm 0.48$ & $38.57 \pm 0.61$ & $-4.23 \pm 0.16$ & $-28.19 \pm 0.27$ \\
\hline Q. myrtifolia & $14.30 \pm 1.19$ & $0.303 \pm 0.02$ & $0.040 \pm 0.001$ & $-1.25 \pm 0.17$ & $22.04 \pm 4.01$ & $1.60 \pm 0.05$ & $52.93 \pm 0.14$ & $33.21 \pm 0.95$ & $-3.44 \pm 0.31$ & $-28.02 \pm 0.18$ \\
\hline S. auriculata & - & - & -- & - & $\cdots$ & $1.54 \pm 0.04$ & $48.17 \pm 0.15$ & $31.38 \pm 0.87$ & $-2.91 \pm 0.35$ & $-28.23 \pm 0.42$ \\
\hline V. myrsinites & - & - & $\cdots$ & - & -- & $0.91 \pm 0.06$ & $53.99 \pm 0.24$ & $60.00 \pm 4.04$ & $-2.05 \pm 0.77$ & $-31.02 \pm 0.56$ \\
\hline X. americana & $13.37 \pm 1.21$ & $0.439 \pm 0.02$ & $0.041 \pm 0.001$ & $-2.82 \pm 0.43$ & $62.26 \pm 12.12$ & $2.44 \pm 0.43$ & $51.64 \pm 0.37$ & $22.84 \pm 4.72$ & $-3.00 \pm 0.62$ & $-30.82 \pm 0.75$ \\
\hline
\end{tabular}




\section{Appendix A (Continued)}

Table 21: Physiological parameters for species in the Kennedy Parkway mechanically treated plot. $\left(A_{\max }, g_{\max }, \Phi, R\right.$, and $C P$ obtained from light curves $n=2$ for 1999, $n=3$ for $2000 ; \% N, \% C, C: N, \delta^{15} N$, and $\delta^{13} \mathrm{C} n=3$ for both years) ${ }^{* *} n=1$

\begin{tabular}{|c|c|c|c|c|c|c|c|c|c|c|}
\hline & $\begin{array}{c}A_{\max } \\
\left(\mu \mathrm{mols} \mathrm{CO}_{2} \mathrm{~m}^{-2}\right. \\
\left.\mathrm{s}^{-t}\right)\end{array}$ & $\begin{array}{c}\mathbf{g}_{\max } \\
\text { mmois } \mathrm{H}_{2} \mathrm{O} \mathrm{m}^{-2} \\
\left.\mathrm{~s}^{-1}\right) \\
\end{array}$ & $\begin{array}{c}\Phi \\
\text { ( } \mu \text { mols } \mathrm{CO}_{2} \\
\text { jumols photons) }\end{array}$ & $\begin{array}{c}\mathbf{R}_{\mathrm{d}} \\
\text { (umols } \mathrm{CO}_{2} \mathrm{~m}^{-2} \\
\mathrm{~s}^{-1} \text { ) }\end{array}$ & $\begin{array}{c}\mathrm{I}_{\mathrm{c}} \\
\text { (umols photons } \\
\mathrm{m}^{-2} \mathrm{~s}^{-1} \text { ) }\end{array}$ & $\begin{array}{c}\% N \\
\left(g g^{-1}\right)\end{array}$ & $\begin{array}{l}\% C \\
\left(g g^{-1}\right)\end{array}$ & $C: N$ & $\begin{array}{c}\delta^{15} N \\
(\%)\end{array}$ & $\begin{array}{l}\delta^{13} \mathrm{C} \\
\left(\%_{0}\right)\end{array}$ \\
\hline Species & \multicolumn{10}{|c|}{$\begin{array}{ll}0 & 1999 \\
\end{array}$} \\
\hline G. elliottii & $22.80 \pm 5.80$ & $0.364 \pm 0.18$ & $0.054 \pm 0.012$ & $-4.48 \pm 0.04$ & $76.79 \pm 16.68$ & $2.38 \pm 0.04$ & $44.58 \pm 0.44$ & $18.73 \pm 0.19$ & $-2.20 \pm 0.17$ & $-27.14 \pm 0.36$ \\
\hline L. ferruginea & - & - & - & $\cdots$ & -- & $1.01 \pm 0.08$ & $49.46 \pm 2.34$ & $49.53 \pm 3.55$ & $-0.13 \pm 0.45$ & $-28.48 \pm 0.29$ \\
\hline L. fruticosa & - & $\cdots$ & - & -- & - & $\ldots$ & -- & - & - & - \\
\hline L. Iucida & $\ldots$ & -- & - & $\ldots$ & -- & $0.67 \pm 0.02$ & $51.46 \pm 0.35$ & $76.54 \pm 1.22$ & $-1.54 \pm 0.46$ & $-28.02 \pm 0.27$ \\
\hline M. cerifera & - & --- & - & - & - & $1.46 \pm 0.14$ & $50.30 \pm 0.121$ & $34.76 \pm 3.20$ & $-2.08 \pm 0.13$ & $-28.26 \pm 0.50$ \\
\hline Q. chapmanii & $\cdots$ & - & - & $\cdots$ & - & $1.53 \pm 0.05$ & $46.39 \pm 0.28$ & $30.26 \pm 0.85$ & $-1.26 \pm 0.57$ & $-27.16 \pm 0.22$ \\
\hline Q. geminata & $17.50 \pm 1.50$ & $0.218 \pm 0.00$ & $0.026 \pm 0.007$ & $-3.50 \pm 0.01$ & $129.06 \pm 32.25$ & $1.26 \pm 0.01$ & $47.01 \pm 0.40$ & $37.22 \pm 0.38$ & $-2.23 \pm 0.28$ & $-27.67 \pm 0.20$ \\
\hline Q. myrtifolia & -- & - & -- & -- & -- & $1.25 \pm 0.02$ & $47.93 \pm 0.69$ & $38.32 \pm 1.19$ & $-1.84 \pm 0.13$ & $-26.93 \pm 0.23$ \\
\hline S. repens & $12.75 \pm 0.45$ & $0.298 \pm 0.05$ & $0.035 \pm 0.000$ & $-2.92 \pm 0.17$ & $78.76 \pm 6.40$ & $1.14 \pm 0.09$ & $43.93 \pm 0.86$ & $39.11 \pm 3.55$ & $-0.71 \pm 0.51$ & $-26.74 \pm 0.23$ \\
\hline S. auriculata & - & - & $-\cdots$ & -- & $\ldots$ & $1.97 \pm 0.60$ & $42.65 \pm 1.55$ & $24.17 \pm 8.17$ & $0.35 \pm 0.89$ & $-27.79 \pm 0.62$ \\
\hline V. myrsinites & $8.56 \pm 1.84$ & $0.158 \pm 0.06$ & $0.032 \pm 0.007$ & $-2.55 \pm 1.22$ & $62.73 \pm 25.31$ & $0.76 \pm 0.05$ & $51.89 \pm 0.99$ & $68.97 \pm 5.97$ & $-0.05 \pm 0.66$ & $-29.85 \pm 0.28$ \\
\hline \multirow[t]{2}{*}{$X$ americana } & $14.40 \pm 1.10$ & $0.562 \pm 0.01$ & $0.041 \pm 0.001$ & $-3.84 \pm 0.76$ & $86.72 \pm 23.21$ & $2.08 \div 0.37$ & $48.39 \pm 0.47$ & $24.94 \pm 4.61$ & $-1.93 \pm 0.25$ & $-31.19 \div 0.42$ \\
\hline & \multicolumn{10}{|c|}{2000} \\
\hline G. elliottii & $22.30 \pm 2.36$ & $0.378 \pm 0.07$ & $0.049 \pm 0.006$ & $-1.80 \pm 0.36$ & $32.28 \pm 3.97$ & $2.49 \pm 0.03$ & $47.81 \pm 2.21$ & $19.20 \pm 0.92$ & $-2.13 \pm 0.18$ & $-25.50 \pm 0.62$ \\
\hline L. ferruginea & - & $\ldots$ & $\cdots$ & -- & - & $1.11 \pm 0.03$ & $54.52 \pm 0.23$ & $49.00 \pm 1.33$ & $-0.60 \pm 0.25$ & $-28.48 \pm 0.06$ \\
\hline L. fruticosa & - & $\ldots$ & $\ldots$ & -- & - & $0.47^{\star \star}$ & $55.99^{\star \star}$ & $120.40^{* \star}$ & -2.48 & $-28.31^{\star \star}$ \\
\hline L. lucida & $13.20 \pm 0.17$ & $0.265 \pm 0.01$ & $0.040 \pm 0.001$ & $-2.28 \pm 0.09$ & $49.44 \pm 3.12$ & $0.74 \pm 0.04$ & $55.38 \pm 0.68$ & $75.49 \pm 4.87$ & $-0.81 \pm 0.13$ & $-27.33 \pm 0.23$ \\
\hline M. cenfera & - & -- & $\cdots$ & - & -- & $1.52 \pm 0.03$ & $53.62 \pm 0.21$ & $35.33 \pm 0.64$ & $-2.07 \pm 0.34$ & $-28.23 \pm 0.07$ \\
\hline Q. chapmanii & $19.60 \pm 0.85$ & $0.303 \pm 0.05$ & $0.032 \pm 0.004$ & $-1.70 \pm 0.19$ & $47.26 \pm 1.79$ & $1.56 \pm 0.06$ & $50.88 \pm 0.60$ & $32.64 \pm 1.14$ & $-1.04 \pm 0.33$ & $-28.01 \pm 0.09$ \\
\hline Q. geminata & $25.43 \pm 1.48$ & $0.367 \pm 0.00$ & $0.041 \pm 0.000$ & $-1.59 \pm 0.14$ & $36.68 \pm 4.12$ & $1.47 \pm 0.02$ & $51.87 \pm 0.09$ & $35.11 \pm 0.40$ & $-2.68 \pm 0.34$ & $-27.97 \pm 0.39$ \\
\hline Q. myrtifolia & $16.97 \pm 0.44$ & $0.311 \pm 0.03$ & $0.047 \pm 0.003$ & $-1.82 \pm 0.41$ & $32.29 \pm 6.04$ & $1.51 \pm 0.03$ & $53.18 \pm 0.30$ & $35.21 \pm 1.02$ & $-2.36 \pm 0.08$ & $-27.50 \pm 0.34$ \\
\hline S. repens & $13.07 \pm 0.27$ & $0.351 \pm 0.02$ & $0.037 \pm 0.001$ & $-2.59 \pm 0.18$ & $62.28 \pm 4.92$ & $1.41 \pm 0.06$ & $50.34 \pm 0.14$ & $35.72 \pm 1.60$ & $-1.88 \pm 0.17$ & $-26.85 \pm 0.09$ \\
\hline S. auriculata & -- & -- & $\cdots$ & - & --- & $0.82 \pm 0.08$ & $48.11 \pm 0.25$ & $25.30 \pm 1.21$ & $-1.05 \pm 0.24$ & $-27.58 \pm 0.58$ \\
\hline V. myrsinites & - & $\ldots$ & $\cdots$ & $\rightarrow$ & - & $0.93 \pm 0.03$ & $55.05 \pm 0.40$ & $59.52 \pm 2.57$ & $-0.07 \pm 0.59$ & $-29.77 \pm 0.55$ \\
\hline$X$ americana & $14.17 \pm 0.90$ & $0.372 \pm 0.05$ & $0.047 \pm 0.003$ & $-3.74 \pm 1.35$ & $70.87 \pm 26.63$ & $2.39 \pm 0.19$ & $53.13 \pm 0.21$ & $22.42 \pm 1.57$ & $-2.91 \pm 0.16$ & $-30.60 \pm 0.29$ \\
\hline
\end{tabular}




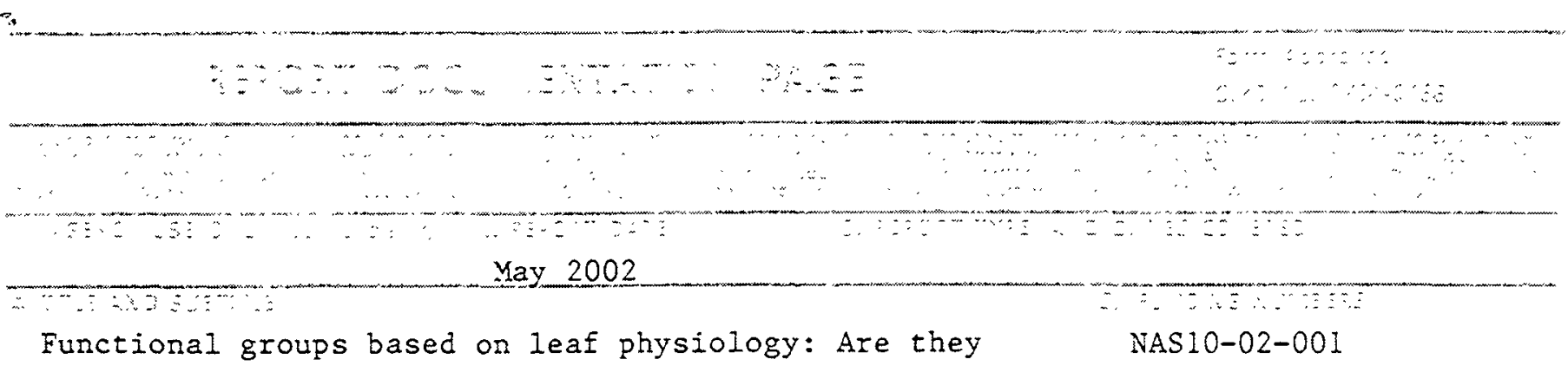
spatially and temporally robust?

Tammy E. Foster and J. Renee Brooks

Dynamac Corporation

Yailcode DYN-2

Kennedy Space Center, FL 32899
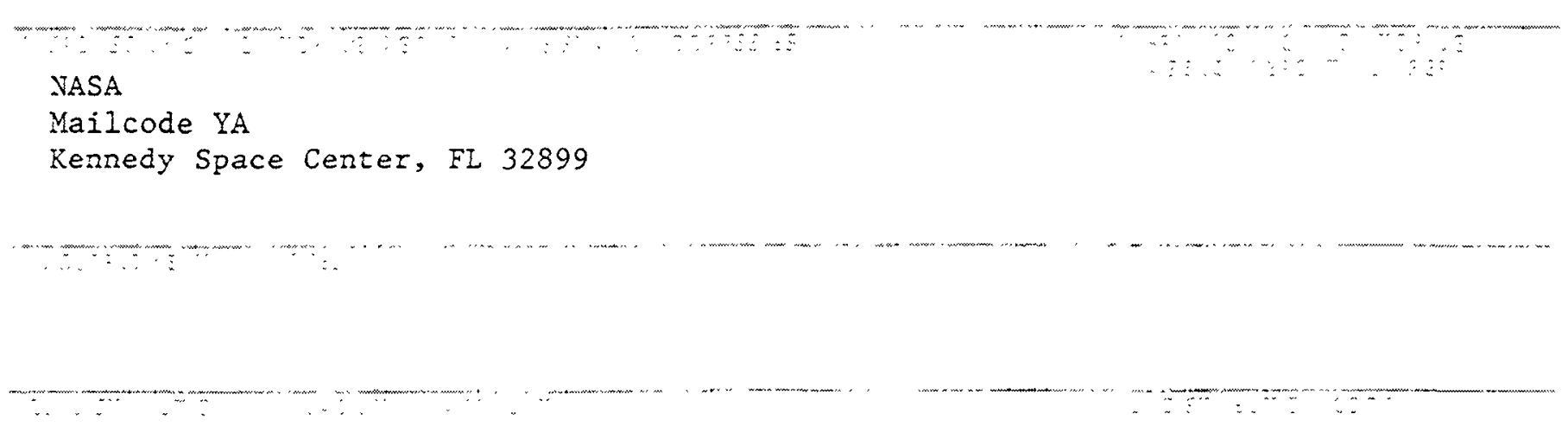

Unlimited

The functional grouping hypothesis, which suggests that complexity in function can be simplified by grouping species with similar responses, was tested in the Florida scrub habitat. Functional groups were identified based on how species in fire maintained FL scrub function in terms of carbon, water and nitrogen dynamics. The suite of physiologic parameters measured to determine function included both instantaneous gas exchange measurements obtained from photosynthetic light response curves and integrated measures of function. Using cluster analysis, five distinct physiologically-based functional groups were identified. Using non-parametric multivariate analyses, it was determined that these five groupings were not altered by plot differences or by the three different management regimes; prescribed burn, mechanically treated and burn, and fire-suppressed. The physiological groupings also remained robust between the two years 1999 and 2000 . In order for these groupings to be of use for scaling ecosystem processes, there needs to be an easy-to-measure morphological indicator of function. Life form classifications were able to depict the physiological groupings more adequately than either specific leat area or leaf thickness. The ability of life forms to depict the groupings was improved by separating the parasitic Ximenia americana from the shrub category.

Functional groupings, plant physiology, stable carbon isotope, water, nitrogen, management regime, temporal variation

84 